\title{
TRANSPIRACIÒN Y BALANCE DE AGUA DE LA BANANERA EN LAS CONDICIONES DE LA CIUDAD DE SÃO PAULO
}

\author{
Jorge Morello * \\ I

\section{INTRODUCCION}

E1 factor más importante en la vida de las plantas, tal vez sea el agua; ella determina el movimiento de los estomas durante el dia, y el rendimiento de las cosechas depende, en gran parte, de la posibilidad que tengan las plantas de mantenerlos abiertos el mayor tiempo posible, porque la rapidéz de absorción de $\mathrm{CO} 2$, al igual que la intensidad de la transpiración, depende del estado de abertura de los estomas.

Como la existencia de determinadas plantas cultivadas está condicionada por el balance de agua, su estudio tornóse indispensable en la moderna agroecología.

Entre los cultivos tropicales, el de la bananera ocupa un lugar destacado, no sólo por la utilización de los frutos, sino por su uso como sombrío transitorio del café y cacao; abono verde, mulch, barreras antierosivas, alimento del ganado en época de sequía; y como mejoradora y regeneradora de los suelos.

En la literatura tropical americana a nuestro alcance, faltan datos sobre el balance de agua de esta planta. En la del continente africano, por el contrario, aparecen con frecuencia observaciones sobre el consumo de agua y su actividad reguladora de la humedad atmosférica:

"Le bananier est grand consommateur aussi bien d'eau que de sels nutritifs"....... (Livens, 22, p. 305).

"Quant aux bananeraies en général et aux bananeraies à bière en particulier et en régions d'altitude, elles devraient être appreciées comme améliorantes et régénératrices des sols, en même temps que régulatrices du climat"... "La grande surface d'evaporation et d'absorption de ses feuilles, gaînes et stipes fait du bananier un précieux régulateur climatique." (Jaumain, 20, p. 1423).

"Au point de vue climat on peut s'attendre que la multiplication des bananeraies régularise le régime des pluies. Le bananier est une plante très aqueuse, susceptible d'emmagasiner d'énormes réserves d'eau qui seront libérées partiellement au cours de la saison sèche"...

\footnotetext{
* Al Prof. Felix Rawitscher, que, además de habernos introducido en el conocimiento de los problemas de transpiración, sugirió, y orientó este estudio, nuestra mayor gratitud. El autor desea también agradecer a la Rectoría de la Universidad de São Paulo, por la beca que le fué otorgada, y al Conselho Nasional de Pesquisas, por la ayuda económica prestada.
} 
"Le microclimat humide et frais qui existe dans toutes les bananeraies entravera efficacement la minéralization des matières organiques et de l'humus" (Hendrickx et Hendrickx, 16, p. 1741).

Como en ninguno de estos trabajos, aparecen observaciones experimentales, sobre los valores de transpiración de la bananera, creimos conveniente iniciar el estudio de la cantidad de agua gastada por la planta en el campo, para obtener una estimativa aproximada de la que necesita anualmente un individuo aislado o un cultivo; y esto requiere un conocimiento detallado de la fisiología de la transpiración de la especie.

La mayor de las incógnitas en el estudio del destino y aprovechamiento de las precipitaciones, es la cantidad de agua transpirada por las plantas; pero esta agua cedida por las hojas, no representa una simple función de la humedad relativa del aire o del déficit de saturación de la atmósfera, sino que el abrir y cerrar de los estomas, es determinado por las condiciones de luz (fotoreacción) y por el estado de saturación de la hoja (hidroreacción). Con estomas abiertos, una planta puede llegar a transpirar el $70 \%$ de la evaporación de igual superficie libre, de agua (vide Stalfelt, 43, y Rawitscher y Ferri, 36) mientras que con estomas cerrados, la pérdida se reduce al $1 \%$.

A fin de caracterizar el hábito transpiratorio de la planta, en las condiciones de la ciudad de São Paulo, se estudió las alteraciones del grado de abertura de los estomas provocadas por la luz y por el contenido de agua de la hoja; los tiempos y déficits de saturación necesarios para que tales reacciones estomáticas ocurran y si los estomas se conservan invariablemente abiertos todo el día o nó.

Si la planta no cierra en ninguna hora del día los estomas, la transpiración total acompañará el grado de evaporación del aire; esto fué estudiado midiendo la transpiración y evaporación en intervalos de 30 a $60^{\circ}$ desde el amanecer al anochecer.

La actitud transpiratoria nos indica si existe o nó agua disponible en el suelo: habiendo transpiración ilimitada todo el día y no manifestándose marchitamiento de las hojas, podemos suponer que el suelo siempre tiene agua disponible y que el abastecimiento es correcto.

Stocker (44), mostró que el hábito de abertura de los estomas depende en gran parte de la profundidad de las raíces, y que el comportamiento estomático puede diferir profundamente entre épocas secas y lluviosas; por cllo estudiamos hasta que profundidad exploran las raíces y el comportamiento transpiratorio en el fin de la seca y comienzo de la época de lluvias, lo que nos permite conocer la disponibilidad anual de agua subterránea.

Para estudiar el balance de agua, se puede determinar, o el agua absorvida o la desprendida por la planta (lo ideal sería conocer los dos valores); estos datos resultan de fácil determinación en el laboratorio, pero la ecología desea estudiar la planta en su ambiente 
natural y allí las cosas cambian; los métodos de laboratorio, como el pesaje de plantas en maceta, no nos garanten que los valores de absorción y de transpiración, sean iguales a los de la planta enraigada en el campo. Por ello hicimos dos grupos de experiencias: en el laboratorio, con ejemplares del jardín, y otro en condiciones naturales, en los bananales del Campo Experimental del Departamento de Botánica, en Butantan.

II

\section{METODOS}

Los métodos usados, han sido descritos por Rawitscher, Ferri y Rachid $(9,32,33,34,36)$ en trabajos anteriores, por lo que no entraremos en detalles.

El estudio de la transpiración fué hecho por el método de pesadas rápidas en la balanza de torsión; método que viene siendo usado con éxito en este tipo de estudios, desde hace más de dos decenios. Sin embargo, Franco e Inforzato (11) basándose en determinaciones porométricas, desaconsejan su uso para estudios de transpiración en café; ellos hicieron determinaciones de pasaje de aire en la hoja "in situ", y, una vez obtenidos valores constantes, cortaron el pecíolo, resultando después del corte, un franco aumento del pasaje de aire, que alcanzaba el máximo, a los 8'después de separar la hoja de la planta. Valores iguales a los obtenidos en la hoja "in situ", sólo se conseguían a los 20 'después de haber practicado el corte.

Esta caída de la curva porométrica, es interpretada como una abertura anormal de los estomas provccada, directa o indirectamente por el corte del pecíolo y sirve de base para desaconsejar el uso del método de pesadas rápidas, lo que nos parece sujeto a las siguientes críticas:

1) Cuando dos métodos dan resultados discordantes, eso no significa que el empleado por el autor sea el correcto, y menos que "a priori" y sin determinar las causas ce la discordancia, se desestime el otro.

2) Las observaciones porométricas no fueron acompañadas por ningún otro test para controlar los resultados.

3) E1 método de pesadas rápidas satisface todas las exigencias para poder ser utilizado, tanto en el laboratorio como en el campo $\mathrm{y}$ ha servido para innumerables trabajos modelares sobre transpiración y balance de agua.

En un trabajo reciente, Rawitscher y Morello (38) estudiaron criticamente la eficacia del mismo, averiguando si el valor inicial, obtenido en la balanza, después del corte del pecíolo, corresponde a la transpiración que se procesaba antes, en la hoja o rama intacta y si el corte produce alguna clase de alteración en la razón de pérdida de agua. 
Hicieron dos grupos de experiencias: uno con plantas cortadas y otro con plantas intactas que se cortaban después de pesarlas durante algún tiempo. Trabajaron con 14 especies (entre ellas el café), haciendo en total 90 pares de experiencias, controladas por el test de infiltración, microscopio de iluminación y método de Stalfelt; concluyendo que:

a) E1 corte no produce alteración alguna en el ritmo transpiratorio, en ninguno de los tres estados de la curva (estomas abiertos, estomas cerrándose y estomas cerrados).

b) Los cortes practicados en hojas saturadas o con fuerte déficit de saturación, no produjeron en ninguno de los dos casos, cambios en los valores de transpiración.

c) Los valores iniciales de pérdida de agua, después del corte, constituyen realmente la transpiración máxima en las condiciones reinantes durante la experiencia.

4) Creemos que la abertura anormal de los estomas, observada por Franco e Inforzato, se debe a condiciones anormales creadas por el propio porómetro y no al hecho de separar la hoja del resto de la planta.

En el último número del "Fortschritte der Botanik", Briuno Huber, dice al respecto del porómetro (19, p. 237): "Con respecto al método porométrico para medir la abertura de los estomas, que fisicamente parece tan limpio, Heath y Williams, encontraron una fuente muy grave de errores fisiológicos.

La separación hermética de la cámara del porómetro, del aire exterior, conduce rápidamente a un empobrecimiento en $\mathrm{CO} 2$, cuando el aparato está expuesto a la luz; esta exitación fisiológica conduce a una ampliación enorme de la abertura de los estomas. De esta manera, pasados pocos minutos, el porómetro ya no registra más la abertura normal de los estomas, volviéndose evidente que mediciones continuadas no tienen sentido. - Experiencias de infiltración en la hoja sacada de la cámara porométrica, muestran aberturas atipicamente grandes de los estomas. - Este error puede ser atenuado, cuando en los intervalos entre las mediciones, se saca y ventila eficazmente la cámara porométrica."

En el caso de las experiencias de Franco e Inforzato, la curva porométrica comienza a caer a los 15 a $17^{\prime}$ de haber colocado la hoja en el aparato (Op. cit., fig. 1), tiempo suficiente para que se haya producido en la cámara porométrica, el déficit de anhidrido carbónico capáz de provocar una abertura atípica de los estomas.

Creemos que experiencias porométricas, sujetas a las fuentes de error, indicadas por Heath and Williams y Huber, no pueden servir de base para desaconsejar el uso de un método, de probada eficacia como es el de la balanza de torsión, máxime cuando la abertura atípica de los estomas puede deberse a alteraciones producidas por el propio aparto y nó a los efectos del corte. 
En nuestras experiencias, siempre trabajamos con la banana "Nanica" (Musa cavendishii Lamb) para poder comparar los resultados. La mayor dificultad, para trabajar con esta especie, es la gran superficie de las hojas, y su correspondiente peso (hasta $1 / 2$ kilo) comparado con el pequeño limite de carga de nuestras balanzas ( $5 \mathrm{~g})$. Por eso, usamos porciones foliares "standard", cortadas apoyando la hoja sobre una madera, y accionando con un anillo de acero de $5 \mathrm{~cm}$. de diámetro $\left(22 \mathrm{~cm}^{2}\right.$ de superficie), afilado en sus bordes. Las porciones de hojas así cortadas, pesaban menos de $1 \mathrm{~g}$.

Para averiguar si por la herida circular, provocada por el disco de acero, se producía alguna evaporación, lo que oscurecería los resultados, comparamos la pérdida de agua de una porción con el márgen desnudo y otra con el borde envaselinado o parafinado, pesándolas al mismo tiempo, una en cada balanza; nunca apareció una diferencia sensible entre la perdida de agua de las 2 porciones.

El déficit de saturatión de la hoja, en el momento de comenzar a pesar o en cualquier etapa de la curva transpiratoria, fué determinado mediante los respectivos datos de peso fresco, peso saturado y peso seco. El estado de saturación se consigue dejando la porción foliar en cámara húmeda, durante 24 ó 48 h. hasta obtener peso constante (se desestimaron las porciones que, después de estar en cámara húmeda, habían perdido peso por respiración o aparecián infiltradas con agua).

El déficit de saturación se calcula según la fórmula de Stocker:

max. cont. de agua - cont. de agua en el estado fresco

max. cont. de agua

Para comparar nuestros datos, expresados en $\mathrm{g} / \mathrm{dm} 2 / \mathrm{min}$, con los de los autores que prefieren hacerlo en $\mathrm{g} / \mathrm{g} / \mathrm{min}$ (gramos de pérdida de agua/gramos de peso fresco/minuto), determinamos la relación: superficie/peso; $1 \mathrm{dm} 2$ pesa, en promedio, $1,4 \mathrm{~g}$ y nuestros valores, expresados en $\mathrm{g} / \mathrm{dm} 2 / \mathrm{min}$, deben dividirse por el factor 1,4 para obtener aproximadamente datos en $\mathrm{g} / \mathrm{g} / \mathrm{min}$.

Las abreviaturas usadas en tablas y gráficos, son:

$x \quad$ el numerador indica la infiltración en la cara superior de $\frac{x}{x}$ la hoja y el denominador en la inferior.

$\mathrm{O}=$ infiltración nula

$(\mathrm{X})$ = infiltración muy débil y dudosa

$\mathrm{X}=$ infiltración reducida

$\mathrm{XX}=$ infiltración moderada

$\mathrm{XXX}=$ infiltración grande

$\mathrm{Tt} / \mathrm{E}=$ Transpiración total/Evaporación

$\mathrm{Tc} / \mathrm{E}=$ Transpiración cuticular/Evaporación 
$\mathrm{Ca} \%=$ contenido de agua en $\%$ del peso fresco

$\mathrm{Ca} \% \mathrm{a}=$ contenido de agua en $\%$ del agua contenida en el estado fresco

$\mathrm{C}_{\mathrm{p}}=$ contenido de agua en peso

$\mathrm{Mgp}=$ miligramos de agua perdidos

H. R. = Humedad relativa

T. ${ }^{\circ} \mathrm{C}=$ Temperatura

Cuando en las tablas aparece "peso de la hoja", se sobreentiende que se trata no de la hoja toda sino de la purción de $44 \mathrm{~cm} 2$ (contando ambas caras, pués las dos poseen estomas) destacada con el anillo de acero.

Evaporación: E1 mejor método para comparar la transpiración de la hoja con la evaporación libre, consiste en cortar un molde exacto de la misma, en papel secante, saturario con agua, y colocarlo en la balanza, en el lugar donde observamos la transpiración de la hoja, dándole la misma posición que aquella.

En nuestras observaciones, cortabamos un disco de papel secante de color verde, con el mismo anillo de acero usado para obtener porciones foliares $\mathrm{y}$, o bien lo colgabamos en el mismo lugar de la balanza donde minutos antes se pesara la hoja, o bién, cuando trabajámos con dos balanzas, en una pesabamos la porción foliar y en la otra el evaporímetro molde de hoja (Blatt-evaporimeter).

\section{III}

\section{SISTEMA SUBTERRANEO}

En esta planta, el desarrolio vertical de las raíces depende de la profundidad a que se encuentia la napa de agua. En un ejemplar desenterrado en Butantán, exploraban hasta los $3 \mathrm{~m}$., estando la napa de agua a $5 \mathrm{~m}$. de profundidad.

En Colombia, se estima como profunciidad normal de las raíces de bananera, $5 \mathrm{~m}$ (12, p. 133).

Un 20 a $35 \%$ de las raíces, se extienden lateralmente, con ángulos variables entre 10 y $300^{\circ}$ con respecto a la superficie del suelo, terminandc, a $\operatorname{los} 3 \mathrm{~m}$ de la proyección del eje caulinar, como máximo; las restantes corren con inclinaciones mayores, algunas verticalmente.

Por ello, el sistema subterráneo explora, desde los $0,20 \mathrm{~m}$ hasta los 3 ó $4 \mathrm{~m}$ de profundidad, lo que hace pensar que, al finalizar la época seca, una parte de las raíces (35 al 45\%) se encontrará en profundidades donde ya no existe agua aprovechable para la planta; suponiendo que la seca penetre hasta los $2 \mathrm{~m}$ (vide 37, p. 272).

Hacia el fin de la época seca, una parte del sistema radicular, estaría con abastecimiento normal de agua (la que va en profundidad) y otra (la que se extiende lateralmente) no tendría agua aprovechable a su disposición. 
Al finalizar la época seca, cavamos um pozo para poner al descubierto las raíces, sacando muestras de suelo de 50 en $50 \mathrm{~cm}$., cuyos contenidos de agua fueron:

$\begin{array}{ccccc}\text { Profundidad } & \text { 24-IX-51 } & \text { 28-IX-51 } \\ 0,30 \mathrm{~m} & 3,6 \% & (*) & 3,8 & \% \\ 0,60 & 4,5 & & 4,5 & \\ 1,00 & 5,9 & & 6,0 \\ 1,50 & 6,9 & & 6,2 \\ 2,00 & 9,6 & & 9,2 \\ 2,50 & 15,5 & & 16,5 \\ 3,00 & 23,0 & & 24,0\end{array}$

*) Porcentaje de agua del suelo, en relación al peso de la tierra seca.

Sin atribuir demasiado valor a estos datos, sujetos a error, parece que desde los $2 \mathrm{~m}$ ya hay agua en condiciones de ser absorvida por la planta.

E1 ejemplar desenterrado, 450 raíces de primer órden y el volúmen de suelo de su rizosfera abarcaba $81 \mathrm{~m} 3(27 \mathrm{~m} 2 \times 3 \mathrm{~m}$ de profundidad).

\section{IV}

\section{REACCIOINES ESTOMATICAS}

\section{A) FOTOREACCION}

Para estudiar la fotoreacción cubrimos de negro seis hojas (**) de una misma planta, dejando dos a la luz para control (en el momento de oscurecer, todas las hojas mostraban fuerte infiltración con xilol).

De 10 em 10', descubriámos una hoja, sacábamos una porción foliar, de ella y otra de la control, pesando al mismo tiempo, una en cada balanza (cada pesada, se acompañaba con el test de infiltración).

En la tabla 1 N. ${ }^{\circ} 1$ vemos que a los 10' de oscurecida, los valores de transpiración eran semejantes a los de la hoja control; a los 20' (a veces menos) los estomas comenzaban a controlar la pérdida de agua y la hoja tapada transpiraba menos que la control. Después de 23' de oscurecida, la hoja transpiraba $4,6 \mathrm{mg} / \mathrm{dm} 2 / \mathrm{min}$ o sea el $64 \%$ de la control; a los $48^{\prime}$ solo el $16 \%$ y a los 60 ' obtuvimos valores que en el futuro permanecerán constantes y que ya son de transpiración cuticular $(0,57) \mathrm{mg} / \mathrm{dm} 2 / \mathrm{min}$, o sea $34,2 \mathrm{mg} / \mathrm{dm} 2 /$ hora).

**) Se usaron seis hojas oscureciclas, porque cada vez se destapaba una para sacar porciones, quedacia inutilizada para posteriores observciones; de volver a taparla, habría recebido un breve período de luz, entre 2 de sobra, lo que alteraría los resultados. 
A las $11 \mathrm{~h} 20$ ' la pérdida de la hoja oscurecida fué el 4,5\% de la control y a las 11 h 42', habiéndo aumentado la transpiración de esta última, decreció al 3,3\%. Desde las 11h20' la infiltración fué nula.

Concluimos entonces que: 60' de conservación de las hojas en la oscuridad es tiempo suficiente para que los estomas aparezcan cerrados.

Comparando este dato con los obtenidos por Rachid (31, p. 29) para una planta de verano del "campo cerrado" (Craniolaria integrifolia); indica cierta pereza en la fotoreacción, pués esta última cierra sus estomas después de cubierta, en la mitad del tiempo empleado por la bananera.

TABLA $\quad 1$

FOTOREACCION DE LOS ESTOMAS

17-XI-51

(N.O 1)

Las hojas fueron cubiertas con cartulina negra a las $10 \mathrm{~h} 32$

\begin{tabular}{l|c|c|c|c|c}
\hline Tiempo & $\begin{array}{c}\text { Hojas cubiertas } \\
\text { Transpiración } \\
\text { (mg/dm2/min) }\end{array}$ & $\begin{array}{c}\text { Hoja control } \\
\text { Transpiración } \\
\text { (mg/dm2/min }\end{array}$ & $\begin{array}{c}\text { Porcentaje } \\
(*)\end{array}$ & $\begin{array}{c}\text { Temperatur } \\
0 . \mathrm{C}\end{array}$ & $\begin{array}{c}\text { Humedad } \\
\text { relativa } \\
\%\end{array}$ \\
\hline $10 \mathrm{~h} 42$ & $6,9(1)$ & 6,9 & 100 & 22 & 70 \\
$10 \mathrm{~h} 55$ & $4,6(2)$ & 7,2 & 64 & 23 & 69 \\
$11 \mathrm{~h} 20$ & $1,15(3)$ & 7,2 & 16 & 23 & 69 \\
$11 \mathrm{~h} 32$ & $0,57(4)$ & 12,65 & 4,5 & 24 & 64 \\
$11 \mathrm{~h} 42$ & $0,57(5)$ & 16,5 & 3,5 & 25 & 60 \\
$12 \mathrm{~h} 51$ & $0,57(6)$ & 16,5 & 3,5 & 25 & 60
\end{tabular}

(*) Transpiración de las hojas cubiertas en porcentaje de la transpiración de la hoja control

(N. 2)

Operación inversa a la N.० 1

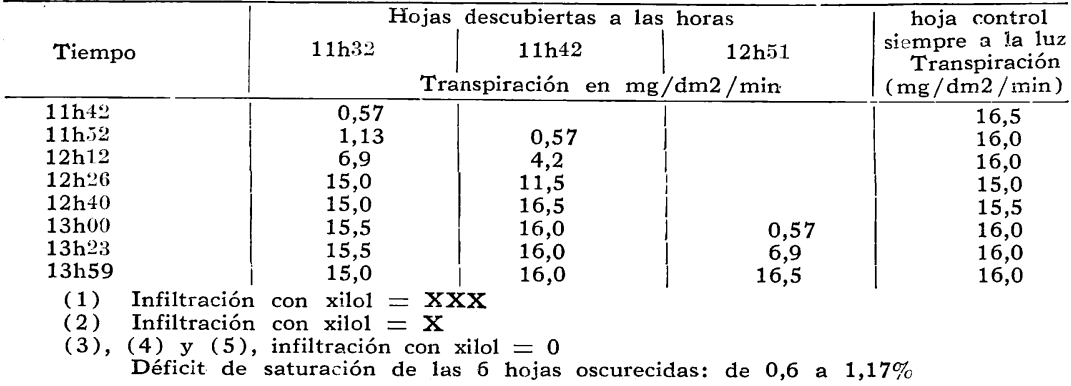

E1 resultado fué controlado haciendo la operación inversa (tabla N. ${ }^{\circ} 2$ ); de la hoja descubierta en último término (12 h 51') continuamos pesando porciones de 10 en 10' comparando con la control. Otro tanto se venía haciendo con las descubiertas a las 11 h 32' y 11 h 42'. En tiempos variables entre 50 y 58', se obtuvieron valores aproximadamente iguales al control, es decir que los estomas tardaron ese tiempo para recuperar su abertura inicial.

Observaciones por la mañana bién temprano (hasta 15' después de la salida del sol) muestran las hojas transpirando con valo- 
TABLA 2

VALORES DE TRANSPIRACION Y DEFICIT DE SATURACION DE LA PORCION FOLIAR EN LAS DIVERSAS ETAPAS DE LA CURVA TRANSPIRATORIA (dia nublado y lluvioso a ratos)
T. $=20,4-20,0 \circ \mathrm{C}$
H. R. $=72-69 \%$ Fecha: $28-\mathrm{X}-51$

Hoja N.O 1

Peso fresco $=723 \quad$ Peso seso $=113,5 \quad$ Contenido de agua $=609,5 \mathrm{mg}$

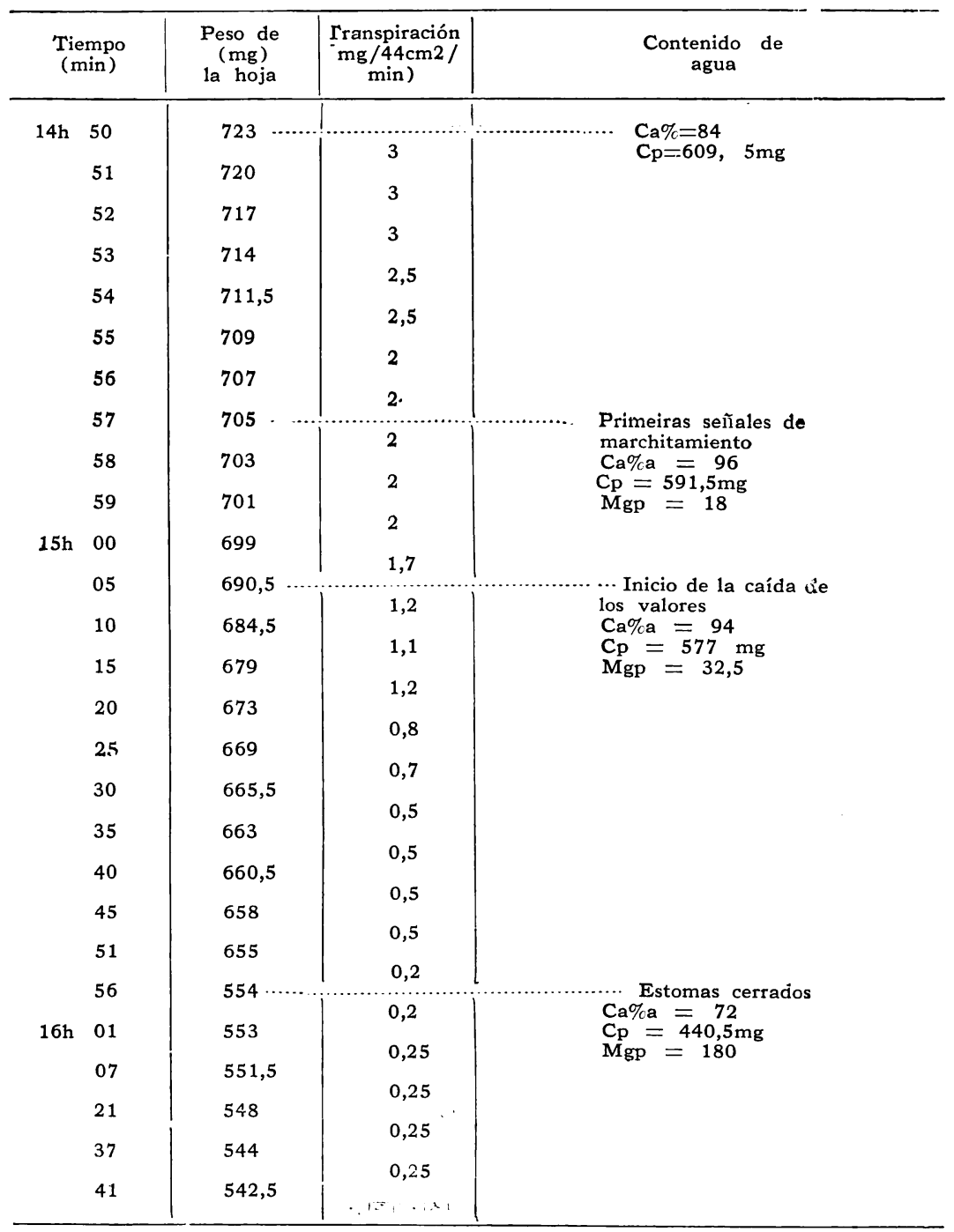


res cuticulares $(0,57$ a $1,13 \mathrm{mg} / \mathrm{dm} 2 / \mathrm{min})$. Esto puede deberse al estado cerrado de los estomas, sino a que, en las primeras horas de la mañana, aún cuando los estomas estén completamente abiertos y no regulen la pérdida de agua, esta es pequeña porque el déficit de saturación de la atmósfera es bajo. En São Paulo, en setiembre, octubre y noviembre, a las $7 \mathrm{~h}$, son casi constantes los valores de H. R. entre 80 y $90 \%$ y de temperatura entre 17 y $19 .^{\circ} \mathrm{C}$ lo que dá

Hoja N.O 2

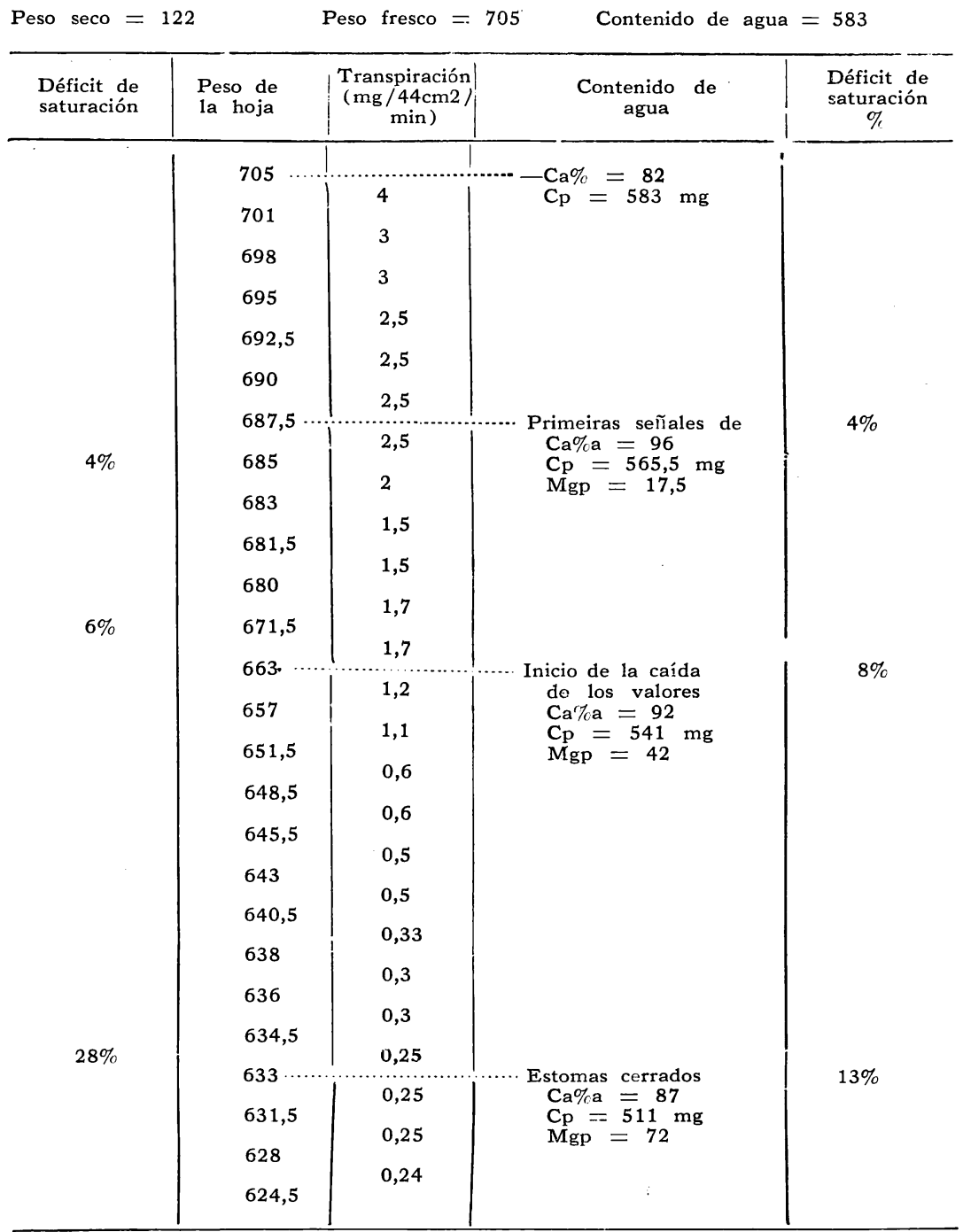

Peso fresco igual a "peso saturado" porque las hojas estaban gutando 
una humedad absoluta de $11,5 \mathrm{~mm}$ de $\mathrm{Hg}$ y un déficit de saturación del aire de 2,5 a $3 \mathrm{~mm}$ de $\mathrm{Hg}$.

Que a esta hora los estomas están parcialmente cerrados, no hay duda pués el test de infiltración indicó entrada sólo de los líquidos menos densos (xilol y eter petroleo) y en puntos aislados.

Al atardecer, los estomas cierran, y entre las 19 y 19 h 30' (*) en octubre, ya están completamente cerrados.

Alteraciones de la iluminación durante el dia, siempre que estas sean de corta duración como la llegada de uma tormenta, que cambia rapidamente las condiciones de luz, parecen no tener influencia notable sobre los estomas. En tales días, después de haber disminuido la luz en un 20 a $25 \%$ de la inicial, ni la balanza ni los infiltrantes, acusan una disminución de la abertura estomática.

\section{B) HIDROREACCIŌN}

La rapidéz de la reacción de los estomas, cuando son obligados a cerrar por falta de agua, constituye un criterio muy importante para juzgar el grado de xerofitismo de una especie.

La tabla 2, ilustra el comportamiento de los estomas en las diversas etapas de la curva transpiratoria, en condiciones de alta humedad relativa. La porción foliar, después de cortada, mantiene su ritmo de pérdida de agua durante un tiempo variable entre 3 y 5' (**); a los 6-7' aparecen las primeras señales de marchitami 3 nto; la porción foliar comienza a enroscarse en el sentido del recorrido de la nervadura central (ápice base) ro pudiendo hacerlo en el opuesto, porque es la dirección de los tejidos mecánicos.

La porción foliar no sólo se enrolla lentamente sino que, siendo en principio un círculo perfecto, va poco a poco acortando uno de sus diámetros (ápice base) mientras que el otro no se modifica (el del sentido de las nervaduras secundarias) de tal manera que al finalizar ( 2 ó 3 horas después de cortada) aparece como una elipse, con escasa diferencia entre el diámetro mayor y el menor.

Casi inmediatamente después de los primeros síntomas de marchitamiento, se vuelve nítido el movimiento de cierre de los estomas, indicado por la caída de los valores; cosa que ocurre en la hoja N.o 1 , con un déficit de saturación del $6 \%$, y en la N..$^{\circ} 2$ del $8 \%$, cuando se han perdido 32,5 y $42 \mathrm{mg}$. de agua respectivamente.

\footnotetext{
*) Se han hecho las correcciones necesarias, en las observaciones efectuadas a partir del adelanto oficial de la hora (noviembre), de tal manera que siempre nos referimos a la hora astronómica.

**) Con frecuencia, el frimer valcr cbten:do en la balanza, es un poco mavor que los siguientes, no por el estado mas abierto de los cstomas, sino porque el movimiento del aire, que acompaña las manipulaciones, durante la colocación de la hoja y de los pesos, provoca un aumento de la iranspiración.
} 
$\mathrm{Si}$ consideramos como cierre principal, el movimiento desde el fin de la abertura máxima, que fué mantenida en la hoja $\mathbf{N}^{\circ}{ }^{\circ}$ hasta las 15 h 05 ', y en la N. 2 hasta las $15 \mathrm{~h} 10^{\prime}$; este cierre se produjo en 15 y 10 minutos respectivamente; el cierre completo consume 36 y 41 minutos más.

Después de transcurridos de 66 a 71 minutos, los valores de pérdida de agua se estabilizan y obtenemos guarismos de pérdida de agua con estomas cerrados.

E1 déficit de saturación obtenido cuando la hoja está transpirando sólo cuticularmente, es variable: en la $\mathrm{N}^{\circ} 128 \%$ y en la $\mathrm{N}^{\circ}$ $213 \%$ (esto déficits son los extremos obtenidos en todas las observaciones; en promedio, cuando las hojas transpiran sólo cuticularmente, sus déficits varían entre 19 y $20 \%$ ).

La fig. 1 muestra la curva transpiratoria de dos hojas pesadas al mismo tiempo, en condiciones de menor humedad atmosfé-

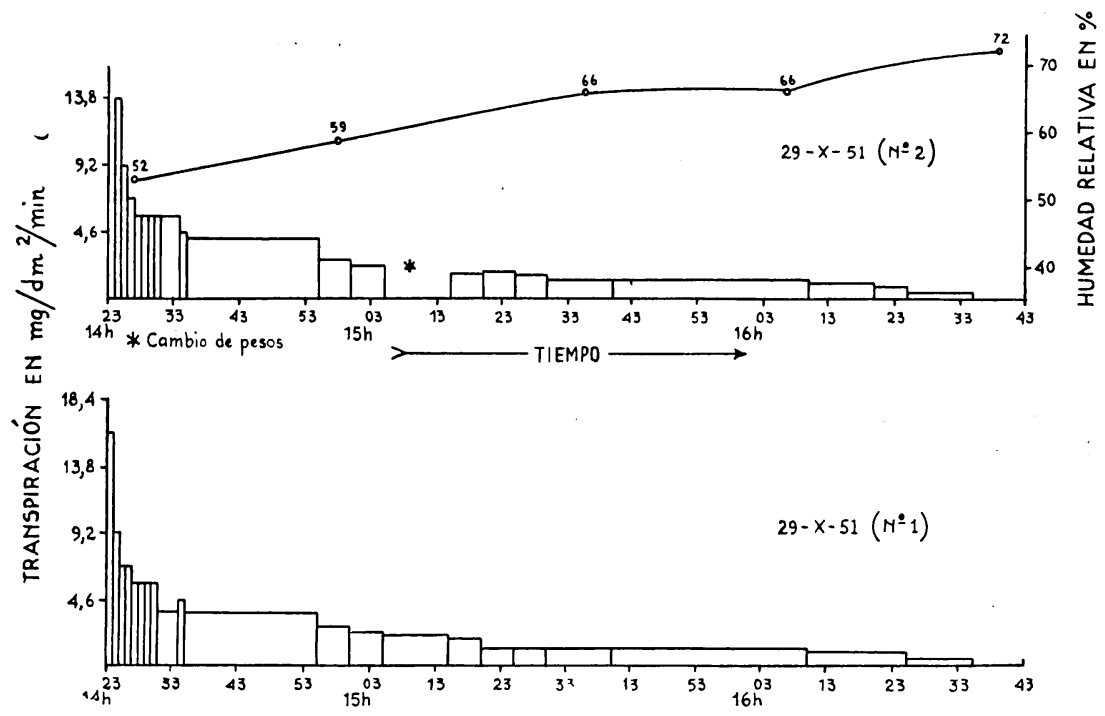

Fig. 1 - Curvas transpiratorias de dos hojas pesadas simultancamente. H.R. $=-52--72 \%$, rica (52\%); vemos desde el inicio, una rápida caída de los valores, de tal manera que a los 3 minutos la razón de transpiración se ha reducido a la mitad; luego los valores continuán decreciendo, pero lo hacen mas lentamente, de tal manera que se necesitan casi 40 minutos para que el valor de las 14 h $26^{\prime}$ se reduzca a la mitad.

La tabla 3 muestra la curva de transpiración en condiciones de humedad casi constante y alta $(\mathbf{H} . \mathbf{R} .=75 \%$, déficit de saturación del aire $4 \mathrm{~mm}$ de $\mathrm{Hg}$.). 
TAB LA 3

VALORES DE TRANSPIRACION Y DEFICIT DE SATURACION DE LA PORCION FOLIAR EN LAS DIVERSAS ETAPAS DE LA CURVA TRANSPIRATORIA

T. $=18.0 \mathrm{C}$ (día nublado y lluvioso a ratos)

Fecha 28-X-51

Pcso fresco (saturado) $=915 \mathrm{mg}$ (1) Peso seco $=153,5 \mathrm{mg}$

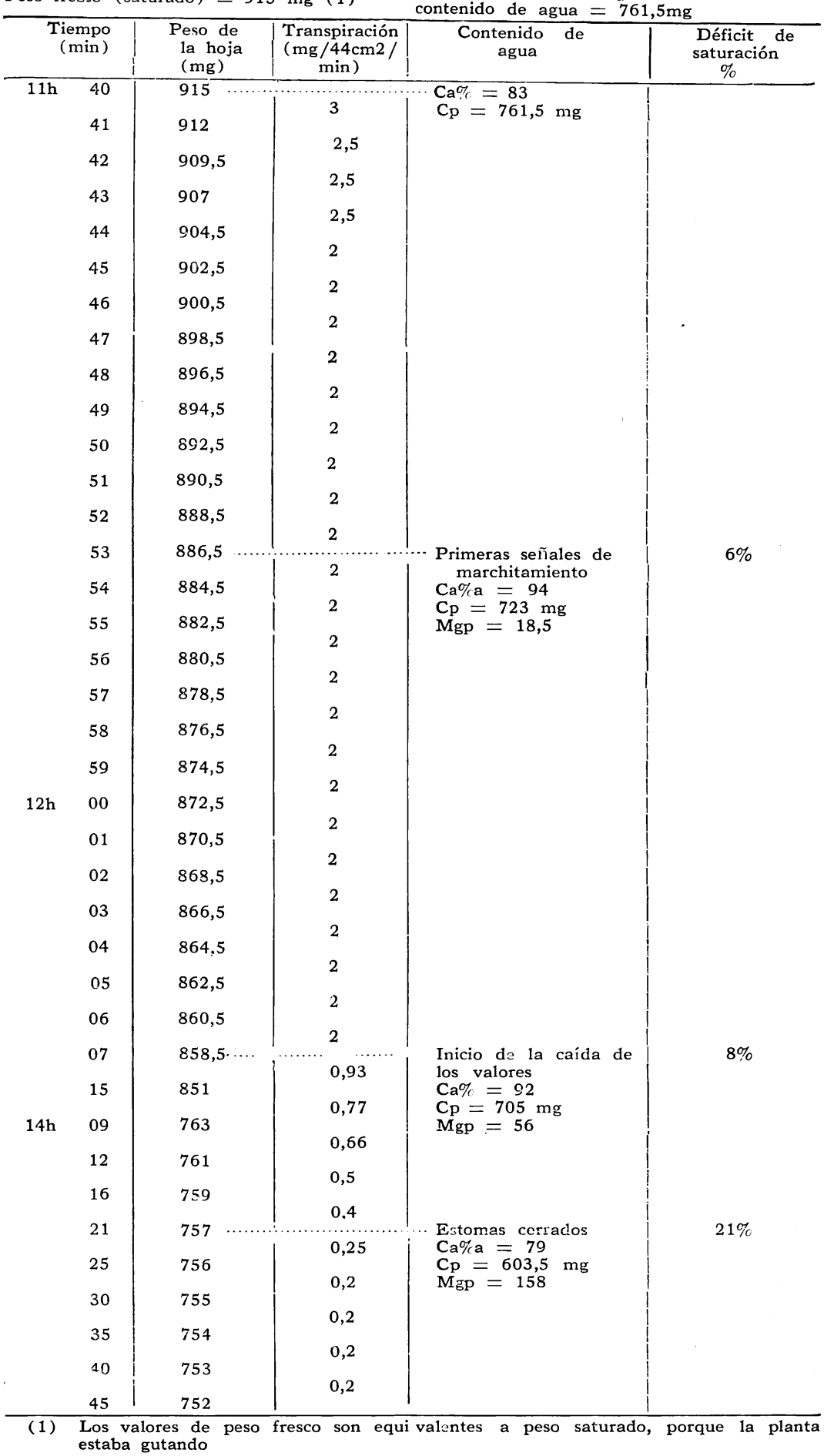


E1 ritmo de pérdida de agua, se mantiene practicamente constante durante 26 minutos, apesar de que a los 13 minutos, habiéndose perdido $18,5 \mathrm{mg}$. de agua, ya aparecen señales de marchitamiento.

Los estomas ya están casi cerrados, con déficits de saturación del $8 \%$, y $56,5 \mathrm{mg}$ de agua perdidos.

En la fig. 2 y tabla 4 aparecen dos curvas, obtenidas en días

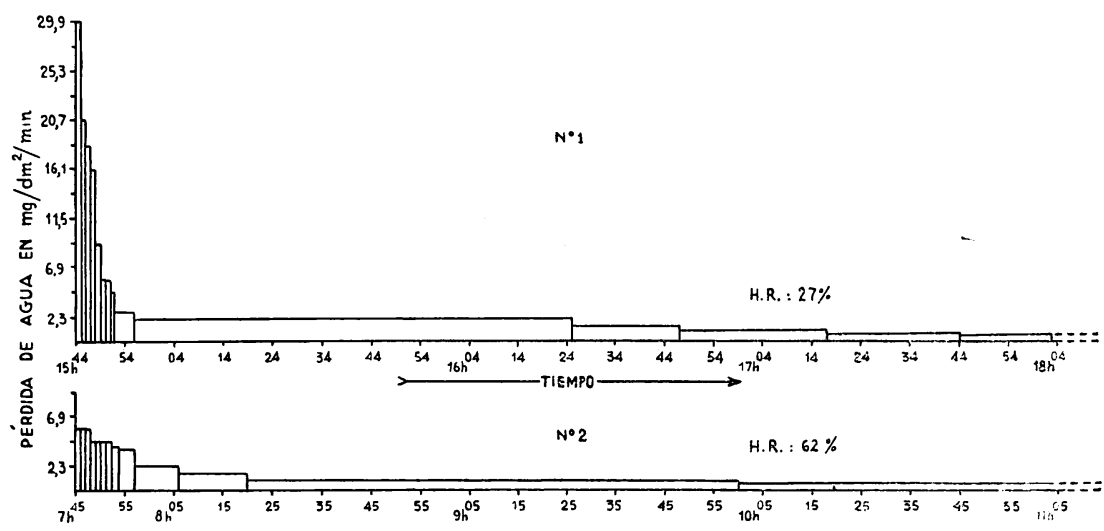

Fig. 2 - Hidroreación estomática en alta y baja humedad atmosférica N. ${ }^{0} 1: H . R .=27 \%$ (déficit de saturación del aire $=35 \mathrm{~mm}$ de $\mathrm{Hg}$ ) N. ${ }^{2}:$ H.R. $=62 \%$ (déficit de saturación del aire $=5,5 \mathrm{~mm}$ de $\mathrm{Hg}$ )

diferentes y en condiciones de humedad atmosférica diametralmente opuestas, una con H. R. $27 \%$ y otra con $62,2 \%$.

Comparándolas podemos ver:

HOJA N. ${ }^{\circ} 1$

a) E1 declinio de los valores c om ie $\mathrm{za}$ inmediatamente después de colocar la porción foliar en la balanza.

b) E1 valor inicial de pérdida de agua es (en igualdad de superficie) 5 veces mayor que el de la hoja $\mathrm{N}^{\circ} 2$.

c) $\mathrm{A}$ los 4 minutos los valores habían declinado en un $50 \%$

d) El deficit de saturación, cuando los estomas están cerrados, es del $19 \%$.

e) Desde el comienzo del declinio de los valores, hasta la obtención de guarismos constantes transcurren 41 minutos.

\section{HOJA N. ${ }^{\circ} 2$}

La caída de los valores comienza a los 3 minutos.

A los 4 minutos, los valores son el $80 \%$ de los iniciales, y a los 9 minutos, el $74 \%$

Es del $20 \%$

Transcurren de 41 a 43 minutos. 
f) Los valores finales, de pérdida de agua con estomas cerrados (cuticular) son aproximadamente iguales: 0,41 y 0,46 mg/ $\mathrm{dm} 2 / \mathrm{min}$ respectivamente.

Resumiendo tenemos:

1) El inicio de la hidroreacción, nos es desconocido porque lo que nos permite saber que los estomas comienzan a cerrarse, es el comienzo del declinio de los valores de transpiración. No se puede establecer un tiempo "standard" para el inicio de la

TABLA 4

HIDROREACCION ESTOMATICA EN ALTA Y BAJA HUMEDAD ATMOSFERICA

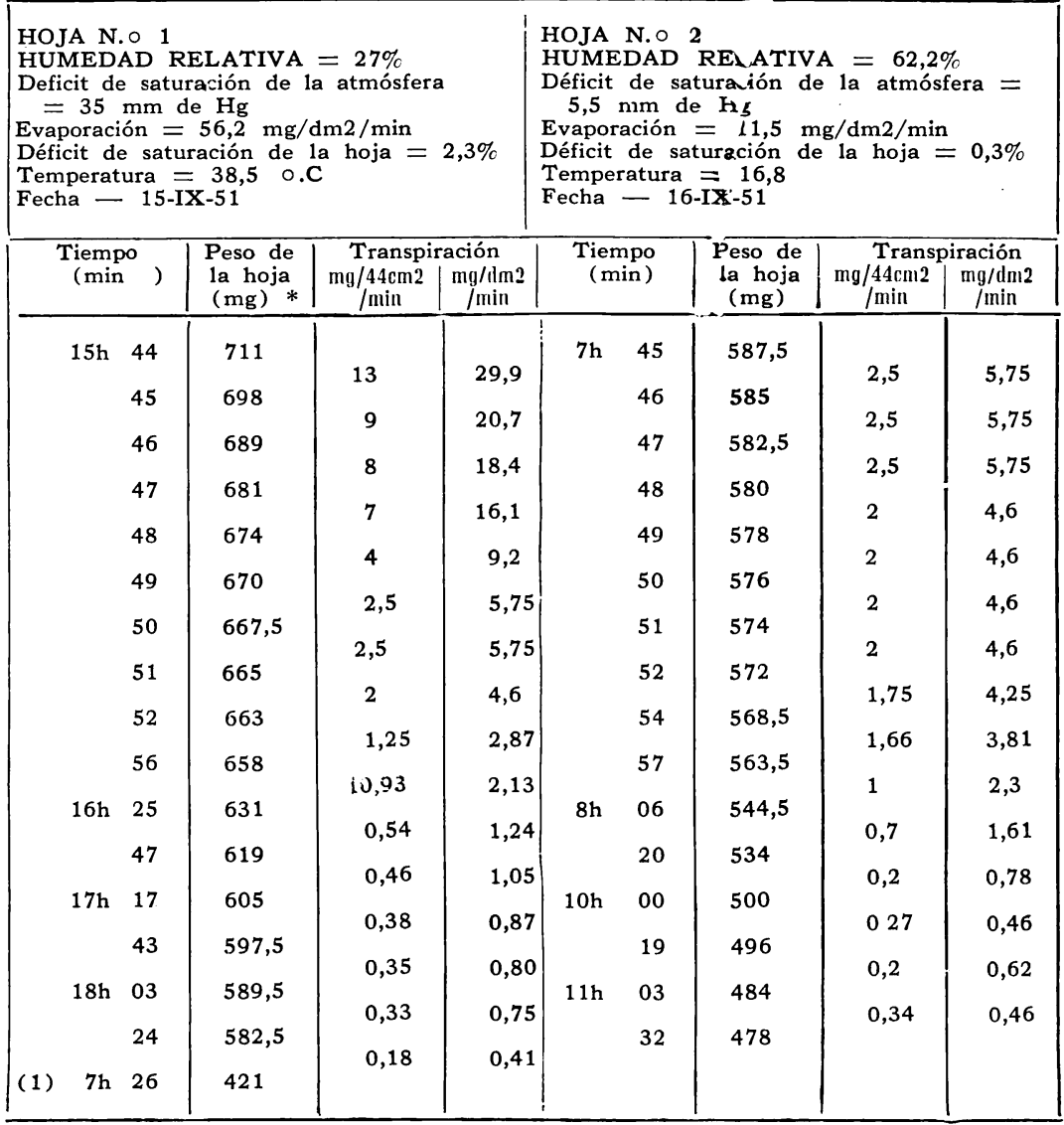

(*) Peso de la porción foliar de $44 \mathrm{~cm} 2$

(1) $7 \mathrm{~h} 26^{\prime}$ del día siguiente

caída de los guarismos, pués varía de acuerdo al déficit de saturación de la atmósfera, al contenido de agua de la hoja en el momento de comenzar a pesar, y a la edad de la misma. En la hoja N. 1 de la tabla 4, desde el primer minuto los va- 
lores declinan, en la N. ${ }^{\circ} 2$ recién después de 3 ó 4 minutos.

Si cortamcs una porción foliar entre las 12 h $30^{\prime}$ y las 14 h 30 ' en un dia de sol y elevado déficit de saturación del aire, las hojas estarán con déficits de saturación vecinos, a aquellos en que se resienten por la falta de agua y comienzan a cerrar sus estomas, en este caso la caída de la curva transpiratoria comenzará inmediatamente después de colocar las hojas en la balanza; si la operación se hace a las 8 ó 9 de la mañana, pueden transcurrir entre 15 y 20 minutos antes del comienzo de la caída de los valores.

2) Los déficits de saturación de las hojas, cuando se inicia la caída de la curva transpiratoria, son valores constantes y útiles para la comparación; oscilando entre el 6 y el $8 \%$.

3) Los déficits de saturación, registrados cuando los estomas están cerrados, oscilan en media, entre 19 y $21 \%$ (extremos 13 y $28 \%$ ), siendo mucho mas variables que los anotados cuando comienza la caída de la curva transpiratoria.

1) Tiempo empleado por la hidroreacción: En promedio, la bananera tarda de 50 a 60 minutos, desde el inicio de la caída de los valores de transpiración hasta el cierre completo de los estomas (extremos 41 y 64 minutos). Este valor es invariable dentro de amplios limites y podemos considerarlo un carácter bien específico de la transpiración de esta planta.

Las comparaciones del tiempo transcurrido entre el inicio de la caída de los valores y el cierre completo, resultan díficiles por la escasés de datos existentes; Rawitscher encontró para café $\mathbf{3 5}$ minutos, y para Cedrela fissilis 22 a 24 minutos (34, p. 8). Los datos de Ferri (9, tabla 1) para las plantas permanentes del "Campo cerrado", indican que, después de 1 hora de iniciada la caída de los valores, no se habían obtenido todavía guarismos de transpiración cuticular.

Comparando el tiempo empleado por la hidroreacción, con el de la fotoreacción, vemos que ambos movimientos consumen aproximadamente 1 hora.

El tiempo que va entre el momento en que se cortó la hoja, hasta que comienza a caer la curva transpiratoria, no es un criterio de juzgamiento, pués en la misma especie varía entre límites amplios; encambio el tiempo transcurrido desde que los estomas comienzan a reaccionar sintiendo la falta de agua, hasta que están cerrados, es invariable para cada especiei y depende del comportamiento fisiológico de la misma.

En nuestras experiencias, tanto en bajo déficit de saturación de la atmósfera, como alto, el tiempo empleado por la hidroreacción fué el mismo.

2) Curva transpiratoria en hojas jóvenes y viejas: La edad de las hojas debe tenerse en cuenta, ya Pisek y Berger (29, p. 128 ) encontraron deficiencias en el cierre de los estomas de hojas 
viejas en Caltha, Veronica y Prenanthes. Rachid constató que en Cedrela fissilis, donde los foliolos adultos, bien desenvueltos pero todavía nuevos, tienen una regulación estomática perfecta, pero cuando envejecidos, esta regulación no existe más; en este caso no sabemos si los estomas no reaccionan más, o si el vapor de agua escapa por hendiduras de la cutícula.

Para nuestras comparaciones (tabla 5 y fig. 3) elegimos una hoja jóven desenrollada 7 dias atrás y otra vieja, con los márgenes

TABLA 5

HIDROREACCION ESTOMATICA EN UNA HOJA VIEJA Y OTRA JOVEN $\begin{array}{ll}\text { T. }=30.0 \mathrm{C} & \text { H. R. }=42 \%\end{array}$

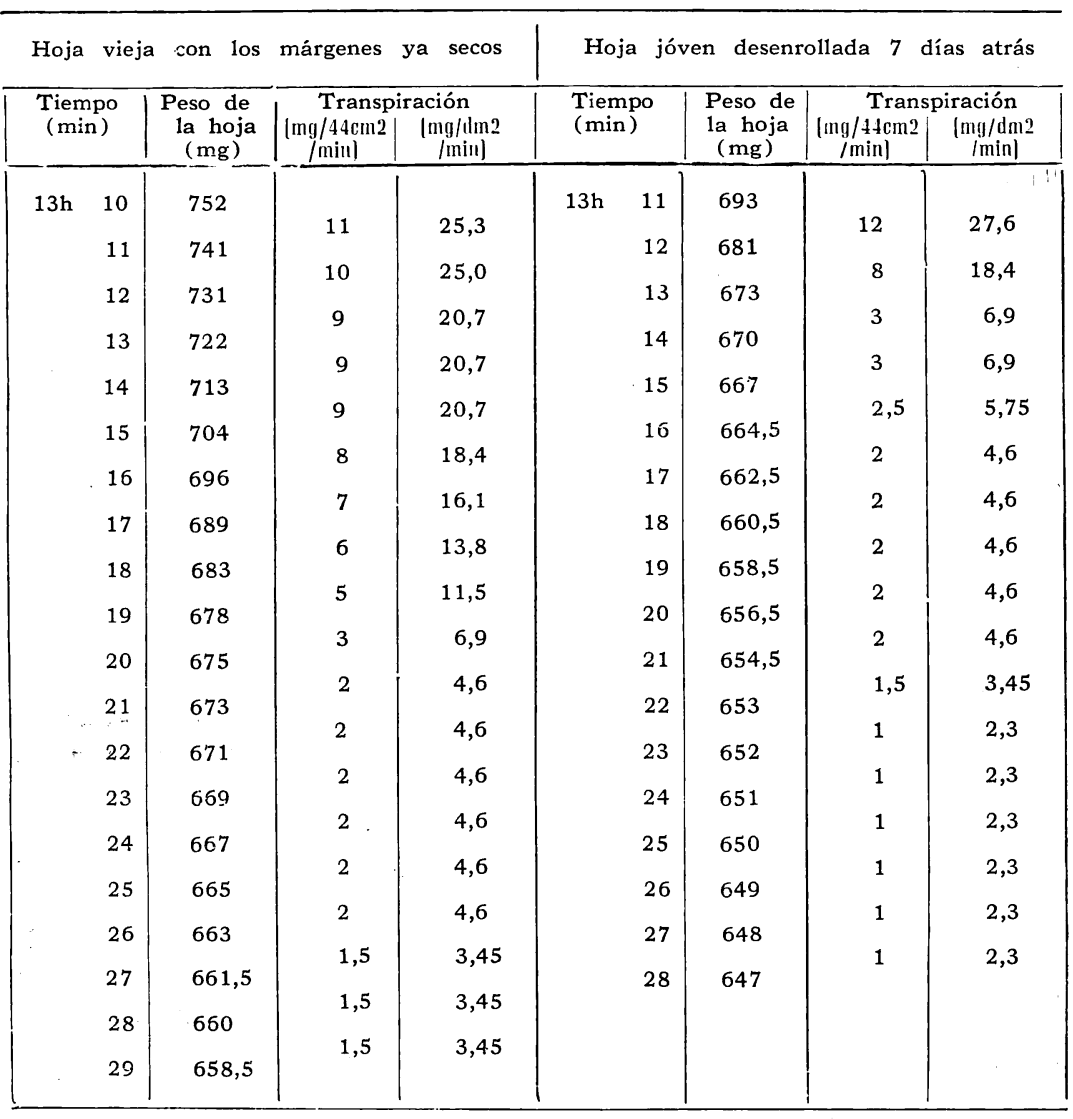

ya secos; ambas fueron pesadas al mismo tiempo, una en cada balanza, para obtener datos en condiciones atmosféricas comparables. 
En la hoja jóven, la curva transpiratoria cae inmediatamente después del corte, en la vieja 6 a 7 minutos más tarde; en ambas hojas al comenzar la experiencia hubo fuerte infiltración con xilol.

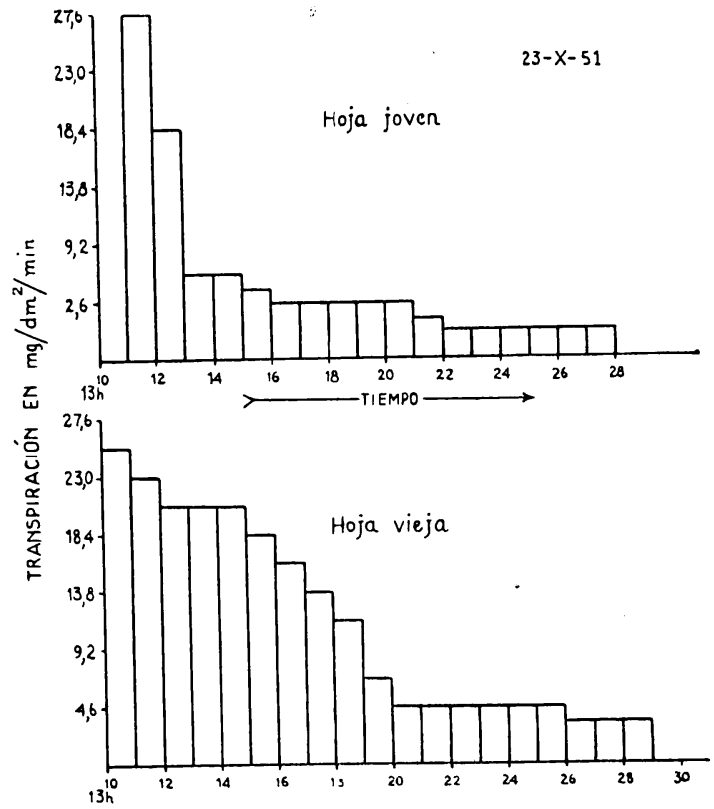

Fig. 3 - Relación entre la hidroreacción de una hoja jóven, desenrollada 7 días atrás y una vieja.

La caída de la curva es mucho más rápida en la jóven que en la adulta; a los 3 minutos, la transpiración es 1/4 de la inicial; para llegar a obtener esta relación, se necesitan en la vieja 20 minutos.

En general podemos afirmar que las hojas viejas todavía regulan su pérdida de agua, pero que la hidroreacción se atrasa unos 6 a 7 minutos con respecto a la de una hoja jóven.

\section{C) DEFICIT DE SATURACION DE LA HOJA}

En las condiciones de la ciudad de São Paulo, nunca encontramos grandes déficits de saturación, aún en las horas más calientes del día.

La marcha diaria del déficit de saturación es aproximadamente la misma, tanto en la época seca como en la lluviosa: por la mañana, entre 7 y 8 horas, encontramos las hojas con défits de 0,5 a $1 \%$ (raramente 2\%) y con frecuencia bajo presión positiva de raíces (hojas gutando); entre las 13 y las 14 horas se obtienen los valores máximos de 6 a 7\% y a las 16-18 horas, los guarismos vuelven a acercarse a los matutinos.

La curva diaria del déficit de saturación aparece así paralela a la de la transpiración (fig. 12).

En la tabla 6 en que comparamos los déficits de saturación de porciones foliares recogidas en distintas horas del dia, se vé que 
TAB LA 6

FLUCTUACION DIARIA DEL CONTENIDO DE AGUA DE LAS HOJAS 9-X-51

\begin{tabular}{|c|c|c|c|c|c|c|c|}
\hline & ra & $\begin{array}{c}\text { Transpira- } \\
\text { ción } \\
\mathrm{mg} / \mathrm{dm} 2 / \\
\mathrm{min} \\
\end{array}$ & $\begin{array}{c}\text { Déficit de } \\
\text { saturación } \\
\%(*)\end{array}$ & $\begin{array}{c}\text { Evaporación } \\
\mathrm{mg} / \mathrm{dm} 2 \\
/ \mathrm{min}\end{array}$ & $\begin{array}{c}\text { Humedad } \\
\text { relativa } \\
\%\end{array}$ & $\begin{array}{l}\text { Tempe- } \\
\text { ratura } \\
\text { o.C }\end{array}$ & $\begin{array}{l}\text { Infiltra- } \\
\text { ción }\end{array}$ \\
\hline $7 \mathrm{~h}$ & 00 & 6,9 & 0,1 & 16,1 & 79 & 18 & $\frac{\mathrm{O}}{\mathrm{x}}$ \\
\hline $8 \mathrm{~h}$ & 11 & 11,5 & 0,3 & 20,7 & 70 & 18,6 & $\frac{\mathrm{O}}{\mathrm{x}} \overline{\mathrm{x}}$ \\
\hline $8 \mathrm{~h}$ & 25 & 16,1 & 1,8 & 32,2 & 44,4 & 20,6 & $\frac{0}{\mathrm{XXX}}$ \\
\hline $9 \mathrm{~h}$ & 18 & 24,15 & 2,7 & 46 & 32,4 & 24,42 & $\frac{0}{x \times x}$ \\
\hline $9 \mathrm{~h}$ & 35 & 24,15 & 2,8 & 46 & 28 & 27 & $\frac{0}{\bar{x} \times \bar{x}}$ \\
\hline $10 \mathrm{~h}$ & 14 & 25,3 & 4,7 & 50,6 & 24,2 & 29 & $\frac{x}{x \times x}$ \\
\hline $10 \mathrm{~h}$ & 46 & 37,95 & 4,8 & 57,5 & 21,8 & 29 & $\frac{0}{x \times x}$ \\
\hline $10 \mathrm{~h}$ & 57 & 42,55 & 6 & 62,1 & 21 & 29,6 & $\frac{0}{x \times x}$ \\
\hline $11 \mathrm{~h}$ & 45 & 47,15 & 6,9 & 82,8 & 18 & 32 & $\frac{0}{x \times x}$ \\
\hline $13 \mathrm{~h}$ & 28 & 43,7 & 5,8 & 85,1 & 19,2 & 32,8 & $\frac{(0)}{\mathrm{xxx}}$ \\
\hline $14 \mathrm{~h}$ & 00 & 36,8 & 4,8 & 78,2 & 24,8 & 31 & $\frac{(\mathrm{X})}{\mathrm{XXX}}$ \\
\hline $15 \mathrm{~h}$ & 45 & 20,7 & 3,2 & 50,6 & 39,8 & 25,7 & $\frac{x}{x \times X}$ \\
\hline $16 \mathrm{~h}$ & 27 & 18,4 & 2,8 & 41,4 & 57 & 22,7 & $\frac{0}{\mathrm{xxx}}$ \\
\hline $17 \mathrm{~h}$ & 00 & 10,35 & 0,8 & 27,6 & 66 & 20 & $\frac{0}{\mathrm{xxx}}$ \\
\hline $17 \mathrm{~h}$ & 22 & 10,35 & 0,8 & 20,7 & 70 & 18,6 & $\frac{0}{x \times x}$ \\
\hline $18 \mathrm{~h}$ & 00 & 6,9 & 0,8 & 13,8 & 75 & 18,4 & $\underset{\mathbf{x} \overline{\mathbf{x}}}{\mathbf{0}}$ \\
\hline
\end{tabular}

(*) Déficit de saturación en \% del máximo contenido de agua 
el balance de agua evidencia alguna tensión a las $11 \mathrm{~h} \mathrm{45}$, cuando el déficit de saturación alcanza el 6,9\%; en esta hora, parecen existir dificultades para suplir el agua perdida; la absorción o la conducción o ambas al mismo tiempo, no acompañan el ritmo transpiratorio. Este desequilibrio se restablece rápidamente $\mathrm{y}$ nunca llega a ser lo suficientemente grande como para provocar una regulación estomática de la pérdida de agua (por lo menos en la cara inferior de la hoja).

El abastecimiento de agua parece regularizarse en 2 a 3 horas (entre las 14 y 17 horas) neutralizando el desequilibrio producido en las horas más calientes del día, cosa que se desprende del comportamiento de los estomas de la cara superior de la hoja.

Observaciones con la balanza muestran que las primeras señales de marchitamiento, aparecen com déficits que oscilan entre 4 y $6 \%$, y que la hidroreacción se hace visible sólo con déficits entre 6 y $8 \%$.

El déficit de saturación de $19-20 \%$ que se obtiene en hojas cortadas y colgadas en la balanza, cuando los estomas ya están cerrados, no se alcanza nunca en las hojas "in situ" en las condiciones de la ciudad de São Paulo; pero sin duda tales déficits se producen en los cultivos de esta planta en los oasis de la "Caatinga", donde en las horas calientes del día el test de infiltración dió resultados negativos (ver pag. 89).

\section{$\mathrm{V}$ \\ MOVIMIENTOS DE LAS HOJAS}

Es sabido que las dos mitades, derecha e izquierda, de una hoja de bananera, se disponen en el mismo plano durante la noche $\mathrm{y}$ en las primeras horas de la mañana, mientras que al mediodía se inclinan hacia abajo, formando un ángulo variable.

La nervadura media actúa como eje del movimiento, de manera que las caras inferiores de ambas mitades se aproximan una a otra.

Según Trelease (46, p. 94) estos cambios en la posición de las dos mitades foliares, se deben a alteraciones en el turgor de las células de dos articulaciones (charnelas), situadas a ambos lados de la nervadura central y visibles en la cara inferior (fig. 4).

Para determinar el ángulo formado por las dos mitades usamos un gran compás de carpintero cuyos brazos se adaptan a los bordes de la hoja resultantes de un corte transversal, y normal a la nervadura (corte practicado para poder aplicar el compás directamente sobre la hoja, pués cabalgando sobre ella, dá ángulos mayores que los reales).

Como el ángulo, aún en la misma hoja, varía de la base al ápice, para uniformizar, lo medimos siempre en la mitad de la distancia base-ápice, haciendo 8 medidas cada vez. 
Después de cada medida, sacamos porciones foliares, averiguando los déficits de saturación de las hojas para los valores angulares determinados (tablas 7 y 8 ).

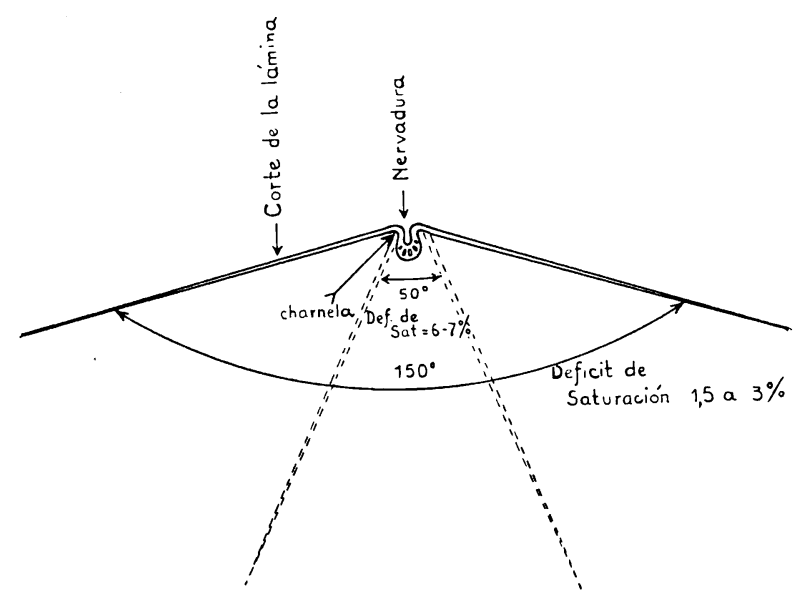

Fig. 4 - Corte transversal de una hoje, mostrando el movimiento de las 2 mitades foliares y los déficit de saturación correspodientes a las aberturas angulares extremas.

Estos movimientos de las mitades de las hojas pueden ser considerados como indicadores de cambios en el contenido de agua

TABLA 7

DEFICITS DE SATURACION DE LAS HOJAS CORRESPONDIENTES A LAS ABERTURAS ANGULARES DE LAS DOS MITADES FOLIARES DE $50.0^{\circ} \mathrm{y} .130 .0^{\circ}$ 17-XI-51

$11 \mathrm{~h} \mathrm{45}$, T. $=28,2 \quad$ H. R. $=55 \%$ ángulo formado por las dos mitades de la Infiltración $=0 \quad$ Transpiración $=13$ a $15 \quad \begin{gathered}\text { hoja }=500^{\circ} \\ \mathrm{mg} / \mathrm{dm} 2 / \mathrm{min}\end{gathered}$ $\overline{\mathrm{XXX}}$

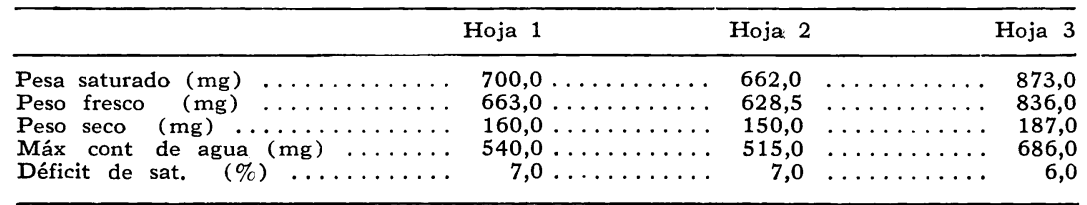

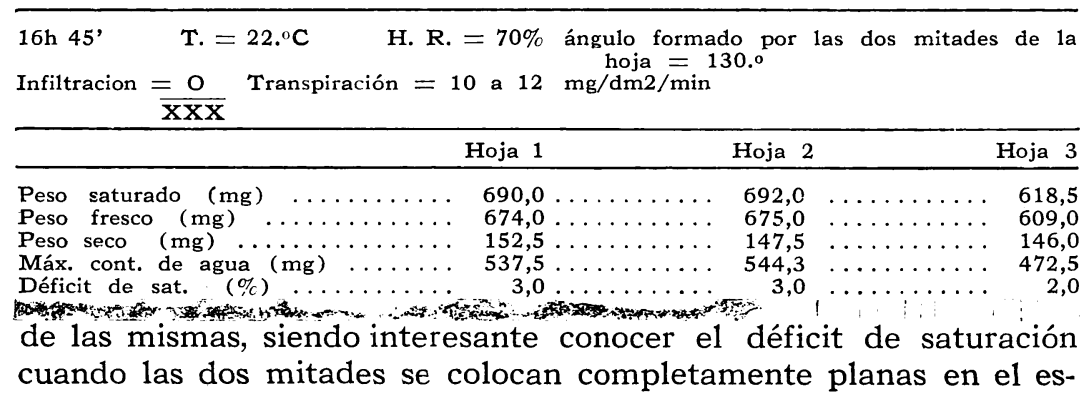


pacio y cuando se acercan lo más posible formando el ángulo menor. (fig. 4).

Considerando los promedios de las lecturas angulares, se puede establecer que el ángulo decrece desde las 8 horas, momento en que alcanza su valor máximo de 140 a $1500^{\circ}$ (las hojas nunca están perfectamente planas, porque la acción mecánica del peso de las mitades, hace que los bordes estén siempre un poco más hacia abajo que la nervadura central) hasta las 13 ó 14 horas (el ángulo menor medido en las condiciones de São Paulo fué de $45^{\circ}$ a las $11 \mathrm{~h} 30^{\prime}$ de un día caliente con temperatura de $32 .{ }^{\circ} \mathrm{C}$ y un déficit de saturación de la atmósfera de $19 \mathrm{~mm}$ de Hg. y H. R. $=45 \%$ (tabla 8).

TABLA 8

DEFICITS DE SATURACIÓN DE LAS HOJAS, CORRESPONDIENTES A LAS ABERTURAS ANGULARES DE 45,120, y $1500^{\circ}$ 16-XI-51

\begin{tabular}{|c|c|c|c|c|c|c|c|}
\hline \multicolumn{2}{|c|}{$\begin{array}{l}\text { Hora } \\
\text { del día }\end{array}$} & $\begin{array}{l}\text { ángulo for- } \\
\text { mado por } \\
\text { las } 2 \text { mi- } \\
\text { tades de } \\
\text { la hoja }\end{array}$ & \multicolumn{3}{|c|}{ Déficit de saturación } & $\begin{array}{c}\text { Temperatura } \\
\text { o.C }\end{array}$ & $\begin{array}{l}\text { Humedad } \\
\text { relativa } \\
\qquad \quad: \quad \cdot .\end{array}$ \\
\hline $11 \mathrm{~h}$ & 30 & $45 .^{\circ}$ & 6,5 & 6,5 & 6,5 & 32 & 45 \\
\hline $13 \mathrm{~h}$ & 50 & $1200^{\circ}$ & 4,0 & 3,7 & 3,5 & 25,8 & 70 \\
\hline $16 \mathrm{~h}$ & 45 & $1500^{\circ}$ & 2,4 & 2,3 & 2,3 & 22 & 75 \\
\hline
\end{tabular}

En el ambiente de la caatinga, con agua subterránea de 6 a 8 $\mathrm{m}$ de profundidad o con riego artificial, se cultivan bananeras. En observaciones practicadas en plantas de Paulo Afonso (Bahía), encontramos ángulos vecinos a $00^{\circ}$, desde las 14 hasta las 17 horas; las dos mitades estaban practicamente pegadas una a la otra por su cara inferior (la fig. 5 ilustra esa posición a las 13 horas del día 7-XII-51). E1 test de infiltración dió resultados negativos desde las 14 a las 16 horas.

En São Paulo es frecuente observar el seguiente fenómeno: en dia caliente, el ángulo declina de $130 .^{\circ}-150 .^{\circ}$ a las 8 horas, hasta $500^{\circ}$ al mediodia; si en ese momento, cambian las condiciones atmosféricas y se produce una lluvia, la abertura angular comienza a ampliarse y a las 2 horas de haber comenzado a llover ya los valores son semejantes a los de las 8 de la mañana.

E1 dia 16-XI-51, pudimos hacer experiencias en tales condiciones (tabla 8): a las $11 \mathrm{~h} 30^{\prime}$ con temperatura de $32 .^{\circ} \mathrm{C}$ y humedad relativa de $45 \%$, el ángulo era de $45 .^{\circ}$ y el déficit de saturación de las hojas se mantuvo entre 6,3 y ó,5\%; à las 12 horas comenzó a llover y a las $13 \mathrm{~h} 50^{\prime}$ el valor angular era de $120 .^{\circ}$, la temperatura de $25,8 .^{\circ} \mathrm{C}$ y la humedad relativa de $70 \%$, el déficit de saturación de las hojas variaba entre 3,5 y $4 \%$.

Quiere decir que en menos de 2 horas, el ángulo formado por las mitades de la hoja, aumentó a más del doble y el déficit de saturación de las mismas disminuyó a la mitad aproximadamente. 
A las 16 h 45' del mismo dia, teniendo un ángulo de $1500^{\circ}$, el déficit de saturación fué de $2,3 \%$.

E1 punto de vista de Trelease, de que las células de la articulación son particularmente sensibles a las variaciones en el contenido de agua de la hoja, variaciones que en todo caso resultan de la relación entre la razón de transpiración y la de absorción, parece confirmado por los datos de las tablas 7 y 8 . Con ángulos de $130-150^{\circ}$, los déficits de saturación son bajos, 2 a $3 \%$, cercanos a la saturación completa; este estado ocurre normalmente por la mañana. Con valores angulares de $50 .^{\circ}$, el déficit de saturación de la hoja oscila entre el 6 y $7 \%$.

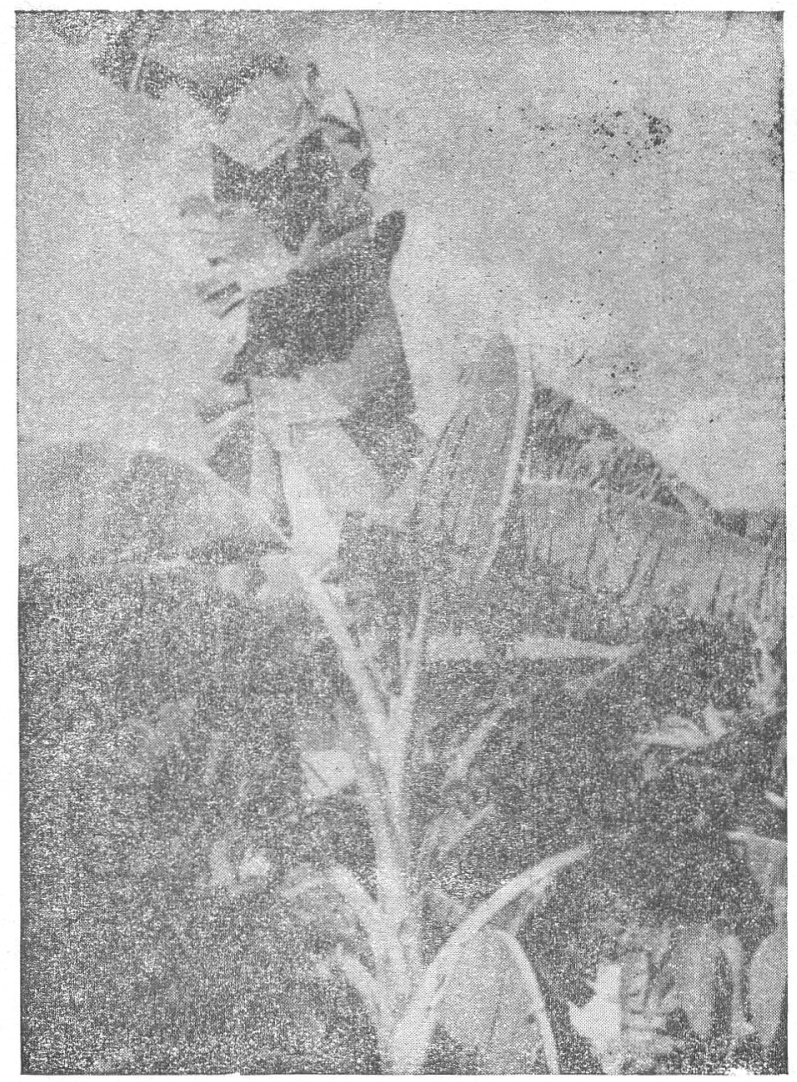

Fig. 5 - Posición de las 2 mitades de la hoje formando un ángulo de 0.0 , a 1 as 13 horas del día 7-XII-51, en Paulo Áfonso (Estado de Bahia).

Es interessante destacar que el déficit de 6-7\% (e1 mayor obtenido en las condiciones de la ciudad de São Paulo) coincide con el obtenido en experiencias con la balanza de torsión cuando comienza la caída de la curva transpiratoria, es decir cuando el movimiento del cierre de los estomas ya es diagnosticable. De 
ello inferimos que al mediodía, aún en los días más calientes, en las condiciones de São Paulo, el máximo déficit de saturación alcanzado, coincide con el inicio de la caída de la curva transpiratoria, pero está muy lejos del déficit obtenido cuando los estomas ya están cerrados (ver hidroreacción).

Además del movimiento de las mitades de las hojas, existe otro de elevación y descenso de la nervadura central; fácil de comprobar en días calmos, midiendo la distancia del ápice de la hoja al suelo, en distintas horas. La mayor elevación del ápice coincide con la mayor abertura angular (primeras horas de la mañana) y la menor con el mayor acercamiento de las mitades foliares (13 a 14 horas). (Fig. 5).

Resumiendo:

1) Aberturas angulares de $500^{\circ}$ conciden con déficits de saturación de 6 a $7 \%$, y los estomas aún no regulan sensiblemente la pérdida de agua.

2) Aberturas vecinas a $00^{\circ}$ coinciden con estomas cerradas (al test de infiltración) y los déficits de saturación deben oscilar alrededor del 20\% (déficit observado cuando los estomas están cerrados herméticamente (tabla 3 ).

3 ) Aberturas de 130 a $1500^{\circ}$ coinciden con déficits de saturación no mayores de 1,5 a: $3 \%$.

VI

\section{TRANSPIRACION}

\section{A) RELACION ENTRE LA PERDIDA DE AGUA DE LA CARA SUPERIOR E INFERIOR}

La cara inferior de la hoja tiene, en promedio, 183 estomas por $\mathrm{mm}^{2}$ y la superior 41 o sea una relación de 2 para 10 , semejante a la encontrada para Fagopyrum esculentum, y entre los valores obtenidos para tomate y zapallo $(1 / 10)$ y Ricinus communis (3/10) (42, Vol. V, p. 126).

La relación 2/10 sólo es válida para plantas desarrolladas al sol, pués en hojas formadas a la sombra, de ejemplares plantados en el interior de la floresta, obtuvimos resultados variables entre $3 / 10$ y $4 / 10$. (*)

Para comparar la transpiración de la cara superior con la de la inferior, sacábamos dos porciones foliares de una misma hoja y al mismo tiempo, una de cada mitad, a idéntica distancia de la

*) E1 material fué recogido de plantaciones en claros de la floreșta, en la isla São Sebastião, y en ésta, como en todas las comparaciones de ejemplares que crecen en distintos habitats, se tuvo el cuidado de trabajar siempre con Musa cavendishii. 
nervadura central; una porción era cubierta con una capa de vaselina en la cara inferior y la otra en la superior, luego se colgaban una en cada balanza y pesaban al mismo tiempo.

En la tabla 9, vemos que los estomas de la cara superior están cerrados desde las 9 h 10' a 9 h 45' (pérdida de agua $=1,15$ $\mathrm{mg} / \mathrm{dm}^{2} / \mathrm{min}$ ), de alli hasta $11 \mathrm{~h} 27^{\prime}$ (durante 1 hora y $22 \mathrm{minu}$ tos) los valores aumentan; de 11 h $27^{\prime}$ hasta las 14 horas, volve-

TABLA 9

RELACION DIARIA ENTRE LA PERDIDA DE AGUA DE LA CARA SUPERIOR E INFERIOR DE LA HOJA

$13-\mathrm{X}-51$

\begin{tabular}{|c|c|c|c|c|c|c|c|}
\hline \multicolumn{2}{|c|}{$\begin{array}{c}\text { Horas } \\
\text { del } \\
\text { día }\end{array}$} & \multicolumn{2}{|c|}{\begin{tabular}{c|c}
\multicolumn{2}{c}{ Transpiración } \\
(mg/dm2/min) \\
inferior \\
envaseli- \\
nada & $\begin{array}{c}\text { superior } \\
\text { envaseli- } \\
\text { nada }\end{array}$ \\
\end{tabular}} & $\begin{array}{l}\text { Porcentage } \\
\qquad(*)\end{array}$ & $\begin{array}{l}\text { Infiltración } \\
\text { xilol }\end{array}$ & $\begin{array}{l}\text { Humedad } \\
\text { relativa }\end{array}$ & $\begin{array}{c}\text { Tempe- } \\
\text { ratura }\end{array}$ \\
\hline $9 h$ & 10 & 1,15 & 9,2 & 12,5 & $\frac{0}{x x x}$ & 49,8 & 24,4 \\
\hline $9 \mathrm{~h}$ & 45 & 1,15 & 9,2 & 12,5 & $\frac{0}{x \times x}$ & 30,6 & 28,5 \\
\hline $10 \mathrm{~h}$ & 05 & 2,3 & 16,1 & 14,2 & $\frac{(x)}{x \times x}$ & 28,4 & 29,2 \\
\hline $11 \mathrm{~h}$ & 27 & 1,15 & 32,2 & 3,5 & $\frac{0}{x \times x}$ & 28,0 & 31 \\
\hline $12 \mathrm{~h}$ & 30 & 1,15 & 34,5 & 3,3 & $\frac{\mathrm{O}}{\mathrm{x} \mathrm{XX}}$ & 28,0 & 32 \\
\hline $14 \mathrm{~h}$ & 00 & 2,3 & 27,6 & 8,3 & $\frac{x}{x \times x}$ & 26,4 & 32,6 \\
\hline $15 \mathrm{~h}$ & 15 & 3,4 & 27,6 & 12,3 & $\frac{x}{x x x}$ & 30,5 & 29,6 \\
\hline $15 \mathrm{~h}$ & 30 & 4,6 & 23,0 & 20,0 & $\frac{x}{x x \bar{x}}$ & 32,4 & 25,5 \\
\hline $17 \mathrm{~h}$ & 30 & 1,13 & 9,2 & 12,4 & $\frac{0}{x \times x}$ & 72,0 & 18,6 \\
\hline
\end{tabular}

(*) Transpiración de la cara superior en $\%$ de la inferior

mos a obtener guarismos de transpiración cuticular, y desde allí en adelante se registra un segundo aumento de la pérdida de agua.

Este comportamiento de ios estomas de la cara superior, lo podemos considerar como típico en dias calientes con fuerte déficit de saturación de la atmósfera. 
Representando graficamente las curvas de las dos caras (fig. 6), vemos que la de la superior es de dos máximos, uno a las $10 \mathrm{~h}$ 05 ' y el otro a las 15 h 30', en cambio la inferior muestra la curva típica de la hoja toda en las condiciones de São Paulo con un sólo máximo a las 12 h 30 '.

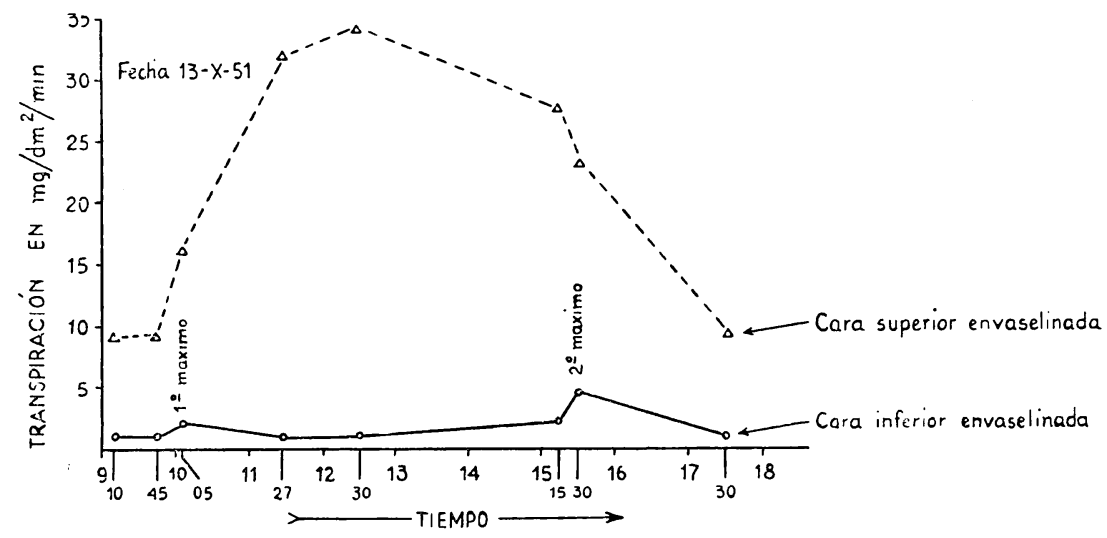

Fig. 6 - Curvas diarias de transpiración de la cara superior e inferior de una mis-

E1 test de infiltración indicó comportamiento semejante, salvo a las 10 h $05^{\prime}$ en que la infiltración fué dudosa y la balanza mostró un aumento en la pérdida de agua.

Los extremos de pérdida de agua de la cara superior, fluctuan entre $3,3 \%$ ( 12 h 30') y 20\% (15 h 30'), siendo 100 la pérdida de la cara inferior; y entre el $2,9 \%$ y el $16,6 \%$ de la transpiración total. Relaciones semejantes obtuvieron Oppenheimer y Mendel $(28$, p. 44$)$ trabajando con naranja en condiciones de pomar: $4,48 \%$ y $18,23 \%$ de la pérdida total de agua.

Resumiendo:

1) La pérdida dorsal de agua representa, en promedio, el $11 \%$ de la ventral y el $10,2 \%$ de la total, hecho que se explica por la pobreza en estomas de la cara superior (un estoma de la cara superior por cada 5 de la inferior) y por estar éstos cerrados total o parcialmente en las horas calientes del dia (a veces durante todo el dia).

2) La pérdida dorsal es proporcionalmente alta en la media mañana y media tarde, declinando al mediodia y al anochecer.

B) TRANSPIRACION DE HOJAS JOVENES

En esta planta no existen mayores dificultades para calcular la edad de las hojas; en promedio, cada 30 a 35 dias aparece una nueva ya desenrollada; por eso resulta fácil estudiar si hojas jóvenes y adultas muestran una intensidad de transpiración similar.

En el mes de octubre (tabla 10) una hoja jóven desenrollada 9 dias atrás, transpiró a las 11 h 01 ' el $70 \%$ de otra desenrollada 
TABLA 10

RELACION ENTRE LA TRANSPIRACION DE UNA HOJA JOVEN Y OTPA ADULTA

$20-\mathrm{X}-51$

\begin{tabular}{|c|c|c|c|c|c|c|}
\hline \multicolumn{2}{|c|}{$\begin{array}{l}\text { Horas } \\
\text { del día }\end{array}$} & \multicolumn{2}{|c|}{$\begin{array}{l}\text { Transpiración } \\
(\mathrm{mg} / \mathrm{dm} 2 / \mathrm{min})\end{array}$} & \multirow{2}{*}{$\begin{array}{c}\begin{array}{c}\text { Evaporímetro } \\
\text { molde de hoja } \\
\text { (mg/dm2/min })\end{array} \\
50,6\end{array}$} & \multirow{2}{*}{$\begin{array}{c}\begin{array}{c}\text { Humedad } \\
\text { relativa } \\
\%\end{array} \\
46,8\end{array}$} & \multirow{2}{*}{$\begin{array}{c}\begin{array}{c}\text { Tempe- } \\
\text { ratura } \\
\text { o.C }\end{array} \\
29,4\end{array}$} \\
\hline $11 \mathrm{~h}$ & 01 & 27,6 & 19.5 & & & \\
\hline $11 \mathrm{~h}$ & 50 & 32,2 & 25,3 & 48,3 & 44 & 29,6 \\
\hline $12 \mathrm{~h}$ & 50 & 32,2 & 27,6 & 50,6 & 42 & 30,0 \\
\hline $13 \mathrm{~h}$ & 00 & 39,1 & 23,0 & 50,6 & 42 & 30,2 \\
\hline $13 \mathrm{~h}$ & 10 & 39,1 & 25,3 & 55,4 & 40 & 30,0 \\
\hline $15 \mathrm{~h}$ & 10 & 32,4 & 27,6 & 50,6 & 41 & 28,0 \\
\hline $16 \mathrm{~h}$ & 20 & 27,6 & 25,3 & 46,0 & 43 & 26,0 \\
\hline $16 \mathrm{~h}$ & 40 & 23,0 & 23,0 & 46,0 & 48 & 25,6 \\
\hline
\end{tabular}

* Desenrollada 60 días atras, con los márgenes completamente laciniados

* Desenrollada 9 días atrás, aún sin lacinias

2 meses atrás; a las 11 h 50 ' el $75 \%$, y entre las 12 h 50 ' y 15 h 10 ' se mantuvo por encima del $80 \%$. Esta relación cambia completamente a partir de las $16 \mathrm{~h}$; desde ese momento la transpiración de la hoja adulta comienza a declinar con rapidéz, mientras la de la jóven lo hace lentamente, de tal manera que a las 16 h 40 minutos, ambas tienem el mismo ritmo de pérdida de agua.

Oppenheimer y Mendel (28, p. 41) habiendo notado este mismo fenómeno en naranja (más pronunciado todavía: pués a las 16 horas, la pérdida de agua de la hoja jóven era mayor que la de la adulta); lo interpretaron asi: "it appears that the young leaves did not restrict their stomatal transpiration as quickly and effectively as did the old", hecho que no pudo ser confirmado para bananera pues comparando la rapidéz de la reacción estomática en una hoja jóven y otra ya vieja (*) obtuvimos resultado inverso (ver hidroreacción); la jóven indica a los 2 minutos de comenzada a pesar, una disminución de la razón de transpiración que en la vieja sólo se obtiene a los 9 minutos (tabla 5 y fig. 3 ).

Oppenheimer y Mendel, encontraron también, en muchos casos, que las hojas jóvens pierden más agua que las ad̉ultas. En nuestras observaciones nunca encontramos hojas jóvenes transpirando más que las adultas; la hoja jóven llegó a perder, como máximo el 100/100 de agua de la adulta y como mínimo el 58/100; la pérdida mayor se produjo a las 16 horas y la menor a las 13 horas.

*) Para estes observaciones consideramos hojas jóvenes (con estomas ya funcionales) desde 7 dias de haberse desenrollado completamente, hasta 30-35 días; adultas desde all, hasta que sus márgenes laciniados comienzan a secarse y viejas en adelante. 


\section{C) TRANSPIRACION CUTICULAR}

El estudio de la transpiración cuticular en la bananera, se vé dificultado por la existencia de estomas en ambas caras de la hoja; con las que los poseen sólo en la cara inferior (hypostomáticas), el método clásico consiste en revestir esa cara con vaselina, la que cierra los estomas perfectamente impidiendo al mismo tiempo casi toda transpiración cuticular.

La fig. 7 muestra los estomas de la bananera: son pequeños, el ostiolo tiene la forma de la letra griega sigma; están distribuidos

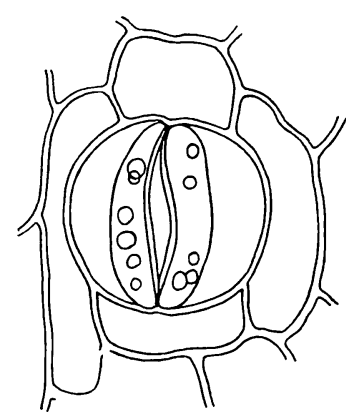

(a)

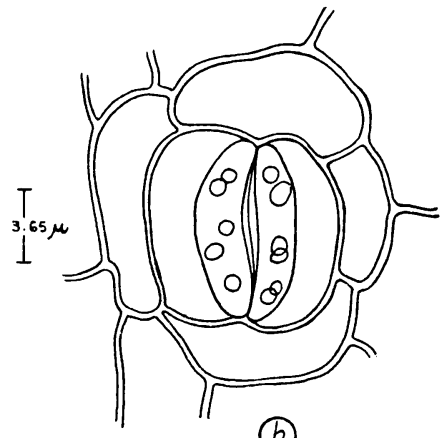

(b)

Fig. 7 - Estomas de bananera.

en número variable por toda la parte aérea de la planta. Las determinaciónes en promedio, por $\mathrm{mm}^{2}$ de superficie, en ejemplares desarrollados al sol, fueron:

Lámina de la hoja Cara superior Cara inferior Región apical ........ . 40 ........ 180

Región basal . . . . . . . . . 43 . . . . . . . . . 180

Vecindad de la nervadura . . . 36 . . . . . . . . 182

Márgen .. . . . . . . . 46 ........ 187

Nervadura central ... . . . . 4 ......... 1

Brácteas de la inflorescencia . . $\quad 1 \quad$. . . . . . . . . . . . 1

Vainas foliares del pseudotron-

co .......... 11

El ostiolo es pequeño, nunca medimos aberturas mayores de 2,77 micrones en el diámetro menor y 13 en el mayor.

1) Determinación del estado cerrado de los estomas

De entre los métodos usados para la observación de la abertura estomática, tratándose de una primera orientación, nos servimos de la infiltración, empleando en general, el xilol, y cuando los estomas parecian cerrados el eter petróleo, que penetra en hendiduras más estrechas.

Los estomas de bananera, a pesar de tener ostiolo tan estrecho, dejan pasar, en el estado mas abierto, todos los líquidos de la serie infiltrante, incluso parafina líquida; pero pequeñas dismi- 
nuciones del diámetro menor, ya vedan el camino a esta última y al alcohol (estomas de diámetro menor ligeramente mas pequeño, como los de Cedrela fissilis que tienem 2 micrones, no dejan pasar nunca, aún en su estado más abierto, ni la parafina líquida ni el alcohol).

La balanza permitió comprobar que la infiltración, aún con xilol y benzol, cesa antes del cierre completo de los estomas; los líquidos dejan de entrar cuando la balanza todavía indica valores que están por encima de la transpiración cuticular.

Tanpoco el microscopio de iluminación vertical nos informa sobre el cierre perfecto de los estomas, pues llega un momento en que se hace imposible distinguir si el estiolo está abierto o nó.

La balanza, en cambio, cuando indica el fin del descenso rápido de los valores de transpiración y comienzan a aparecer guarismos casi constantes, está marcando, al mismo tiempo, el cierre perfecto de los estomas y podemos contar entonces sólo con la transpiración cuticular.

2) Determinación de la transpiración cuticular

En la transpiración cuticular, son dos los valores importantes para la ecología:

I) La transpiración que se procesa cuando la cutícula desempeña su papel protector, es decir cuando los estomas se han cerrado por hidroreacción.

Esta pérdida de agua se procesa con cutícula no saturada y sus valores son de fácil obtención destacando porciones foliares y pesando en la balanza hasta obtener guarismos constantes.

II) La pérdida cuticular que se opera en la hoja saturada donde hay relativa abundancia de agua en las camadas externas de la cutícula, la que evapora entonces con más facilidad.

a) Porciones foliares pesadas en la balanza hasta obtener valores constantes (cutícula no saturada).

En este caso, cuando nuestros datos indican perfecto cierre de los estomas (valores mas o menos invariables) la transpiración cuticular que resta es la de una hoja con déficits de saturación del 13 al 28\%; variable según el estado de abertura inicial de los estomas. Esta cutícula ya no está saturada de agua.

Los valores así obtenidos, son los realmente importantes cuando se estudia la resistencia de las plantas a la sequía, porque a la ecología le interesa conocer esta pérdida de agua que se procesa cuando la cutícula desempeña su papel protector.

La tabla 11 muestra el valor obtenido en tales condiciones: $0,48 \mathrm{mg} / \mathrm{dm} 2 / \mathrm{mm}$ que representa el $1,4 \%$ 
TABL A 11

RELACION DE LA TRANSPIRACION TOTAL Y CUTICULAR CON EL BLATT. EVAPOR IMETER

$$
17-\mathrm{X}-51
$$

$\mathrm{T} .=24,8 .{ }^{\circ} \mathrm{C}$

H. R. $=63 \%$ (al comenzar la experiencia $)$

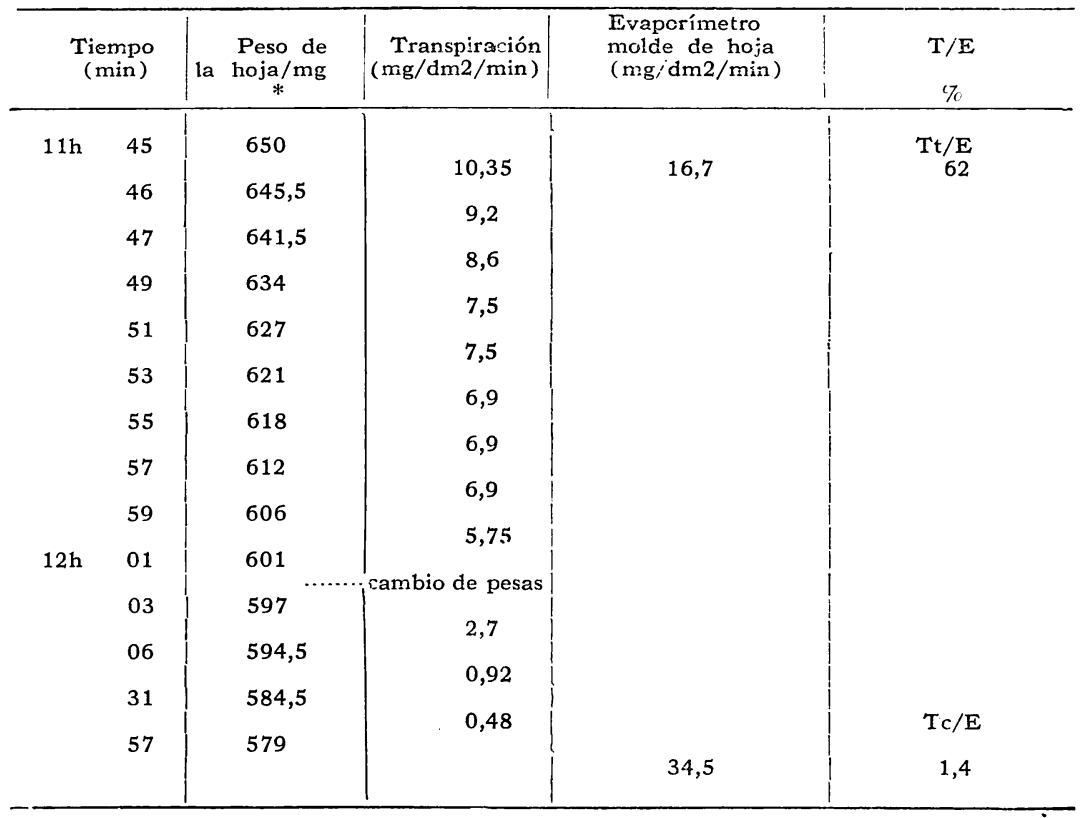

Peso de la porción foliar de $44 \mathrm{~cm} 2$ mas la vaselina del márgen (se tomó esta precaución para evitar cualquier posible pérdida de agua por la superficie del corte)

de la evaporación libre y el 3,2\% de la transpiración total.

Comparando este dato con los obtenidos por Pisek y Berger (29) y Kamp (21) vemos que las higrófitas transpiran con estomas cerrados de 2 a 2,5 veces más que bananera (Impatiens noli tangere $60 \mathrm{mg} / \mathrm{dm} 2 /$ hora y Veronica beccabunga 86). Nuestro valor de 0,48 $\mathrm{mg} / \mathrm{dm} 2 / \mathrm{min}$, que corresponde a $29 \mathrm{mg} / \mathrm{dm} 2 /$ hora, es comparable a la transpiración cuticular de un roble europeo (Quercus robur) con $27 \mathrm{mg} / \mathrm{dm} 2 /$ hora; mayor que Fagus silvatica $22 \mathrm{mg} / \mathrm{dm} 2 /$ hora y menor que Coryius avellana con $38 \mathrm{mg} / \mathrm{dm} / 2 /$ hora, los tres árboles de hojas caducas.

Este valor de $29 \mathrm{mg} / \mathrm{dm} 2 /$ hora, o sea el $3,2 \%$ de la transpiración total obtenida en las mismas condiciones, es la transpiración cuticular procesada con cutícula reseca, y, como veremos adelante los valores extraídos de cutícula saturada, son mayores ( $34 \mathrm{mg} / \mathrm{dm} 2 /$ hora), pero siempre entran dentro de los árboles europeos de hojas caducas. 
La porción foliar de la tabla 12, estudiada en el

TABL A 12

VALORES DE TRANSPIRACION Y DEFICIT DE SATURACION DE LA PORCION FOLIAR EN LAS DIVERSAS ETAPAS DE LA CURVA TRANSPIRATORIA T. $=17-20 .{ }^{\circ} \mathrm{C} \quad$ H. R. $=69-64 \% \quad$ Fecha 2-IX-51

Peso fresco (saturado) $=731 \mathrm{mg}$ (1) Peso seco $=110 \mathrm{mg}$ Contenido de agua $=621$

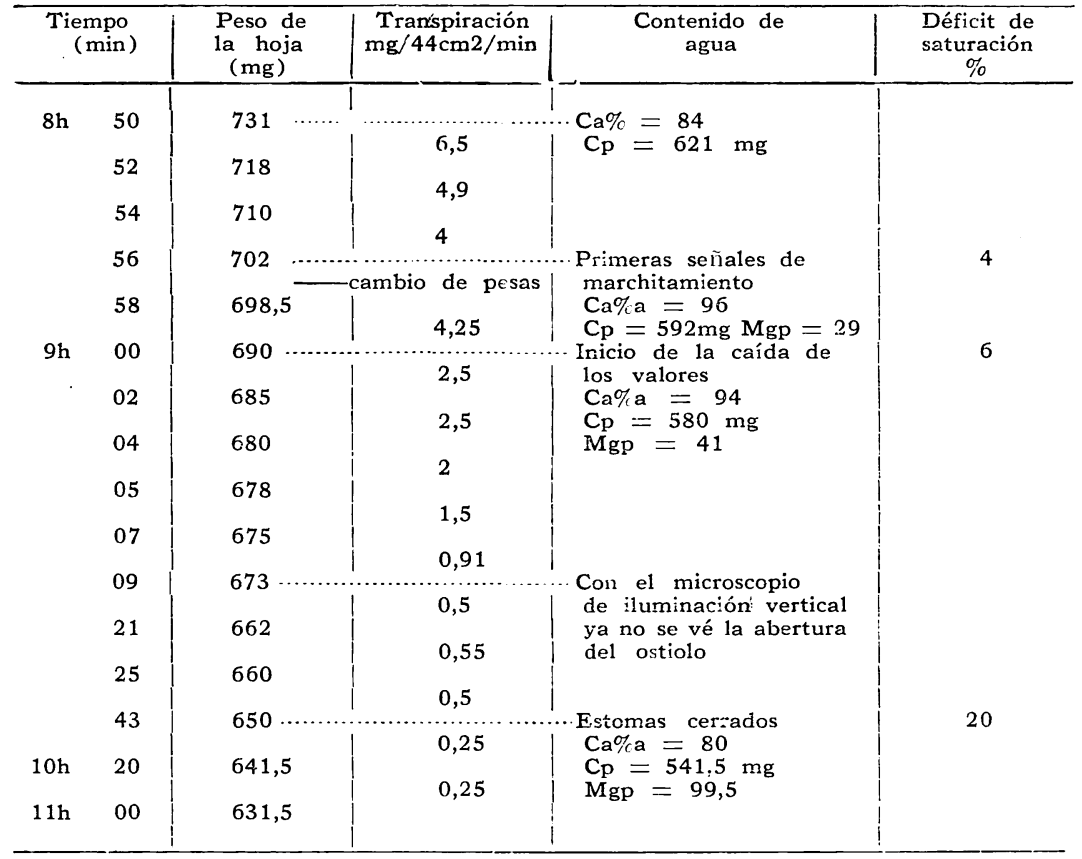

(1) E1 peso fresco es equivalente a peso saturado; la planta estaba gutando

laboratorio en condiciones normales de humedad y temperatura, pesó al comienzo $731 \mathrm{mg}$, su peso seco fué de $110 \mathrm{mg}$; el agua contenida en la porción de $44 \mathrm{~cm} 2$ era de $621 \mathrm{mg}$. Por la transpiración total de $65 \mathrm{mg} / 44$ $\mathrm{cm} 2 / 10 \mathrm{~min}$, perdería $390 \mathrm{mg} /$ hora, lo que significa que en una hora y 35 minutos habría evaporado tanta agua cuanta contiene.

E1 marchitamiento se dá, cuando faltan 30 miligramos de agua. La transpiración cuticular significa para este ejemplo una pérdida de $2,5 \mathrm{mg}$ de agua en $10 \mathrm{mi}$ nutos o sea $15 \mathrm{mg}$. por hora.

Para gastar $621 \mathrm{mg}$ conteridos en la porción foíiar, se necesitarían 41 horas en las mismas condiciones; y, saturada de agua, la hoja podría transpirar cuticularmente 2 horas, antes de dar las primeras señales de marchitamiento. Esto nos da una idea de la eficiente protección cuticular que tiene la bananera, aún cuardo la anatomía pareceria indicar lo contrario. 
b) Hojas envaselinadas (cutícula saturada)

A pesar de tratarse de hojas con estomas en ambas caras, los de la superior permanecen cerrados durante gran parte del día y en esas horas se puede trabajar como si se tratara de hojas hypostomáticas; envaselinar la cara inferior y determinar los valores de transpiración que se procesan al travéz de la cutícula.

La hoja N. ${ }^{\circ} 1$ de la tabla 13, al comenzar la experien-

TABL A 13

RELACION ENTRE LA TRANSPIRACION DE LA CARA SUPERIOR CON ESTOMAS CERRADOS (CUTICULAR) Y LA INFERIOR (TOTAL)

T. $=24,4^{\circ} . \mathrm{C}$ $15-\mathrm{X}-51$

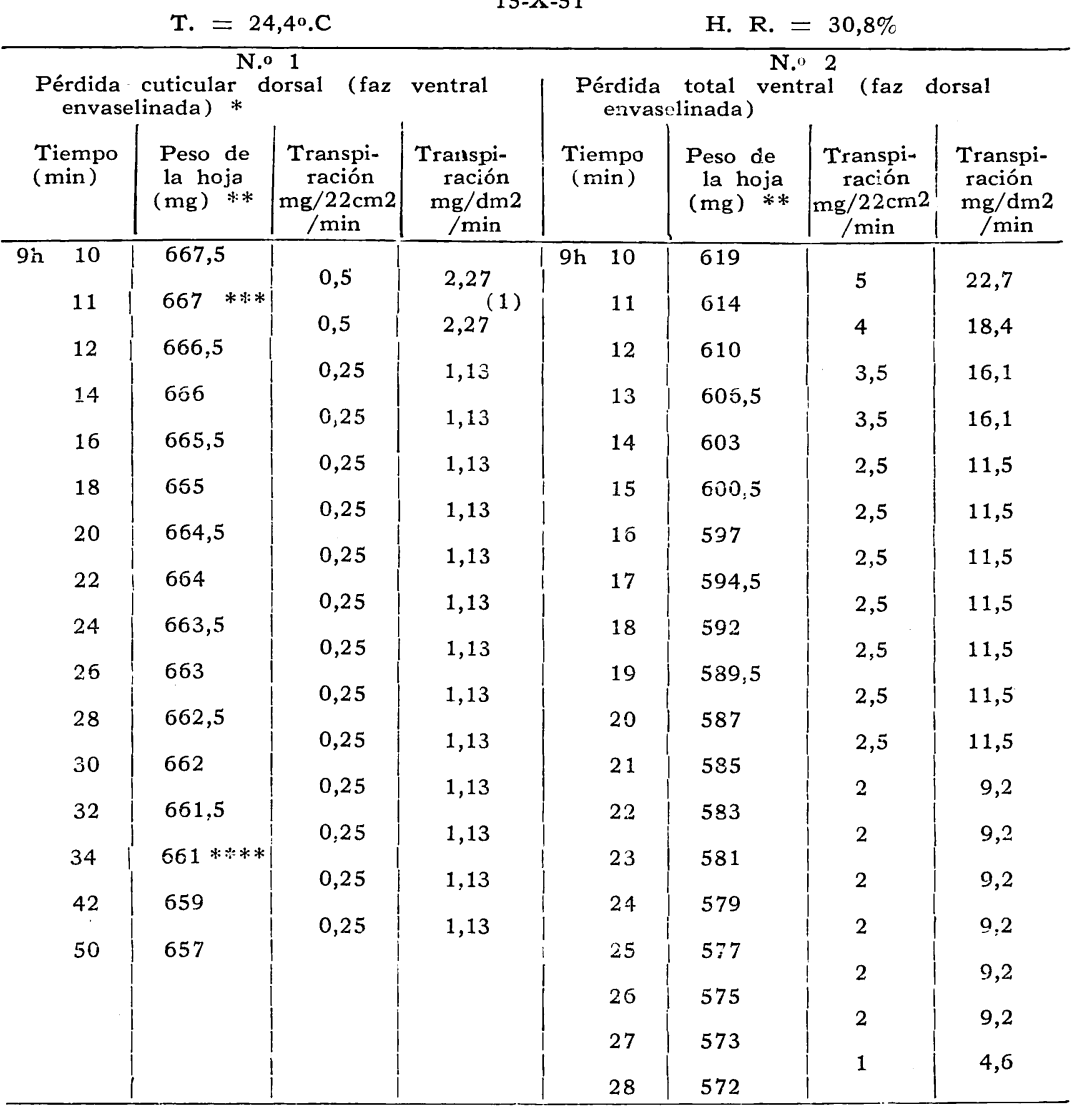

* La observación del estado cerrado de los estomas se hizo con el microscopio de iluminación vertical, metodo de Stalfelt y test de infiltración.

** Peso de la porción foliar de $44 \mathrm{~cm} 2$ (ambas caras) mas la vaselina de la ca:a dorsal o ventral respectivamente.

*** test de infiltración $\frac{\mathrm{O}}{\mathrm{XXX}}$

HOJA N.o 1: Peso saturado $=670 \mathrm{mg}$

$\begin{aligned} \text { HOJA N. } 1: & \text { Peso saturado }=670 \mathrm{mg} \\ & \text { Peso fresco }=667,5 \mathrm{mg} \\ & \text { Peso seco }=89 \mathrm{mg}\end{aligned}$ $* * *$ test de infiitración $=\frac{\mathrm{O}}{\mathrm{O}}$

Déficit de saturación en $\%$ del máximo contenido de agua $=0,5 \%$

Evaporimetro molde de hoja de $9 \mathrm{~h} 10^{\prime}$ a $9 \mathrm{~h} 13^{\prime}=45 \mathrm{mg} / \mathrm{min} / 100 \mathrm{~cm} 2$ 
cia presentaba un déficit de saturación del $0,5 \%$, es decir que estaba saturada. Los guarismos de los 2 primeros minutos, deben desestimarse pues la superficie foliar estaba aún levemente humedecida por el rocío ma. tinal.

Al valor $1,13 \mathrm{mg} / \mathrm{dm} 2 / \mathrm{min}(67,8 \mathrm{mg} / \mathrm{dm} 2 /$ hora $)$ debe restársele $1 \mathrm{mg} / \mathrm{dm} 2 /$ hora $(21$, p. 416 y 36, p. 126) que corresponde a la pérdida de agua a travéz de la vaselina, valor que por lo exiguo, puede ser negligenciado.

Esta pérdida cuticular de $66,8 \mathrm{mg} / \mathrm{dm} 2 /$ hora es 2,3 veces mayor que la obtenida con cutícula no saturada $(29 \mathrm{mg} / \mathrm{dm} 2 /$ hora $)$.

Es también 1,9 veces mayor que la establecida por otros métodos y eso se debe a tres factores:

a) E1 hecho, ya conocido en la literatura que, cuando la hoja es protegida de un lado por la sustancia impermeable, queda más saturada y transpira más del otro, libre.

b) Con los métodos a nuestro alcance para conocer el estado mas cerrado de los estomas (de Stalfelt, microscocopio de iluminación vertical, e infiltración) nunca estamos seguros que los estomas de la cara superior que suponemos cerrados, lo estén perfectamente, particularmente en estomas de diámetro menor o pequeño como los nuestros.

c) En estas experiencias trabajamos con hojas adultas, laciniadas en parte, y sin duda, con la edad, la cutícula sufre, por influencias mecánicas, lesiones que van a influenciar primero la cara superior, es decir la faz que nos servía para medir la transpiración cuticular en estas observaciones.

Estas lesiones pueden tener consecuencias importantes en la pérdida de agua, cuando imposibilitan el funcionamiento de un grupo de estomas particularmente en hojas homobáricas como las de banana, donde no existen cámaras que separen pequeñas áreas (en las hojas heterobáricas existen una serie de compartimentos incomunicados y cualquier lesión cuticular quedará localizada en esas cámaras).

E1 valor $66,8 \mathrm{mg} / \mathrm{dm} 2 /$ hora representa el $4,8 \%$ de la transpiración total (hoja N. ${ }^{\circ} 2$ ) obtenida en las mismas condiciones atmosféricas y de tratamiento (cara superior envaselinada) con un valor de $1361 \mathrm{mg} / \mathrm{dm} 2 /$ hora, hechas las correcciones de la pérdida de agua por la cara envaselinada.

El evaporímetro molde de hoja registró un valor promedio de $2700 \mathrm{mg} / \mathrm{dm} 2 /$ hora durante los primeros 
20 minutos de la experiencia. La transpiración total fué el $50 \%$ de la evaporación; y la cuticular el 2,4\% de esta última.

c) Hojas jóvenes con estomas cerrados (cutícula saturada) Para eludir las dificultades de las estimaciones efectuadas envaselinando la cara inferior, tentamos determinar la pérdida cuticular (con cutícula saturada) basándonos en el hecho de que las hojas más jóvenes de cada pié, todavía enrolladas en la base, presentan los estomas: cerrados durante todo el día (por lo menos en los meses de agosto a diciembre).

La tabla 14 muestra la relación entre la transpiración de la hoja mas jóven (pérdida cuticular de agua) y de otra adulta (pérdida total). Previamente el test de infiltración indicó la nó penetración del xilol ni del eter petroleo en la hoja jóven.

Los valores obtenidos (hoja N. ${ }^{\circ} 1$ ) en los primeros 26 minutos, desde las 10 h $35^{\prime}$ hasta las 11 h $01^{\prime}$, de $48,3 \mathrm{mg} / \mathrm{dm} 2 /$ hora (promedio) representan la transpiración cuticular en la hoja saturada (déficit de saturación al inicio de la experiencia $=64 \%$ ) con la sóla salvedad que se trata de una pérdida de agua al travez de una cutícula todavía delicada y un poco mayor a la que se procesa en una hoja adulta, en las mismas condiciones de saturación y bajo las mismas influencias del medio (36, p. $126 \mathrm{y}^{\prime}$ tabla 7) como fué demonstrado con la la siguiente experiencia: porciones foliares de hojas recién desenrolladas, y de hojas aduitas, fueron mantenidas en cámara húmeda, a la oscuridad durante 1 día y luego pesadas simultaneamente una en cada balanza (previo secado con papel de filtro de las superficies y después de haber establecido que Ios estomas estaban cerrados al test de infilttración con xilol). Se estableció que la eficiencia de la protección cuticular es mayor en la hoja adulta que en la jóven; en promedio una hoja adulta pierde cuticularmente el 70 a $75 \%$ de la transpiracición cuticular de una hoja jóven, en idénticas condicio. nes atmosféricas.

E1 valor de $48,3 \mathrm{mg} / \mathrm{dm} 2 /$ hora, obterido en los primeros 26 minutos en la hoja N..$^{\circ}$, se alcanza en la N..$^{\circ}$ 2 a los 22 minutos de comenzar a pesar con un déficit de saturación del $15 \%$.

La transpiración cuticular final, en las dos hojas, alcanza valores iguales: $0,46 \mathrm{mg} / \mathrm{dm} 2 / \mathrm{min}$.

Se nota que la hoja $\mathrm{N}^{\circ} 1$ perdió muy poca agua en total, quedanclo hasta el fin de la experiencia, muy cerca de la saturación completa. 
TABLA 14

RELACION ENTRE LA TRANSPIRACION DE UNA HOJA JOVEN TODAVIA ENROLLLADA, CON ESTOMAS CERRADOS $Y$ OTRA ADULTA CON ESTOMAS ABIERTOS

$2-\mathrm{X}-51$

T. $=23^{\circ} . \mathrm{C}$ H. R. $=58 \%$ (al comenzar la experiencia $)$

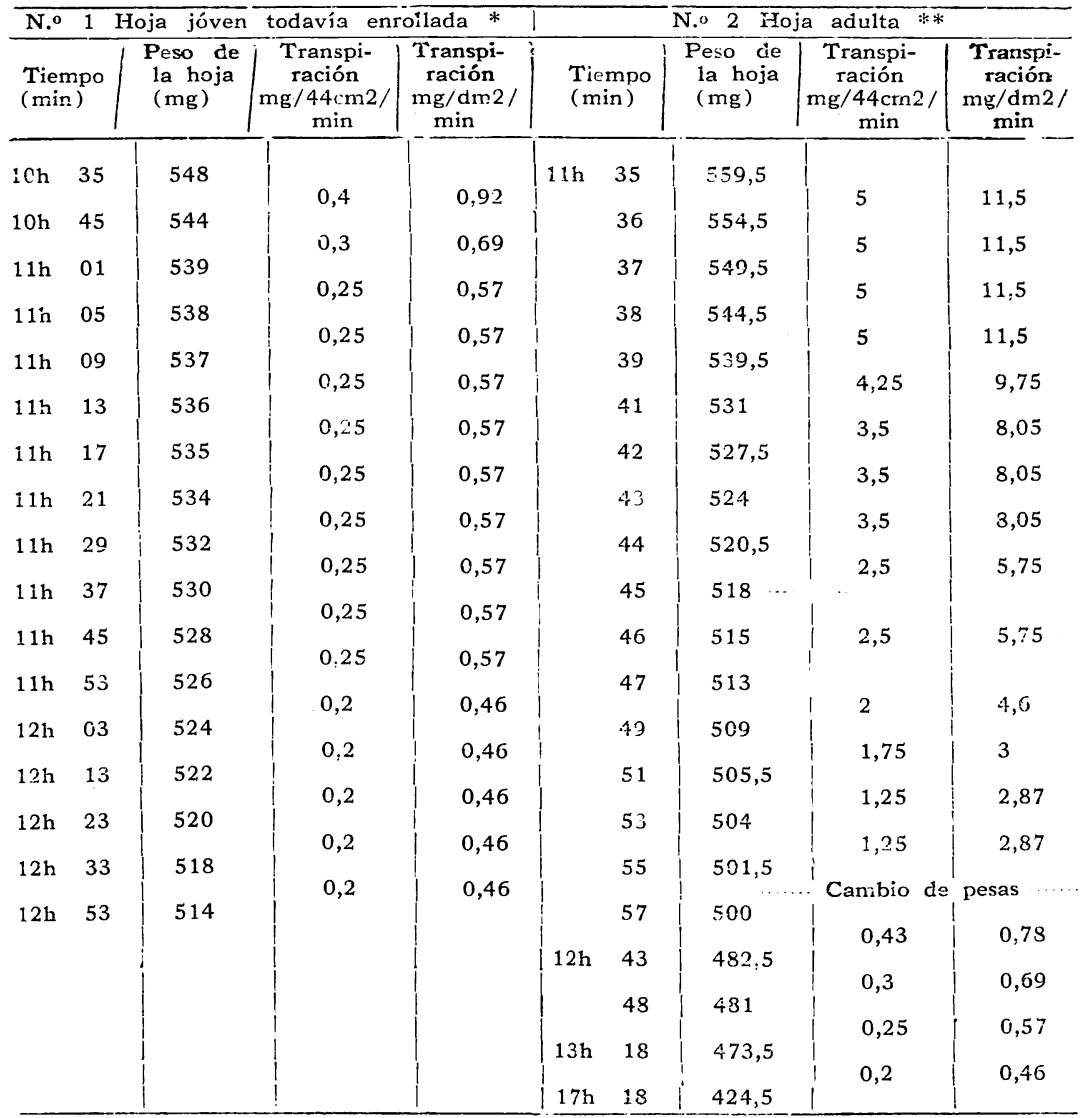

* Test de infiltración al comienzo de la experier cia $=0$

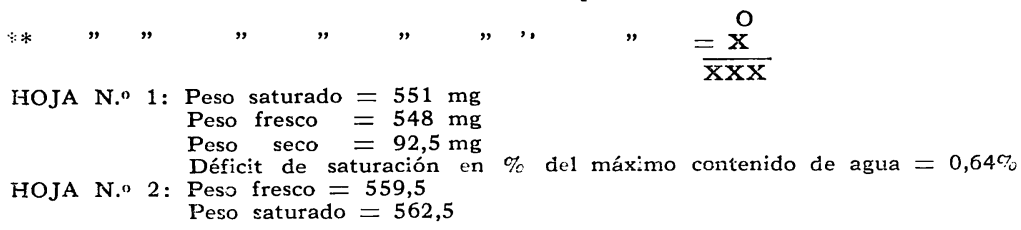

d) Transpiración nocturna (cutícula saturada)

Queriendo trabajar con cutícula de hojas adultas, hicimos determinaciones durante las primeras horas de la 
noche, cuando los estomas estaban cerrados al test de infiltración.

Las observaciones de la tabla 15 , a las 20 h $25 \mathrm{mi}-$ nutos, mostraron que efectivamente lo estaban; los va-

TABL A 15

TRANSPIRACION NOCTURNA

28-XI-51

T. $=20-18$

H. R. $=75-80$

\begin{tabular}{cc|c|c|c}
\hline $\begin{array}{c}\text { Tiempo } \\
(\text { min })\end{array}$ & $\begin{array}{c}\text { Peso de la } \\
\text { hoja (mg) }\end{array}$ & $\begin{array}{c}\text { Transpiración } \\
(\mathrm{mg} / 44 \mathrm{~cm} 2 / \mathrm{min})\end{array}$ & $\begin{array}{c}\text { Transpiración } \\
(\mathrm{mg} / \mathrm{dm} 2 / \mathrm{min})\end{array}$ \\
\hline $20 \mathrm{~h}$ & $25 *$ & 570 & 0,25 & 0,57 \\
$20 \mathrm{~h}$ & 31 & 568,5 & 0,25 & 0,57 \\
$20 \mathrm{~h}$ & 37 & 567 & 0,25 & 0,57 \\
$20 \mathrm{~h}$ & 49 & 564 & 0,25 & 0,57 \\
$21 \mathrm{~h}$ & 01 & 561 & 0,25 & 0,57 \\
$21 \mathrm{~h}$ & 13 & 558 & & \\
\hline
\end{tabular}

* Infiltración con xilol negativa

lores de la balanza fueron bajos y constantes desde el principio $(0,57 \mathrm{mg} / \mathrm{dm} 2 / \mathrm{min})$.

La pérdida así obtenida, de $34 \mathrm{mg} / \mathrm{dm} 2 /$ hora, la podemos considerar como típica de una cutícula saturada, de una hoja adulta, en las condiciones de la experiencia, particularmente porque saturando artificialmente en cámara húmeda porciones foliares adultas, obtuvimos resultados ligeramente superiores $(38 \mathrm{mg} / \mathrm{dm} 2 / \mathrm{min})$ y aquí es necesario considerar, que aún secando cuidadosamente con papel de filtro, es imposible retirar toda el agua que queda en la superficie de la cutícula y que las pesadas de las hojas mantenidas en cámara húmeda, fueron hechas durante el día y con humedad relativa mucho menor que durante la noche.

E1 valor de $34 \mathrm{mg} / \mathrm{dm} 2 / \mathrm{min}$, servirá de base a nuestros cálculos, porque ya no se trata de cutícula delicada ni alterada por la deposición de una capa impermeable en una de las caras.

Para confirmar nuestro valor, cubrimos de negro, durante el período luminoso del día, 6 hojas de un mismo pié (tabla 1) cuando mostraban fuerte infiltración con xilol, (ver fotoreacción) y a los 60 minutos de oscurecida, obtuvimos guarismos de $34 \mathrm{mg} / \mathrm{dm} 2 / \mathrm{min}$, pérdida que se mantiene constante, aún después de 2 horas y 59 minutos de haber tapado la hoja (lo que nos dá la seguridad del cierre perfecto de los estomas). Las hojas 
con que trabajamos, tenían un déficit de saturación, promedio, de $1 \%$ es decir que estaban practicamente saturadas.

\section{3) Transpiración cuticular en relación con la evaporación ( Tc/E)}

Trabajando con dos balanzas al mismo tiempo (una con la porción foliar y otra con el Blatt-evaporimeter), obtuvimos una relación $\mathrm{Tc} / \mathrm{E}$, variable entre 1,4 y $1,6 \%$ para una cutícula no saturada, y para cutícula saturada, esta relación fué de 2,5\% (tabla 13).

Estos datos nos permiten hacer el siguiente cálculo: con estomas abiertos la transpiración total puede alcanzar, como máximo, el $62 \%$ de la evaporación libre; en 50 a 60 minutos la planta puede reducir su transpiración de $62 \%$ para $1,5 \%$ de la evaporación libre (en porcentual de 100 para 2,4).

TABL A 16

Tc/E, SIENDO E LA EVAPORACION DE BLATT-EVAPORIMETER (seg. Pisek y Berger, 29)

\begin{tabular}{|c|c|}
\hline PLANTA & $\mathrm{Tc} / \mathrm{E}$ en $\%$ \\
\hline Pulmonaria offcinalis & 8,6 \\
\hline Coronilla varia & 3,8 \\
\hline Sedum Maximum & 5,0 \\
\hline Stachys recta $\ldots \ldots \ldots \ldots \ldots \ldots \ldots$ & 2,6 \\
\hline Convolvulus arvensis & 3,3 \\
\hline Rhododendron ferrugineum & 1,3 \\
\hline Oxalis acetosella & 1,4 \\
\hline Arctostaphylos uva ursi & 0,88 \\
\hline
\end{tabular}

TABL A 17

TC/E, SIENDO E LA EVAPORACION DEL BLATT-EVAPORIMETER (seg Ferri, 9, p. 213)

\begin{tabular}{|c|c|}
\hline PLANTA & $\mathrm{Tc} / \mathrm{E}$ en $\%$ \\
\hline Andira humilis $\quad \ldots \ldots \ldots \ldots \ldots \ldots \ldots$ & de 8,2 a 13,7 \\
\hline Byrsonima coccolobifolia & 5,7 \\
\hline Palicourea rigida $\quad \ldots \ldots \ldots \ldots \ldots \ldots$ & 11,2 \\
\hline Anona coriacea $\ldots \ldots$ & de 0,9 a 1,02 \\
\hline
\end{tabular}

Volviendo a los valores de Pisek y Eerger (29) vemos que nuestra determinación ( $34 \mathrm{mg} / \mathrm{dm} 2 / \mathrm{min}$ ) queda siempre entre los árboles de hojas caducas; exactamente entre Corylus avellana 
con $38 \mathrm{mg} / \mathrm{dm} 2 / \mathrm{min}$ y Quercus robur con 27 , siendo también semejantes los valores de Tc/E (29, tabla 17).

La bananera, a pesar de su excelente protección cuticular, presenta una estructura foliar del tipo normal de las plantas mesofíticas: cutícula delgada, estomas en las dos caras de la hoja, localizados en la perifería de la epidermis, con las células compañeras formando una pequeña saiiencia para el exterior, quedando así, el ostiolo en una depresión poco pronunciada; tejido en empalizada poco desenvuelto; en la cara inferior, hacia adentro de la epidermis, hay un tejido incoloro, de grandes células de forma regular (hipodermis) entre las que no aparecen cámaras de aire (fig. 8). Los pequeños estomas comunican con amplias cámaras

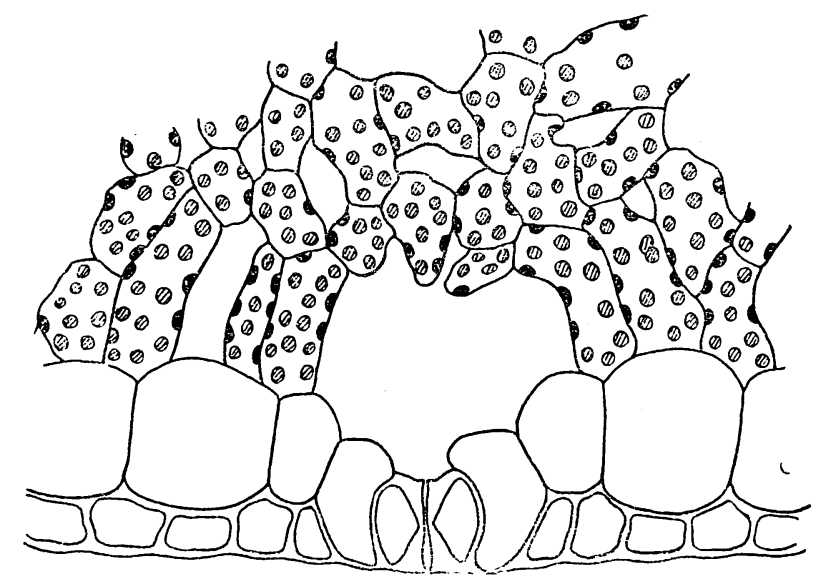

Fig. 8 - Corte del aparato estomático en la cara inferior de la hoja.

subyacentes y las células compañeras forman una gran saliencia hacia el interior de las cámaras aeríferas.

La única característica de planta higrofítica, serían sus excepcionales dimensiones, pero en cultivos no sombreados, se produce un prematuro laciniamiento de las mismas.

En la literatura hay casos de hojas aparentemente delicadas, con transpiración cuticular reducida: Oxalis acetosella $\mathrm{Tc} / \mathrm{E}=$ 0,014 .

Si comparamos con las plantas permanentes del "Campo Cerrado", estudiadas por Ferri, (tabla 17) vemos que sólo Anona coriacea, muestra valores de Tc/E, menores que bananera, y en ese sentido, las restantes plantas que aparecen en la tabla, tienen un comportamiento menos xerófítico que nuestra especie.

Ferri trabajó con plantas que, excepción hecha de Palicourea rigida, tienen cutícula muy espesa, particularmente Andira humilis, especie que presenta valores de $\mathrm{Tc} / \mathbf{E}$ cinco veces mayores que bananera, hecho interesante que confirma que no hay correlación 
èntre el espesor de la cutícula y la protección ejercida por ella (vide 9 y 21 ).

$$
* \quad * \quad \dot{*}
$$

Podemos calcular la cantidad de lluvia necessaria para equilibrar la pérdida de agua por transpiración cuticular.

Musa cavendishii, tiene en media siete hojas por planta; tomándose como superficie total de cada hoja (considerando las dos caras pués hay estomas tanto en la superior como en la inferior) un valor medio de $1,5 \mathrm{~m} 2$, la superficie total de hojas es de $10,5 \mathrm{~m} 2$ (*).

A los 10,5 m2 ,debemos adicionar $3 \mathrm{~m} 2$ de superficie de vainas $(* *)$ que no pueden ser negligenciados pués aún en la base del pseudo-tronco aparecen estomas, la cutícula es delgada y hay infiltración con xilol.

La superficie del suelo, cubierta por la planta, se calcula en $7 \mathrm{~m} 2$.

Como el valor de $34 \mathrm{mg} / \mathrm{dm} 2 /$ hora, fué determinado repetidas veces en el campo, podemos considerarlo como típico de las condiciones naturales de la bananera, cuando la cutícula está saturada, y tendremos como máxima transpiración cuticular de toda la planta $1,101 \mathrm{~kg}$ por dia, o sea que por la cutícula de un ejemplar, pasa como máximo 1 litro de agua por dia. Para suplir esta pérdida, serían suficientes precipitaciones de $0,16 \mathrm{~mm}$ por día o sea 4,8 mrn por mes.

En el estado de São Paulo, en todos los meses, incluyendo los más secos, ese valor es ultrapasado por las precipitaciones, y una caída diaria de $0,16 \mathrm{~mm}$ existe en tode lugar donde hay rocío nocturno.

Concluimos que: la precipitación en forma de rocío, por sí sola, supliría, la máxima pérdida cuticular de una płanta de bananera.

Creemos que gracias a esta eficiente protección cuticular, es posible el cultivo de esta especie en los oasis de la "Caatinga"; allí la planta cierra sus estomas en las horas mas calientes del día transpirando sólo cuticularmente, y esta pérdida debe ser bastante menor que la calculada por nosotros para una cutícula saturada, porque sólo en las últimas horas de la noche y primeras de la mañana, la hoja puede estar saturada; en el resto del dia la transpiración cuticular se procesa a través de una cutícula seca. En tales condiciones la pérdida cuticular diaria, no puede exceder de los $800 \mathrm{~g}$, calculados en base a la transpiración obtenida cuando los estomas han cerrado por falta de agua, que es de 29 $\mathrm{mg} / \mathrm{dm} 2 /$ hora.

*) Las superficies extremas medidas fueron: $1 \mathrm{~m} 2$ y $3,2 \mathrm{~m} 2$, y en el cálculo de ia superficie total de hojas de una planta se tuvo en consideración, que la superficie de la hoja más jóven, rezién desenrollada, es no menor del $70 \%$ de la de una adulta.

**) De la porción libre de las vainas, contamos ambas caras, y la que forma el pseudotronco, sólo la superficie exterior del cilindro. 


\section{VII}

\section{CONSUMO DE AGUA}

\section{A) MAXIMO CONSUMO HORARIO}

Para obtener información sobre el máximo consumo horario, "in situ", los autores acostumbran colocar las hojas durante el lapso de tiempo entre dos pesadas, en el mismo lugar de donde fueron cortadas, y en la misma posición. Nosotros no pudimos proceder así, porque la rapidéz de la reacción estomática a la pérdida de agua, en las horas más calientes del día, no permite: pesar; sacar la porción foliar; recolocíría en el lugar de donde fué cortada; esperar unos minutos; volver a colocarla en la balanza y pesar nuevamente.

En días calmos, la pérdida de agua obtenida en porciones foliares colgadas en la balanza, es igual a la de la hoja "in situ", pués pudimos trabajar sin ninguna clase de protección contra el viento, al pié de la bananera de donde extraíamos las porciones foliares, y por supuesto, en condiciones meteorológicas iguales a las de la planta.

En días de viento la situación cambió; debimos colocar las balanzas en una caja cuyas caras, con excepción de la anterior, eran de celofán, de otra manera las pesadas exactas serían dificultadas por el viento. En tales días nuestros valores deben ser sensiblemente menores que los registrados al aire libre.

El valor máximo de pérdida de agua, obtenido en un día calmo de sol, en pleno campo, fué de $47 \mathrm{mg} / \mathrm{dm} 2 / \mathrm{min}$, con H. R. $=35 \%$ y T. $=32^{\circ} . \mathrm{C}$, a las 14 horas.

En un día también de sol, pero con viento (8-X-51), obtuvivimos un valor un poco más alto: $48,3 \mathrm{mg} / \mathrm{dm} 2 / \mathrm{min}$, con $\mathrm{H}$. $\mathbf{R}$. $=15,7 \%, \mathrm{~T}=34^{\circ} . \mathrm{C}$, déficit de saturación del aire $=32 \mathrm{~mm}$ de Hg., evaporación (Blatt-evaporimeter) $=89,7 \mathrm{mg} / \mathrm{dm} 2 / \mathrm{min}$, a las 13 horas 47 minutos, protegiendo las balanzas (una con la porción foliar y otra con el evaporímetro molde de hoja) contra el viento.

E1 día 20-X-51, a la misma hora en que obteníamos el valor de $48,3 \mathrm{mg} / \mathrm{dm} 2 / \mathrm{min}$, el evaporímetro molde de hoja, también protegido del viento, daba pérdidas de $90 \mathrm{mg} / \mathrm{dm} 2 / \mathrm{min}$; y un evaporímetro de Piche, colgado en la planta de donde extraímos las porciones foliares, a un metro de distancia de la mesa de trabajo, acusó $140 \mathrm{mg} / \mathrm{dm} 2 / \mathrm{min}$, es decir que entre el Blatt-evaporimeter (protegido contra el viento, lo mismo que la porción foliar) y el evaporímetro de Piche, expuesto al viento, había en ese momento, una relación de 1 para 1,56 .

En nuestro caso especial, y solo en el, son comparables las evaporaciones obtenidas con los evaporímetros de Piche y el molde de hoja. 
Aquí el tubo calibrado conteniendo agua, del evaporímetro de Piche, está ligaäo a un disco de papel secante, exactamente

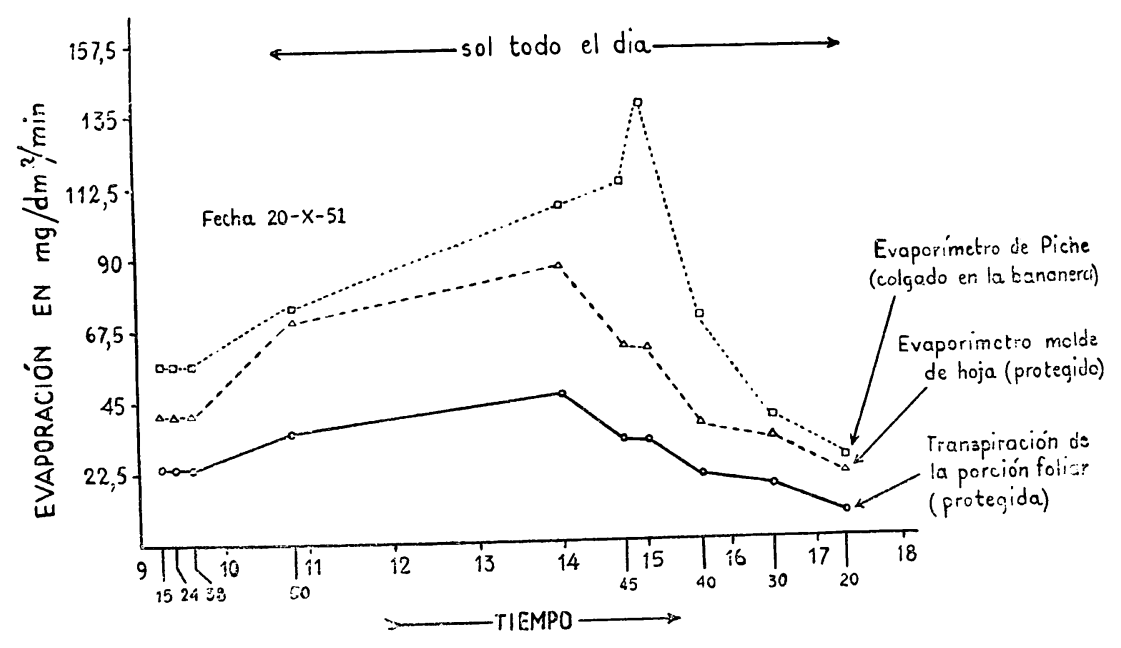

giF. 9 - Relación entre las curvas diarias de la evaporación (al viento y en aire calmo) y la transpiración (en aire calmo).

igual, en forma, dimensiones y color, al evaporímetro molde de hoja.

Se sabe que la evaporación de una superficie, depende de la forma de esta, mas que de sus dimensiones; en nuestro caso, la porción foliar, el evaporímetro molde de hoja y el de Piche, nos proporcionan datos de pérdida de agua de una superficie igual (44 cm2), de forma idéntica (circular) y del mismo color (verde).

En cualquier otro caso, los valores obtenidos con los dos evaporímetros no pueden comparase, pués una superficie, digamos un círculo, dos veces mayor que otro, no evapora dos veces más que el menor (vide 34, p. 71).

La relación diaria entre el evaporímetro de Piche, expuesto al viento y el molde de hoja, protegido, fué la siguiente:

Se nota que los valores se aproximan en los períodos de calma (evaporímetro molde de hoja 98\% del de Piche) y alejan cuando sopla fuerte viento (evaporación bajo la caja protectora igual al $44 \%$ de la que se procesa al aire libre). En media, la evaporación en la caja protectora es el $70 \%$ de la que ocurre al aire libre).

Nuestro máximo valor de transpiración, obtenido en condiciones de aire calmo, de $48,3 \mathrm{mg} / \mathrm{dm} 2 / \mathrm{min}$, sería bastante más alto en lugares expuestos al movimiento del aire.

Sin embargo la relación: evaporación al aire libre para evaporación en la caja de protección, no nos habilita a establecer el 
incremento de la pérdida máxima de agua al viento. En tales comparaciones debe tenerse en cuenta el hecho, ya constatado por varics autores $(24 ; 40$ y 28 , p. 17) que el evaporímetro de Piche es fuertemente influenciado por el viento y menos sensible a las radiaciones, mientras que las hojas de las plantas son mucho menos afectadas por los movimientos del aire que por los rayos del sol.

\section{COMPARACION ENTRE LAS EVAPORACION DE UN EVAPORIMETRO DE PICHE Y UN BLATT-EVAPORIMETER}

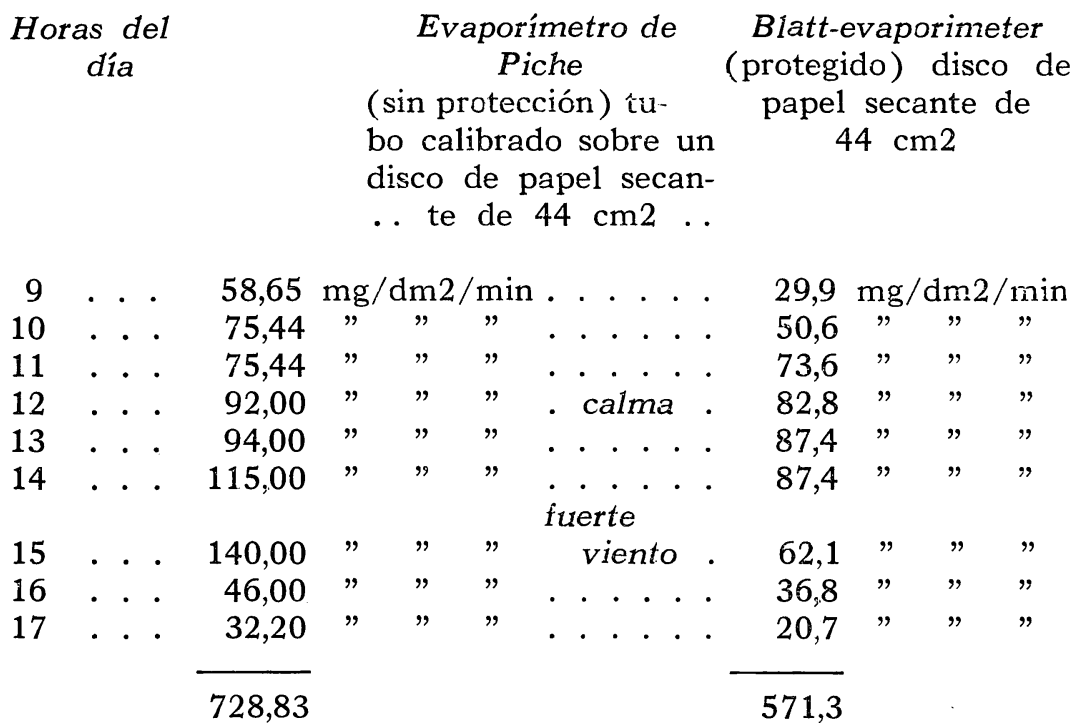

Como en las condiciones de São Paulo, la bananera, tanto en la época seca como en la lluviosa, transpira libremente durante tcdo el día, acompañando la curva de la evaporación (los estomas de la cara inferior no regulan la pérdida de agua aún en las horas más calientes del día) podemos considerar como valor máximo $52 \mathrm{mg} / \mathrm{dm} 2 / \mathrm{min}$ o sea $3,12 \mathrm{~g} / \mathrm{dm} 2 / \mathrm{h}(2,2 \mathrm{~g} / \mathrm{g} / \mathrm{h})$, notándose que la pérdida máxima horaria, de agua, alcanza en pleno sol, a más del doble del peso fresco.

Henrici (18, tabla 3) obtuvo en árboles exóticos, en la estación lluviosa, en Drakensburg (Sudafrica), valores de transpiración máxima horaria 2 y 3 veces mayores: en condiciones de sol brillante, Cupressu lúsitanica perdió $9,61 \mathrm{~g} / \mathrm{dm} 2 / \mathrm{min} ;$ Acacia decurrens 8,28; A. dealbata 3,25; Jacaranda ovalifolia 5,41; Euca. liptus diversicolor 4,82 . 
Stocker, en sus investigaciones en Java con árboles de la selva pluvial, en observaciones de corta duración, obtuvo un valor máximo muy cercano al nuestro: $50 \mathrm{mg} / \mathrm{dm} 2 / \mathrm{min}$ o sea $3 \mathrm{~g} / \mathrm{dm} 2 /$ hora.

Los valores máximos obtenidos en el "campo cerrado" por Ferri (9) son bastante modestos:

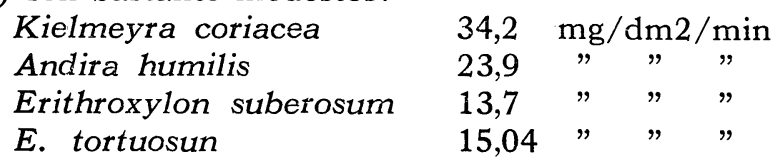

Los valores máximos, para plantas de desierto en época 1luviosa, e con abastecimiento subterráneo de agua, son mucho más altos.

Excluyendo los valores obtenidos por Wassiljev para plantas del Kara Kum, que la mayoría de los autores se inclinan a considerar excesivamente altos, hasta donde alcanzan nuestros conocimientos, el valor mas alto obtenido es el de Zilla macroptera que llegó a perder $136,6 \mathrm{mg} / \mathrm{dm} 2 / \mathrm{min}$ (dato obtenido por Harder (14) en el Sahara argeliano).

Valores igualmente altos son los obtenidos por Evenari (8): Haplophyllum tuberculatum . . . $95 \mathrm{mg} / \mathrm{dm} 2 / \mathrm{min}$

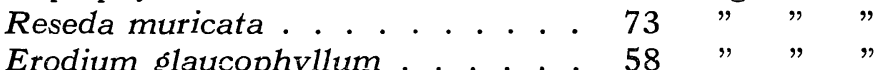

\section{B) MARCHA DIARIA DE LA TRANSPIRACION EN EL CAMPO}

Nuestras observaciones regulares abarcan desde fines de julio hasta diciembre de 1951, es decir la época invernal seca, que culmina en julio e agosto, extendiéndose hasta mediados de setiembre y buena parte de la estación lluviosa.

La fig. 10 muestra la marcha de la transpiración en un día de sol de lá época lluviosa (8-X-51); los valores anotados caminan paralelamente a los de la evaporación libre; durante todo el día la planta transpiró sin restricción; el test de infiltración en la cara ventral de la hoja dió siempre resultados positivos, no pudiéndose constatar una disminución en la abertura estomática. Por la mañana al cortar la hoja, hubo salida de líquido de los vasos con cierta presión.

La curva transpiratoria sube abruptamente desde las 10 horas 45 minutos, hasta las $10 \mathrm{~h} 57$; luego el ascenso se hace lentamente hasta la cuiminación, que se produce a las $13 \mathrm{~h} 47$ con el valor máximo de pérdida de agua de $48,3 \mathrm{mg} / \mathrm{dm} 2 / \mathrm{min}$; desde ese momento comienza un rápido descenso del ritmo transpiratorio, que en 3 horas, declina de $48,3 \mathrm{mg} / \mathrm{dm} 2 / \mathrm{min}$ a 13,8 . - 
Hacia el final de la época seca, la situación es exactamente la misma; la curva del día 18-IX-51 de la fig. 11, indica la transpiración sin economía procesada antes de la caída de las primeras lluvias; también aquí se alcanzaron a las 14 horas valores de 48

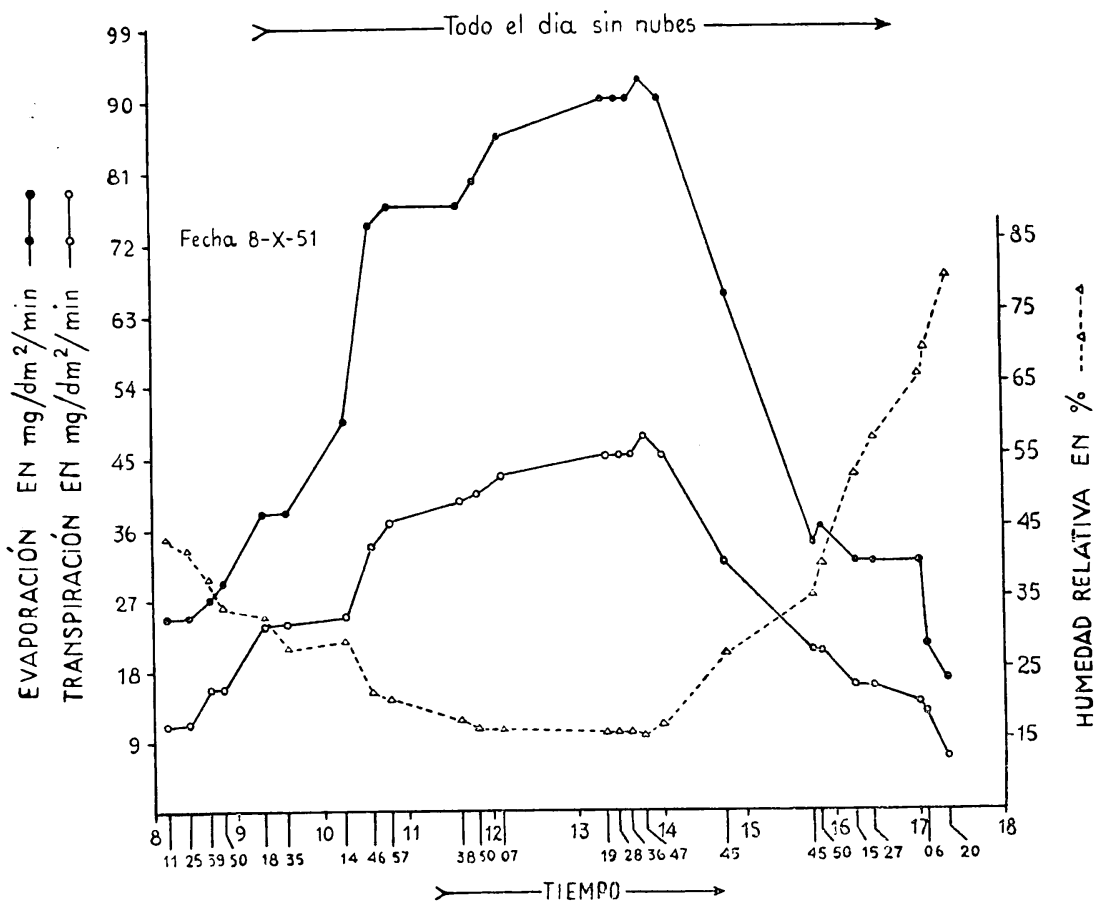

Fig. 10 - Curva diaria de transpiración, evaporazión y humcdad relativa, en un día de sol de la época lluviosa.

$\mathrm{mg} / \mathrm{dm} 2 / \mathrm{min}$; los estomas estuvieron abiertos todo el día, y la pérdida de agua acompaña fielmente la curva de evaporación.

Todas las curvas obtenidas son de una sola cumbre tanto en la época seca como en la lluviosa, tanto en las plantas del jardín del Departamento de Botánica como en el Campo Experimental de Butantán.

E1 valor transpiratorio, bajo en las primeras horas de la mañana $(1,15$ a $4,6 \mathrm{mg} / \mathrm{dm} 2 / \mathrm{min}$ ) aumenta hacia un máximo que se alcanza entre las $11 \mathrm{~h} 30$ y $14 \mathrm{~h} 30$ (lo más frecuente es a las 14 horas) y luego decrece, llegando, a las 18 horas a valores iguales a los obtenidos a las 7 horas.

La transpiración diaria se presenta así como una curva de una sola cumbre, claramente paralela con las de evaporación y déficit de saturación de la atmósfera, durante todo el año.

E1 comportamiento transpiratorio parece indicar que no existe desequilibrio entre el consumo, transporte y absorción, pero el curso diario del déficit de saturación de las hojas muestra que partiendo 
de saturación casi completa por la mañana, al mediodía se alcanzan déficits de 6 a $7 \%$ (casi iguales a los valores necesarios para que la hidroreacción se haga visible: 6 a $8 \%$ ) y al atardecer vuelven a estar como en las primeras horas del día.

Este hecho, sumado al cierrre parcial o total de los estomas de la cara superior de la hoja en las horas calientes de los días de sol, muestra que en las horas vecinas al mediodía, hay una pequeña deficiencia en el abastecimiento de agua (en la conducción o en la absorción) que no llega a ser lo suficientemente grande como para

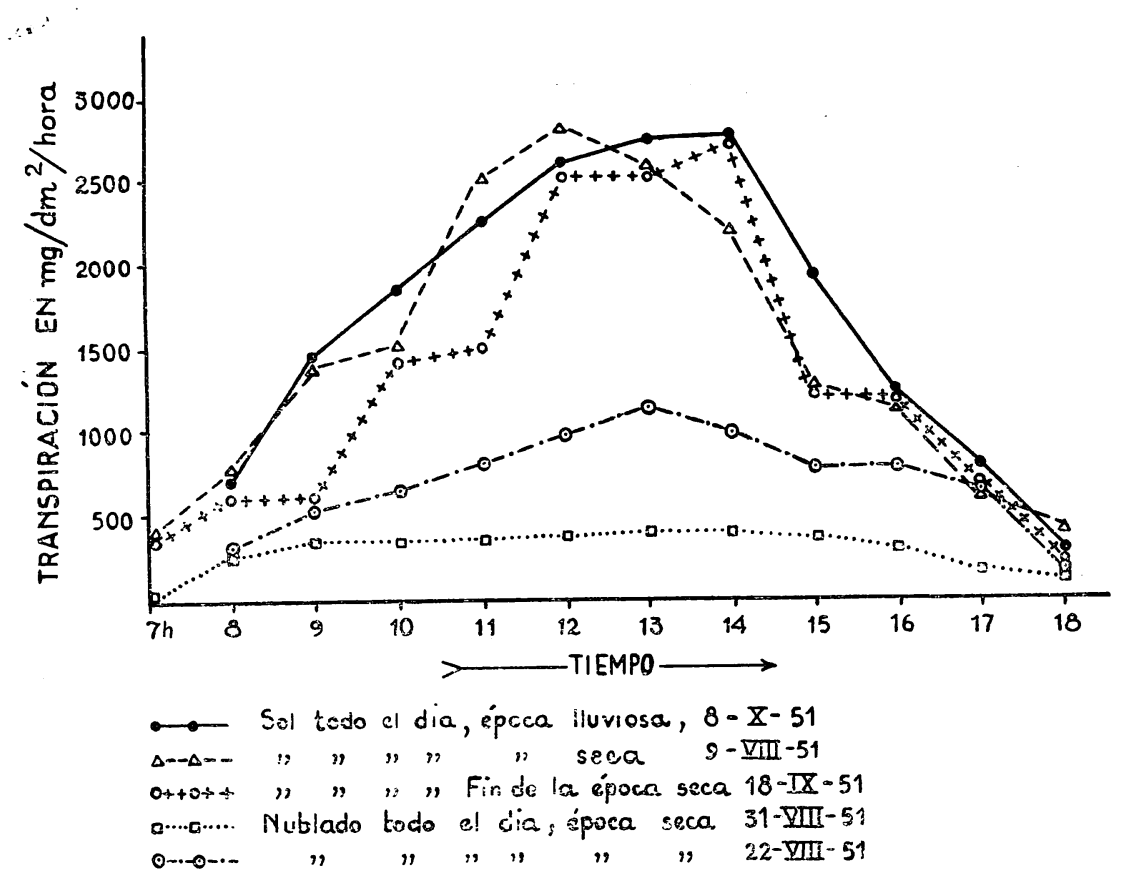

Fig. 11 - Curvas diarias de transpiración, en días de sol y nubiados; tanto en la
época seca como en la lluviosa. provocar el cierre de los estomas en la cara inferior de la hoja y que la recuperación vespertina se prođuce sin necesidad de restringir el consumo de agua.

Durante el día no se alcanza déficits tales que provoquen el cierrre de los estomas en la cara inferior de la hoja, lo que daría una curva transpiratoria de dos cumbres (en el caso de que se produzca una reabertura de los estomas al atardecer) o de un solo máximo (si los estomas no abren al atardecer) pero en ambos el recorrido de las curvas transpiratorias sería opuesto a la de la evaporación en las horas calientes del día. 
La fig, 12 muestra el curso diario del déficit de saturación de la hoja, de la transpiración y evaporación; el balance de agua mues-

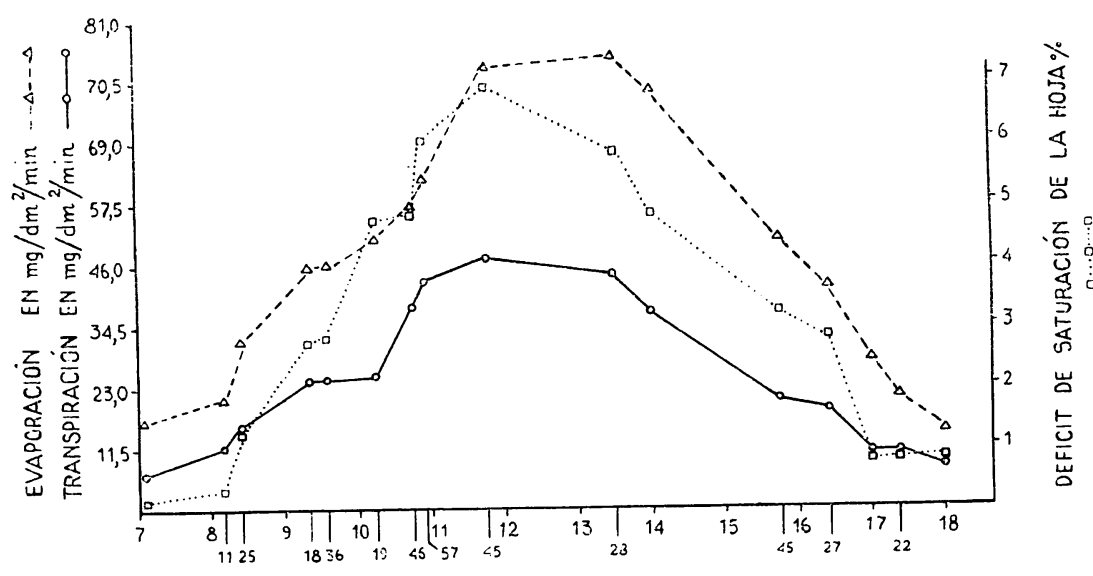
Fig. 12 - Curvas diarias de transpiración, evaporación y déficit de saturación de

tra evidencias de tensión desde las $11 \mathrm{~h} 45$ hasta las $13 \mathrm{~h} 28$, momento en que el déficit de saturación alcanza el $7 \%$, pero se restablece a la tarde a las $17 \mathrm{~h} 22$, cuando reaparecen los valores de las 7-8 horas.

Es sabido que una hoja que mantiene abiertos sus estomas durante todo el día, muestra una transpiración proporcional a la evaporación libre.

Podría pensarse que el paralelismo de las dos curvas se debe a la incapacidad de regulación estomática por parte de las bananera; que en nuestro caso tal cosa no ocurre, se desprende del estudio de la foto e hidroreacción: una colgada en la balanza reduce su transpiración y los estomas dan los primeros indicios de cierrre con déficit de saturación de 6 a $7 \%$.

Con el fin de averiguar directamerite el estado de abertura de los estomas durante todo un día, usamos el método de Stalfelt, que consiste en sumergir hojas o en nuestro caso porciones de hojas en parafina líquida (sustancia osmoticamente inactiva) que no altera las dimensiones del ostio!o, y luego destacar porciones de epidermis para la observación en el microscopio común. Los resultados aparecen en la tabla 18, e indican aberturas casi constantes desde las 16 a las 18 horas. 
TABL 118

MARCHA DIARIA DE LA ABERTURA DEL OSTIOLO EN LA CARA INFERIOR DE LA HOJA

28-I X-51

\begin{tabular}{|c|c|c|c|c|c|}
\hline $\begin{array}{r}\text { Horas } \\
\text { día }\end{array}$ & del & $\begin{array}{c}\text { Diámetro } \\
\text { menor del } \\
\text { ostilo (*) } \\
\text { Micras }\end{array}$ & $\begin{array}{l}\text { Humedad } \\
\text { relativa }\end{array}$ & $\begin{array}{c}\text { Temperatura } \\
\text { o.C }\end{array}$ & $\begin{array}{l}\text { Infiltración con xilol } \\
\text { en las dos caras }\end{array}$ \\
\hline $8 \mathrm{~h}$ & & 1,4 & 77 & 17,6 & $\frac{\mathrm{O}}{\mathrm{x}}$ \\
\hline $10 \mathrm{~h}$ & & 2,1 & 70 & 18,6 & $\frac{x}{x \times \bar{x}}$ \\
\hline $12 \mathrm{~h}$ & & 2,8 & 68 & 20,4 & $\frac{0}{x \times x}$ \\
\hline $14 \mathrm{~h}$ & & 2,8 & 40 & 26,2 & $\frac{\mathrm{o}}{\mathrm{XXX}}$ \\
\hline $15 \mathrm{~h}$ & & 2,8 & 38 & 27 & $\frac{\mathrm{O}}{\mathrm{XXX}}$ \\
\hline $16 \mathrm{~h}$ & & 2,1 & 45 & 25 & $\frac{(X)}{X X X}$ \\
\hline $17 \mathrm{~h}$ & & 2,1 & 55 & 23 & $\frac{x}{x x x}$ \\
\hline $18 \mathrm{~h}$ & 00 & 2,1 & 60 & 18 & $\frac{x}{x x}$ \\
\hline $18 \mathrm{~h}$ & 10 & 1,4 & 64 & 18 & $\frac{x}{x}$ \\
\hline $18 \mathrm{~h}$ & 30 & 1,4 & 76 & 18 & $\frac{\mathrm{O}}{\mathrm{O}}$ \\
\hline $18 \mathrm{~h}$ & 35 & $\begin{array}{l}\text { ? } \\
\text { no se pueden } \\
\text { medir (pare- } \\
\text { cen cerrados) }\end{array}$ & 78 & 18 & $\frac{\mathrm{O}}{\mathrm{O}}$ \\
\hline
\end{tabular}

(*) Promedio de 15 medidas en cada hora del día

De esta table no pueden sacarse muchas conclusiones dadas las pequeñas dimensiones del ostiolo, pero indica que en las condiciones del día de la observación, a pesar de haberse alcanzado a las 15 horas un déficit de saturación de la atmosfera de $19 \mathrm{~mm}$ de $\mathrm{Hg}$, no se produjo modificación visible del diámetro menor de la abertura estomática.

La teoría que explica este, tipo de curvas de un sólo máximo, ha sido desarrollada por Stocker (44); se trata de plantas que 
pueden (en las condiciones ecológicas de las región estudiada) transpirar durante todo el día sin restricción, porque siempre existe agua al alcance de sus raíces y que la conducción es adecuada.

La bananera, en las condiciones de Butantán, con profundidad des raíces de mas de 3 metros y agua subterránea a 5 metros, se encuentra practicamente funcionando como una phreatophyta, es decir plantas cuyas raíces llegan a la napa de agua, teniendo provisión abundante durante todo el año.

No es necesario ni posible que las raíces de este ejemplar sean mas profundas, porque tendrían que pasar por camadas de tierra cuyos intersticios están perfectamente llenos de agua, y como consecuencia la respiración sería deficiente por falta de 02 .

\section{Transpiración en días nublados}

Los datos de que disponemos nos permiten establecer que los bajos valores de transpiración, observados en días nublados, no se deben a movimientos de cierrre parcial de los estomas provocados por la escasa luminosidad (fotoreacción) sino a que la evaporación era débil.

La fig. 13 muestra las curvas de evaporación y transpiración obtenidas en un día nublado; ambas son perfectamente paralelas;

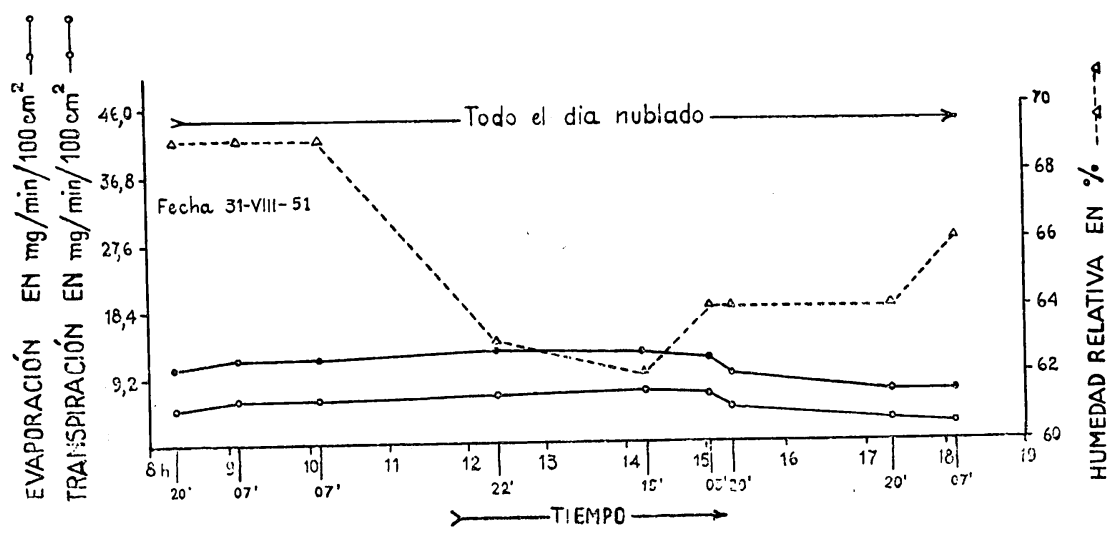

Fig. 13 - Curvas diarias de transpiración, evaporación y humedad relativa, en un dia nublado.

esa concordancia no aparecería, de existir cierre parcial o total de los estomas.

La relación $\mathrm{Tt}$ t $\mathrm{E}$ durante todo el día se mantuvo entre $50 \mathrm{y}$ 62 (salvo en las primeras horas de la mañana y al atardecer), lo que indica que los estomas estaban perfectamente abiertos. 
El test de infiltración dió siempre resultado positivo en las dos caras de la hoja, aún con el infiltrante más denso: parafina líquida.

La fig. 14 muestra la absoluta concordancia entre las fluctua-

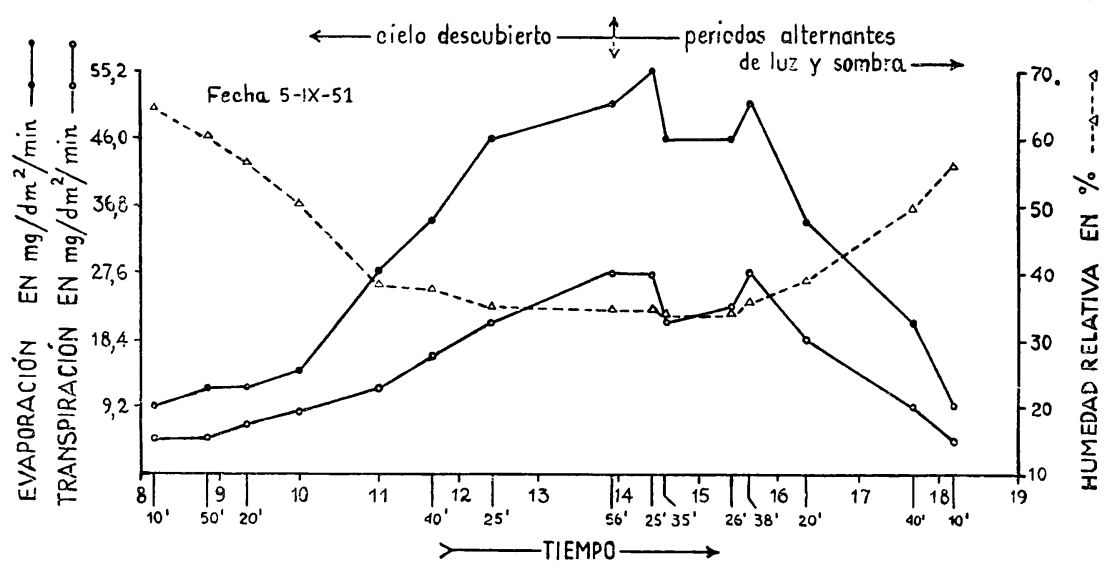

Fig. 14 - Curvas de transpiración, evaporación y humedad relativa, en un dia con períodos alternantes de luz y sombra.

ciones de las curvas de evaporación y transpiración en un día en que hubo períodos alternantes de luz y sombra.

Por último, con el metodo de Stalfelt, vimos los estomas ampliamente abiertos todo el día en ambas caras de la hoja.

\section{C) CONSUMO DIARIO}

Carecemos de un aparato de fácil manejo en el campo, que nos permita obtener la suma total de agua perdida por una superficie o peso determinado de hoja, durante el día.

Para averiguar la transpiración total diaria se acostumbra, trazar la curva diaria de pérdida de agua y averiguar su superficie por medio de un planímetro. Por ejemplo, la curva transpiratoria de la fig. 10, del 8-X-51 (día de sol) obtenida en el campo de Butantán, tiene una superficie de $36,085 \mathrm{~cm} 2,1 \mathrm{~cm} 2$ representa en el gráfico una pérdida de $500 \mathrm{mg} / \mathrm{dm} 2 /$ hora, luego: $36,085 \mathrm{~cm} 2$ X 500 $\mathrm{mg} / \mathrm{drn} 2 /$ hora $=18029 \mathrm{mg} / \mathrm{dm} 2 /$ día ó sea $1802,9 \mathrm{gr} / \mathrm{m} 2 /$ día .

El valor que servirá para los cálculos es $18,029 \mathrm{~g} / \mathrm{dm} 2 /$ día que es comparable con los obtenidos por otros autores pués está expresado en unidad de superficie y puede llevarse a $\mathrm{g} / \mathrm{g}$ de peso fresco/día. 
Si se quiere obtener la pérdida total por día y por planta, debe considerarse la superficie promedio, de transpiración de la planta toda, $13,2 \mathrm{~m} 2$.

$1802,9 \mathrm{~g} / \mathrm{m} 2 /$ día $\times 13,5 \mathrm{~m} 2=24000 \mathrm{~g} /$ planta $/$ día o sea $24 \mathrm{Kg} / \mathrm{planta} /$ día o, lo que es lo mismo, litros/planta/día; hasta aquí considerando sólo la transpiración que se procesa en las 10 horas diarias de sol, a lo que debemos sumar la pérdida cuticular de las 14 horas restantes, que alcanza como máximo, a $642 \mathrm{~g} / \mathrm{p}$ lanta/14 horas, pués en la noche la pérdida cuticular probabelmente es nula. En el caso extremo, esta pérdida representaría el $2 \%$ de la transpiración diaria en las 10 horas decisivas.

Hechas todas las correcciones, la pérdida total por planta, en base a la curva de la fig. 10, sería de 25 litros/planta/día, valor mùr cercano al promedio obtenido que fué de 25,5 litros/planta/ día.

La pérdida diaria de agua en días calmos de sol, expresada en gramos/dm2, fué determinada como promedio de las observaciones de varios días, tanto en la época seca como después de las lluvias, en el campo de Butantán (tabla 19) y fué de $19 \mathrm{~g} / \mathrm{dm} 2$ $(13,5 \mathrm{~g} / \mathrm{g})$. Este valor es superior al de casi todos los árboles dc hojas caducas del centro de Europa; Pisek y Cartellieri (30, tabla 9) obtuvieron para Betula verrucosa $8.05 \mathrm{~g} / \mathrm{g} /$ día, y para Quercus robur 7,6.

Con respecto a las coníferas, la bananera transpira 6 a 7 veces más, Picea excelsa $1,42 \mathrm{~g} / \mathrm{g} /$ día y Pinus silvestris 2 .

Los árboles record en consumo de agua, del centro de Europa, son los estudiados por Stocker en la estepa alcalina húngara (44), Populus alba con $16 \mathrm{~g} / \mathrm{dm} 2 /$ día, Eleagnus angustifolia 11,4; Populus virginiana 9,8 y Robinia pseudacacia 6,1 ; tales pérdidas fueron determinadas para una evaporación diaria de $53 \mathrm{~g} / \mathrm{dm} 2$, en cambio nuestros datos, a pesar de haberse establecido con evaporaciones diarias que, cuanto más alcanzaban $34,4 \mathrm{~g} / \mathrm{dm} 2$ (evaporación diaria del día $8-\mathrm{X}-51$ ) son mayores en 3 gramos al valor de Populus alba, el más alto obtenido por Stocker (44, p. 839, tabla 9) en condiciones de fuerte viento.

Ciertos arbustos y hierbas de las estepas centrceuropeas,, aún con viento débil y valores de evaporación de $25 \mathrm{~g} / \mathrm{dm} 2 ;$ Artemisia monogyna 20,8 g/dm2/día, muestran guarismos altos: Statice gmelini 15,6 g/dm2; Artemisia monogyna $20,8 \mathrm{~g} / \mathrm{dm} 2$ (44, p. 823, tabla 5); pero tales cantidadies de consumo de agua ya son de las más grandes obtenidas, y sólo superadas por plantas de desierto en condiciones favorables de abastecimiento de agua (época de lluvias), por ejemplo, las especies estudiadas por Evenari y Richter (7) en el desierto de Judea; dan: Haplophyllum tuberculatum 26,6 g/g; Reseda muricata $21,9 \mathrm{~g} / \mathrm{g}$; Heliotropium rotundifolium 15,29 y Erodium glaucophyllum 14,7. 
Guttenberg (13) estudiando la transpiración de arbustos de la "macchia" mediterránea encontró como valores máximos: 20,8 g/dm2/día en Rhamnus alaternus (hojas viejas) y $30 \mathrm{~g} / \mathrm{dm} 2 /$ día en Cistus villosus y C. monspeliensis, pero el proprio autor encuentra estos valores excessivos.

Si llevamos nuestra comparación a las regiones lluviosas in. tertropicales vemos que el valor de bananera, es casi 3 veces mayor que los obtenidos para tres árboles en Buitenzorg (Java) por Stocker (45); este autor, trabajando de 6 a 18 horas en el mes de noviembre, obtuvo los datos siguientes: Cassia fistula 6,5 g/dm2; Calophyllum inophyllum 6,9; y Eleaeodendron glaucum 7,8 (datos obtenidos con evaporación diaria de $27,7 \mathrm{~g} / \mathrm{dm} 2$ y déficit de saturación de $10,7 \mathrm{~mm}$ de $\mathrm{Hg}$ ). Las plantas del sotobosque no llegan a perder $1 \mathrm{~g} / \mathrm{dm} 2 /$ día.

Henrici, trabajando en Drakensburg (Sudafrica) distribuyó las especies estudiadas en grupos con valores crecientes de pérdida de agua (18, tabla 5); nuestra transpiración diaria supera al grupo de plantas indígenas dia hojas delicadas con pérdidas entre 4-12 g/g/día (Gymnosporia buxifolia, Heteromorpha arborescens, Calpurnia lasiogyyne etc.) y al de exóticas compuesto por Eucalyptus macarthuri, E. diversicolor, Grevillea robusta, Acacia dealbata y Jacaranda ovalifolia. 'Sólo el grupo con los máximos valores transpiratorios, supera la pérdida diaria de bananera, y está formado por Acacia dealbata y A. Mollisima (exóticas) y Polygala speciosa yBudleia salvifolia (indígenas) que pueden perder como mínimo $4 \mathrm{~g} / \mathrm{g} /$ día y como máximo 16.

Nuestro valor promedio para días de sol es 13,5 veces mayor que el peso fresco y el día 20-XI-51 llegó a 14 veces el peso fresco (tabla 19); la mencr pérçida diaria fué 11 veces el peso fresco (18-IX-51).

TABLA i 9

CONSUMO DIARIO DE AGUA E Y EL CAMPO DE BUTANTAN a) Días de sol

\begin{tabular}{|c|c|c|c|c|}
\hline \multicolumn{3}{|c|}{$\begin{array}{r}\text { Pérdida de agu } \\
\text { g/dm } 2 / \text { día }\end{array}$} & \multicolumn{2}{|c|}{$\begin{array}{c}\text { Pérdida de agua } \\
\mathrm{g} / \mathrm{g} / \mathrm{d} \text { ía }\end{array}$} \\
\hline $\begin{array}{l}27-V I I I-51 \\
8-X-51 \\
9-X-51 \\
20-X I-51 \\
18-I X-51 \\
4-X-51\end{array}$ & 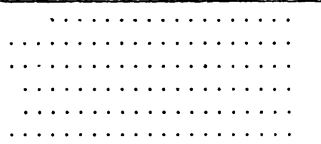 & $\begin{array}{l}19 \\
18,7 \\
17,8 \\
20,6 \\
16,1 \\
20,8\end{array}$ & 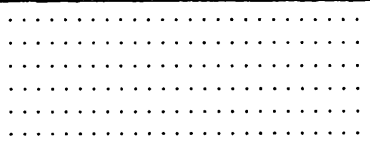 & $\begin{array}{l}13,5 \\
13,3 \\
12,7 \\
14 \\
11,4 \\
14,1\end{array}$ \\
\hline \multicolumn{5}{|c|}{ b) Dias cubiertos } \\
\hline $\begin{array}{l}31-V I I I-51 \\
22-V I I I-51 \\
7-I X-51 \\
5-I X-51\end{array}$ & $\begin{array}{c}\ldots \ldots \ldots \\
\ldots \ldots \ldots \ldots \\
\ldots \ldots \ldots \ldots\end{array}$ & $\begin{array}{l}4 \\
9 \\
8 \\
8\end{array}$ & $\begin{array}{c}\cdots \\
\cdots \cdots \\
\cdots \cdots\end{array}$ & $\begin{array}{l}2,85 \\
6,42 \\
5,7 \\
5,7\end{array}$ \\
\hline
\end{tabular}

En días cubiertos, la planta pierde, como máximo 6 veces mas agua que su peso fresco (tabla 19, día 22-VIII-51) y como mínimo, 2 veces y media (31-VIII-51); y el valor promedio fué de 7 g/dñ $2 /$ día (5 g/g/día). 
En días semicubiertos la pérdida en promedio fué de $13,5 \mathrm{~g} /$ $\operatorname{dm} 2(9,64 \mathrm{~g} /)$.

\section{D) CONSUMO ANUAL}

Los datos de consumo de agua se vuelven ecologicamente interesantes cuando son comparados con la economía hídrica total de la región, o sea cuando se relacionan con las precipitaciones.

Para ello es necesario calcular la cantidad de agua caída sobre el radio de acción de las raíces durante el año, correspondiendo cada milímetro de lluvia a 1 litro de agua por $\mathrm{m} 2$, y la cantidad de agua que ha perdido la planta por transpiración durante el mismo lapso. Este último dato se puede expresar en masa de follaje por unidad de superficie de suelo ocupado por la planta e como hemos hecho: transpiración de la unidad de superficie foliar por unidad de superficie del suelo. Esto nos dará una idea clara de si la pérdida por transpiración está en concordancia con la cantidad de precipitaciones del lugar y si la pérdida de agua debe considerarse elevada o nó.

Para calcular la pérdida total por año fué necesario contar con los siguientes datos:

1) Transpiración diaria

Días de sol ........ 19,0 g/dm2 ó 13,5 g/g

Días semicubiertos . . 13,5 " " 9,64 "

Días cubiertos .... $7,0 \quad " \quad$ " 5,0 "

2) Area del suelo cubierta por la planta: Se calcula este valor basándose en que el área que explora la rizosfera, es aproximadamente igual a la proyección de la copa. En ejemplares aislados, el área cubierta por las raíces suele ser mayor que la proyección de la copa pero en cultivos hay coincidencia entre ambas.

Un ejemplar aislado, desenterrado en Butantán, cubría con su riszosfera, una superficie de $27 \mathrm{~m} 2$, mientras que la proyección de su copa era de $22 \mathrm{~m} 2$.

Consideramos como promedios de áreas de suelo cubiertas por la planta (cálculo hecho determinando la superficie del circulo de suelo donde se proyecta la copa), los siguientes:

$$
\begin{aligned}
& \text { Ejemplares aislados } \ldots \ldots \ldots \ldots \quad 15,0 \quad \mathrm{~m} 2 \\
& \text { Cultivo abierto ( } 3 \text { metro entre plan- } \\
& \text { ta y planta ........... } 7,0 \quad \mathrm{~m} 2 \\
& \text { Cultivo cerrado (2 } \mathrm{m} \text { entre planta y } \\
& \text { planta) . ............. } 3,15 \mathrm{~m} 2
\end{aligned}
$$

3) Area total de la superficie transpirante de la planta Promedio .......... 13,5 m2

4) N.o de días de sol, semicubiertos y nublados por año (fig. 15) 
Días de sol ....... 67

Días semicubiertos $(*)$. 170

Días nublados ........ 128 (Datos de Morize, 46)

En climas regulares no es necesario hacer esta distinción, pero en la ciudad de São Paulo, las condiciones atmosféricas, aún en el transcurso de 24 horas, son extremadamente variables; y el cálculo, usando sólo valores de pérdida de agua en días de sol, sería extremadamente alto y alejado de la verdad.

Durante la estación lluviosa (verano) hay una fuerte opacidad atmosférica, nebulosidad correlativa e insolación deficiente (entre enero y marzo, hay sólo 9 días con sol desde las 8 horas hasta las

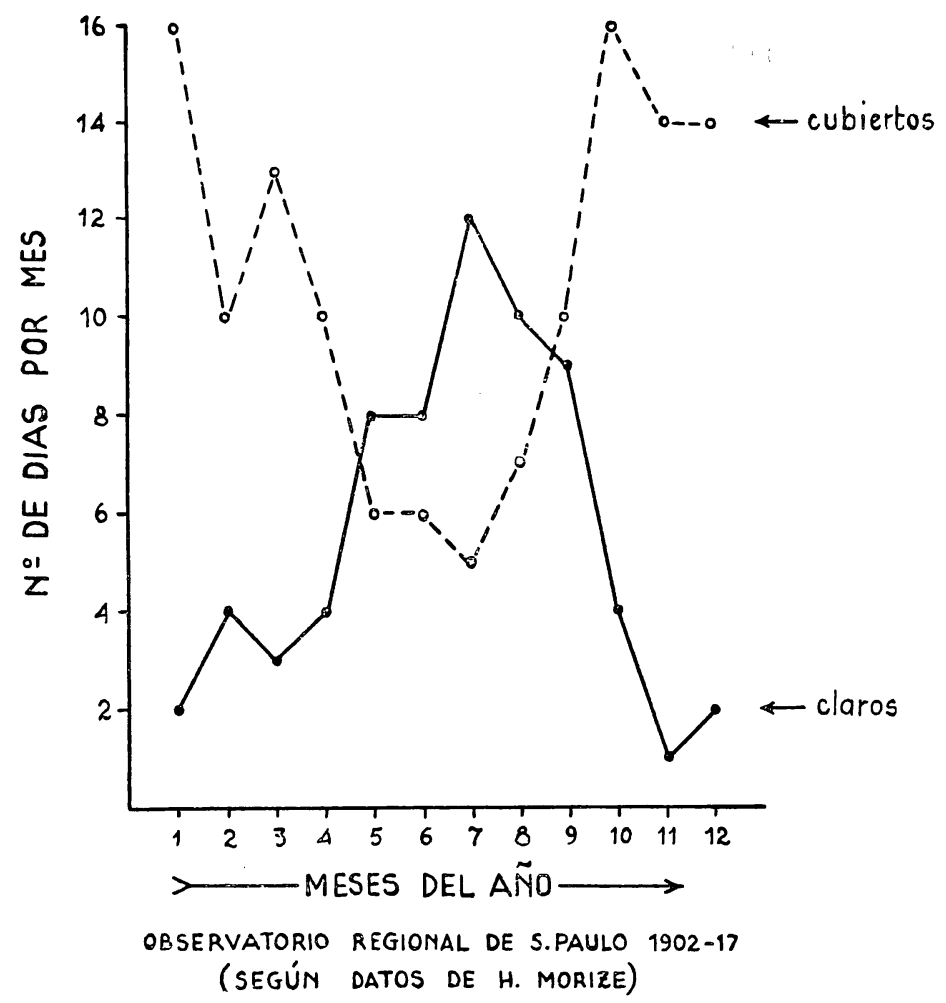

Fig. 15 - Relación mensual entre el número de días claros y cubiertos durante el 18). A pesar de ser el período de mayor duración del sol encima del horizonte, la fuerte nebulosidad determina la caída de los valores de insolación (horas por mes) es de 147 en enero y febrero, 163 en marzo, 158 en abril, 140 en setiembre, 138 en octubre, 139 en noviembre y 150 en diciembre; sólo en agosto puede llegar a valores superiores a 180 horas $(10$, p. 23 , tabla 4$)$.

(*) Se entiende por semicubiertos, aquellos días en que, de las 10 horas decisivas para ia transpiración, 5 están bajo insolación deficiente. 
5) Media anual de lluvias

$1327 \mathrm{~mm}$ (promedio de 56 años; observatorio Estação da Luz)

6) Consumo diaria de agua por planta

Días de sol ........... 25,65 litros

" semicubiertos $\ldots \ldots \ldots \ldots 18,20$ "

$"$ cubiertos .......... 9,45 "

7) Consumo diario por metro cuadrado de superficie de suelo

Días de sol ........... 3,65 litros

" semicubiertos ...... 2,60 "

" cubiertos ......... 1,35 "

8) Consumo por planta, en el total de días de sol, nublados y seminublados

En condiciones de sol (67 días) ... 1718 litros

$" \quad " \quad$ seminubladas (170 días) $3098 "$

9) Consumo total por año y por planta nubladas (128 días) .. 1209 "

6025 litros

Este valor no es alto si se piensa que un arbusto áfilo del desierto de Judea, Retama retam, muy parecido al Spartium junceum, pierde por transpiración de 1500 a 3500 litros de agua por año y por planta y que esta región recibe, en media $120,6 \mathrm{~mm}$ de lluvias por año (8).

10) Consumo total por año, por $m 2$ de superficie de suelo Plantas aisladas ............ 402 litros

Cultivo abierto $(3 \mathrm{~m} \times 3 \mathrm{~m}) \ldots \ldots .861$ "

Cultivo cerrado $(2 \mathrm{~m} \times 2 \mathrm{~m}) \ldots \ldots .1913$ "

Estos ,datos resultan ilustrativos: los ejemplares aislados cuyas raíces ocupan área mayor que la proyección de la copa, consumen sólo el $31 \%$ de las precipitaciones. Ejemplares en cultivo abierto, pueden todavía cubrir el grueso de sus necesidades con las lluvias, sin echar mano de las reservas subterráneas de agua, pero en cultivo denso ya exceden la caída anual de lluvias en $596 \mathrm{~mm}$.

Varios autores han encontrado desequilibrios aún mayores entre transpiración de cultivos densos y lluvias; Coster (4) por ejem. pio, registró en Java, para un cultivo denso de Leucaena glauca (altura de las plantas: 5 metros; distancia entre planta y planta: 1 metro; edad del cultivo: 21 meses) un consumo anual de 4673 $\mathrm{nm}$, contra $3600 \mathrm{~mm}$ aportados por las lluvias, es decir un déficit Le $1073 \mathrm{~mm}$.

Fs necesario considerar que el total de las lluvias no está disponible para el consumo de la planta. La única fracción de agua negiigenciable, es la integrada a la planta durante el crecimiento, que comparada con el consumo por transpiración, resulta insignificante. Una hoja grande de bananera de $3,108 \mathrm{~m} 2$ (ambas caras) pesa 533 gramos, quiere decir que no necesita mas de $1 / 2$ litro da agua para desarrollarse; suponiendo una planta de 7 hojas, cada una 
de 1,5 m2 de superficie, se gastaría 1,75 litros de agua para compensar la integrada por crecimiento.

Esta cantidad resulta ínfima si se piensa que la planta g.asta por transpiración, como mínimo mensual 61,6 litros por m2 cle superficie de suelo, en un cultivo abierto.

i)el valor de la pérdida de agua por deslizamiento en la superficie del suelo, de la que se pierde en profundidad sin poder ser alranzada por las raíces, y de la que se evapora directamente de 1 a superficie del suelo, sólo tenemos estimaciones practicadas en otras regicnes, particularmente en climas templados (vide Engler, 6 y Brocks 3).

La sección de Conservación del Suelo del Instituto Agr mico de Campinas, estima el deslizamiento superficial en un cafezal plantado en "terra roxa", con declive de $6,5 \%$, en una media de $3,7 \%$ de las lluvias.

Se estima en un $20 \%$ de las precipitaciones, la cantidad de agua interceptada por una floresta pluvial tropical, e inmediatamente evaporada, cifra que coincide con la determinada para bosques de regiones templadas.

Resuita difícil calcular este porcentaje para plantaciones de bananera, pero debe ser considerablemente menor por las siguientes causas: las hojas no se dejan humedecer y una parte del agua que cae scbre la superficie de las mismas, es recogida por sus porciones basales que actúan como embudos colectores de las precipitaciones. El agua que cae en cada hoja, desliza en parte siguiendo la pendiente, hasta la nervadura central y ésta, que es acanalada, la conduce hasta el lugar donde las vainas se reúnen for mando verdaderas cisternas, al igual que en las Bromeliáceas.

E1 destino de esta agua acumulada en el pseudo-tronco (parte terminal), es duđoso; una parte deslizará hasta el suelo, otra, evaporará directamente sin llegar al suelo, y no sabemos si la cara interna de las vainas es capáz de absorver una porción de esta agua acumulada, Lo cierto es que si después de una lluvia se hace una herida en la parte terminal del pseudo-tronco, por ella sale un chorro que puede llegar a dar 2 litros de agua.

Consideramos que, cuanto más, un bananal evapora directamente de las hojas el $5 \%$ de las lluvias caídas, o sea que por este camino, se pierden anualmente 67 litros por m2 de superficie de suelo.

Tomando como base los 861 litros/m2 que pierde anualmente por transpiración un cultivo abierto, podemos hacer el siguiente cálculo:

Sumando a los 861 litros/m2, la pérdida de agua por evaporación directa desde el follaje, tendriamos que de los 1327 litros/m2 caídos por año, restan 400, cuyo destino nos es desconocido; parte irá a engrosar la reserva subterránea de agua, parte será evaporada 
de la superficie del suelo, y parte deslizará superficialmente sin penetrar en él.

Si bién en este caso, la caída anual de lluvias excede en 466 litros a la pérdida por transpiración, este balance no es favorable durante todos los meses del año. La tabla 20 y fig. 16 muestran

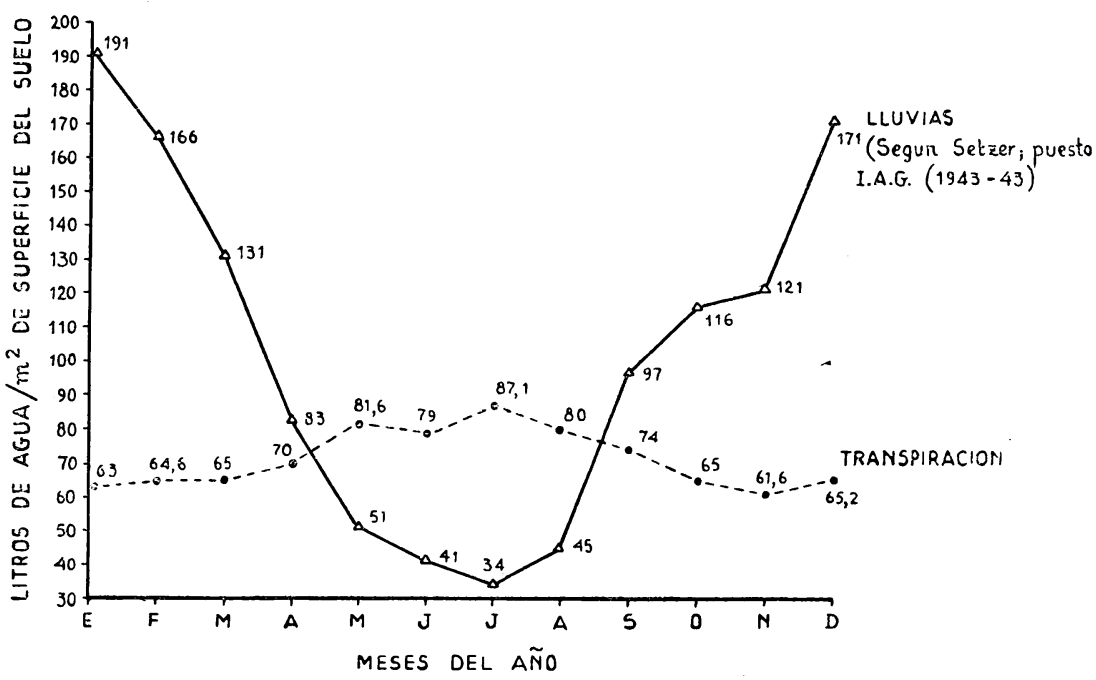

Fig. 16 - Relación mensual entre transpiración de un bananal en cultivo abierto ( $3 \mathrm{~m}$ $\mathrm{x} 3 \mathrm{~m}$ ) y lluvias (precipitaciones según Setzer, 40 ).

que en mayo, junio, y agosto, el consumo supera al aporte por lluvias.

De donde obtiene la planta el excedente necesario para cubrir la pérdida invernal?

Aquí tenemos que considerar el hecho estudiado por Rawitscher y colaboradores $(34,37$ y 39$)$ de la profundidad de los suelos tropicales y las reservas invisibles de agua que pueden almacenar.

El excedente de las lluvias estivales, no consumido por la vegetación, ni perdido por otros caminos, puede ser alamacenado en las capas inferiores del suelo y consumido en la época invernai.

En la tabla 20 y fig. 16, se vé que en enero la pérdida por transpiración es apenas el $33 \%$ del agua aportada por las precipitaciones; relación semejante se observa en noviembre, diciembre, febrero y marzo.

Schubart y Rawitscher (39, p. 71) mostraron que el agua de las precipitaciones estivales, necesita entre 4 y 5 meses para llegar a profundidades de 15 a 20 metros( napa de agua); la subida de la napa culmina entre mayo y agosto, lo que indica que en la época seca aún hay movimiento de agua gravitativa. Esta agua, retenida 
con poca fuerza por el suelo, es facilmente aprovechable por las raíces cierta parte se encuentra a profundidades accesibles a ellas.

Del agua gravitativa, que desciende lentamente en el período de sequía, es de donde plantas como la nuestra podrían extraer la cantidad de agua necesaria para compensar el déficit de precipitaciones y cubrir sus necesidades.

Nuestros valores de consumo mensual de agua (tabla 20) por

TABLA 20

CONSUMOS MENSUALES POR METRO CUADRADO DE SUPERFICIE DE SUELO, CALCULADOS EN BASE A LOS PROMEDIOS METEOROLOGICOS

\begin{tabular}{|c|c|c|c|c|c|}
\hline MESES & $\begin{array}{c}\text { Días de } \\
\text { sol }\end{array}$ & $\begin{array}{l}\text { Días semi- } \\
\text { cubiertos }\end{array}$ & $\begin{array}{c}\text { Días } \\
\text { cubiertos }\end{array}$ & \begin{tabular}{|c|}
$\begin{array}{l}\text { Consumo } \\
\text { mensual } \\
1 / \mathrm{m} 2 \text { de suelo }\end{array}$ \\
\end{tabular} & $\begin{array}{l}\text { Lluvias } \\
1 / \mathrm{m} 2 \text { de } \\
\text { suelo (*) }\end{array}$ \\
\hline Enero & 2 & 13 & 16 & 63 & 191 \\
\hline Febrero & 4 & 14 & 10 & 64,6 & 166 \\
\hline Marzo & 3 & 15 & 13 & 65 & 131 \\
\hline Abril & 4 & 16 & 10 & 70 & 83 \\
\hline Mayo & 8 & 17 & 6 & 81,6 & 51 \\
\hline Junio & 8 & 16 & 6 & 79,01 & 41 \\
\hline Julio & 12 & 14 & 5 & 87,1 & 34 \\
\hline Agosto & 10 & 13 & 7 & 80 & 45 \\
\hline Septiembre & 9 & 10 & 11 & 74 & 97 \\
\hline Octubre & 4 & 11 & 16 & 65 & 116 \\
\hline Noviembre & 1 & 15 & 14 & 61,6 & 121 \\
\hline Diciembre & 2 & 15 & 14 & 65,2 & 171 \\
\hline
\end{tabular}

(*) Datos de Setzer (40) puesto del I. A.G. observaciones de 1 333-1943

un bananal en cultivo, abierto, no puden compararse a los obienidos en plantas con período de reposo; por ejemplo el avellanero (Corylus avellana), la especie más exigente de entre las estudiadas por Pisek y Cartellieri (30, tabla 9) con $92 \mathrm{~mm}$ de consumo mensual, excede al máximo obtenido en bananeras plantadas a distancias de $3 \mathrm{~m}$, en el mes de julio, que es de $87,1 \mathrm{~mm}$; pero el valor obtenido para el avellanero, sólo ocurre en los meses de verano (época de actividad de la planta). En media, por año gasta $360 \mathrm{~mm}$ o sea menos de la mitad del consumo de un bananal abierto ( $861 \mathrm{~mm})$. 
Los valores obtenidos por Coster (4) en Java, para varios tipos de vegetación, con aporte anual por lluvias de $3600 \mathrm{~mm}$, son del siguiente orden de grandeza: sabana de Imperata cylindrica, consume por año $1750 \mathrm{~mm}$, o sea el $48 \%$ de las lluvias; plantación cerrada de Hevea brasiliensis $1300 \mathrm{~mm}$ (36\% de las lluvias); plantación de Thea assamica de 5 años de edad, con densidad de 1 a $1,5 \mathrm{~m}$, por planta, $900 \mathrm{~mm}$ ( $25 \%$ de las lluvias); floresta densa umbrófila de montaña a $1750 \mathrm{~m} \mathrm{~s} / \mathrm{m}, 864 \mathrm{~mm}$ ( $24 \%$ de las lluvias). En este último caso se trata del consumo de una floresta esclerófila de montaña, adaptada a la grande xerotermia de las horas más calientes del día y que tendrá un poder de evaporación visiblemente menor que la floresta umbrófila de altitudes bajas (vide 1 , p. 334).

\section{E) CONSUMO DE AGUA DE UN BANANAL POR HECTAREA}

Las bananeras en cultivo, suelen plantarse en distancias variables: en la planicie litoral de Santos, en las tierras separadas del mar por diques; antes cubiertas de manguezáles (mangrove), los espaciamientos son de 2 metros; allí el suelo, rico en materias húmicas y siempre húmedo, permite tal densidad de cultivo. En suelos mas pobres e con menor cantidad de lluvias, ya en el planalto del estado, los espaciamientos son de 3 a 3,5 entre planta y planta. Ha:

Para nuestro cálculo necesitamos saber el N. ${ }^{\circ}$ de plantas por

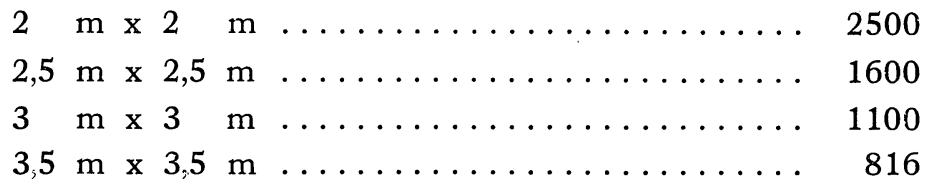

Siendo la transpiración en media, por planta y por año de 6000 litros de agua, los cultivos consumirán por Ha y por año:

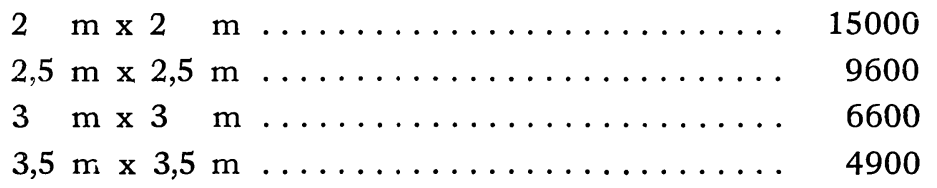


Las precipitaciones anuales en Santos, alcanzan a $24250 \mathrm{~m} 3$ por $\mathrm{Ha}$ ( $1 \mathrm{~mm}$ de lluvias aporta a la $\mathrm{Ha} 10 \mathrm{~m} 3$ de agua, correspondiéndo así $24250 \mathrm{~m} 3$ por $\mathrm{Ha}$ a $2450 \mathrm{~mm}$ de lluvias que es la caída anual promedio de dicha ciudad) y las de São Paulo 13270 m3 por Ha.

Las lluvias en Santos compensan el consumo anual, aún de plantaciones densas ( $2 \mathrm{~m} \times 2 \mathrm{~m}$ ), las de São Paulo, por el contrario, sólo cubren las pérdidas de aquellas donde el espaciamiento es de 2,5 a $3,5 \mathrm{~m}$, pero no alcanzan cuando se cultiva a $2 \mathrm{~m}$ de distancia.

La tabla 21 , muestra el consumo mensual en $\mathrm{m} 3$ por $\mathrm{Ha}$, en

TABL A 21

\begin{tabular}{|c|c|c|c|c|c|}
\hline \multirow[b]{2}{*}{$\begin{array}{l}\text { Meses } \\
\text { del } \\
\text { año }\end{array}$} & \multirow[b]{2}{*}{$\begin{array}{l}\text { Por Planta } \\
\text { Litros/mes }\end{array}$} & \multicolumn{2}{|c|}{ TRANSPIRACION } & \multicolumn{2}{|c|}{$\begin{array}{l}\text { PRECIPITACIONES } \\
\mathrm{m} 3 / \mathrm{Ha}\end{array}$} \\
\hline & & $\begin{array}{c}\mathrm{m} 3 / \\
\text { Densidad } \\
3,5 \mathrm{~m}\end{array}$ & $\begin{array}{c}\text { Densidad } \\
2 \mathrm{~m}\end{array}$ & SANTOS & PAULO \\
\hline Enero & 441 & 352,5 & 1102,5 & 3190 & 1910 \\
\hline Febrero & 452,5 & 362 & 1131,25 & 2890 & 1660 \\
\hline Marzo & 455 & 364 & 1137,5 & 2680 & 1310 \\
\hline Abril & 490 & 392 & 1225 & 2320 & 830 \\
\hline Mayo & 571,2 & 455,96 & 1428 & 1360 & 510 \\
\hline Junio & 553,5 & 442,79 & 1333,72 & 1520 & 410 \\
\hline Julio & 609,7 & 487,76 & 1524,25 & 1280 & 340 \\
\hline Agosto & 560 & 448 & 1400 & 1220 & 450 \\
\hline Septiembre & 518 & 414,4 & 1275 & $14=0$ & 970 \\
\hline Octubre & 455 & 364 & 1137,5 & 1520 & 1160 \\
\hline Noviembre & 431,2 & 344,96 & 1078 & 1410 & 1210 \\
\hline Diciembre & 455,4 & 364,32 & 1138,5 & 2430 & 1710 \\
\hline $\begin{array}{l}\text { Total anu } \\
\text { aproximado }\end{array}$ & 5992,5 & 4793,69 & 14951,22 & 23310 & 12470 \\
\hline
\end{tabular}

las densidades extremas de p'antación (3,5 m x 3,5 m y $2 \mathrm{~m} \mathrm{x} 2 \mathrm{~m}$ ) y las precipitaciones mensuales en Santos y São Paulo.

Nuestro máximo valor de $15000 \mathrm{~m} 3$ por $\mathrm{Ha}$ y por año $(2 \mathrm{~m}$ x $2 \mathrm{~m}$ ) es visiblemente menor a los valores obtenidos por Henrici (que deben ser tomados con cautela pues necesitan de ulterior confirmación) para una plantación vieja de Acacia mollisima (25000

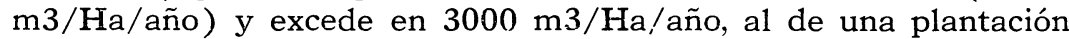
igualmente vieja de Eucalyptus ( $12000 \mathrm{~m} 3 / \mathrm{Ha} / \mathrm{año}$ ) (datos publicados por Valter, 47). Pero el desequilibrio que esta autora encuentra entre consumo anual y aporte por lluvias está muy lejos del obtenido por nosotros para un bananal. 
De los datos de la tabla de Henrici, se desprende que las plantaciones de Eucalyptus en Africa del Sur (Betschuana), consumen, siendo las precipitaciones igual a 1) 1,6 veces más que el aporte de las lluvias ( $7600 \mathrm{~m} 3 / \mathrm{Ha} /$ año) y las de Acacia mollisima, 3,3 veces más. En nuestro caso, un bananal con una densidad de plantación de $2 \mathrm{~m} \times 2 \mathrm{~m}$, consumiría 1,1 veces más que el aporte por lluvias en la ciudad de São Paulo.

Una plantación de Acacia mollisima, en las condiciones estudiadas en Sudafrica; necesitaría cubrir un déficit de $17400 \mathrm{~m} 3 /$ $\mathrm{Ha} /$ año y una de Eucalyptus de 3400.

No existiendo riego artificial, cultivos como los estudiados por Henrici, solo pueden realizarse donde a las lluvias se suma un aporte de agua considerable por ríos, que traen para allí el restante de las precipitaciones de otros lugaresi (riego natural), pués de existir reservas de agua en el suelo, éstas serían agotadas por las plantaciones (vide 34, p. 88 ).

En la ciudad de São Paulo, una plantación a $2 \mathrm{~m} \times 2 \mathrm{~m}$, ne-

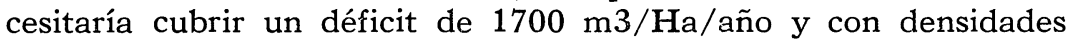
menores, ya existiría superávit sólo con el aporte por lluvias; por ello sería aconsejable espaciamientos no menores de $2,5 \mathrm{~m} \mathrm{x} 2,5 \mathrm{~m}$.

En la planicie litoral del estado, este desequilibrio no existe y además allí llegan gran cantidad de ríos y arroyos que bajan de la Serra do Mar, lo que sumado a las lluvias cubriría con creces las necesidades de agua de cultivos densos.

Expresando el consumo de agua en litros por Ha por día, dato que obtenemos multiplicando el consumo diario promedio por planta, de 25 litros, por el N..$^{\circ}$ de plantas por $\mathrm{Ha}$; vemos que oscila entre $19500(3,5 \mathrm{~m} \times 3,5 \mathrm{~m})$ y $61000(2 \mathrm{m \times 2} \mathrm{m})$.

Los datos en ese sentido, obtenidos para plantas cultivadas en Europa son: cultivos de repollo, consumen $200001 / \mathrm{Ha} /$ día y de avena, $250001 / \mathrm{Ha} /$ día $(23$, p. 31$)$.

Un bosque de haya (Fagus) de Europa, consume 20000 1/ $\mathrm{Ha}$ /día y valor aproximadamente igual fué cbtenido por Bernard (2) para la floresta pluvial tropical de la Cuveta Central del Congo Belga.

\section{VIII}

\section{DISCUSION}

El cultivo de la bananera en el estado de São Paulo, ha pasado en estos últimos años, del litoral para el planalto donde ya se hacen plantíos regulares en condiciones ecológicas completamente distintas a la de la faja litoral.

Estimamos conveniente estudiar el balance de agua de este cultivo en el planalto paulista, donde las lluvias son casi la mitad de las que caen en el litoral (Santos: $2425 \mathrm{~mm}$, ciudad de São 
Paulo: $1327 \mathrm{~mm}$ ). Para ello fué necesario conocer con ciertos detalles la forma de vida y la fisiología de la transpiración de Musa cavendishii Lamb. (banana nanica) especie con la que trabajamos por ser la más ampliamente cultivada para exportación.

Forma de vida: La bananera florece y fructifica una sóla vez en su vida, pero por la particular forma de reproducción vegetativa pcdemos considerarla como planta permanente; la parte aérea nunca desaparece porque mucho antes de la muerte del pseudo-tronco, las yemas laterales del buibo ya han producido los brotos que lo substituirán después de la fructificación.

Este medio de reproducción vegetativa es espesialmente favorable para impedir la lixiviación de los suelos, pués en ninguna época del año, las capas inferiores del mismo dejan de estar vinculadas a la superficie.

Esta especie presenta raíces tanto superficiales como profundas, las últimas exploran hasta 5 metros por debajo de la superficie del suelo, es decir 3 metros más abajo de la zona que puede llegar a ser afectada por la sequía (hasta $2 \mathrm{~m}$ ). Las raíces superficiales permiten aprovechar mayor volumen de suelo y obtener agua, no sólo de la conservada en las camadas superficiales con las primeras lluvias estivales.

Transpiración: Concordante con el sistema subterráneo, muchas de las características fisiológicas, son las de una planta derrochadora de agua:

1) Hay pereza en los movimientos de fotoreacción, el cierre de los estomas se produce a los 60 minutos de haber oscurecido la hoja; las plantas que economizan agua, particularmente las de regiones secas, tienen gran sensibilidad del aparato estomático a la luz $(8$, p. 133), recientemente Ferri y Labouriau encontraron que el umbú (Spondias tubercsa) en la "Caatinga" de Paulo Afonso, cierra sus estomas por fotoreacción, en menos de la mitad del tiempo empleado por la bananera (*).

2) Los movimientos de hidroreacción también son lentos; desde el inicio de la caída de la curva transpiratoria, hasta el cierre completo de los estomas transcurren de 50 a 60 minutos, casi el doble del tiempo empleado por los estomas de café ( 35 minutos) y más del doble que en $\mathrm{Ce}$ drela fissilis (24 minutos).

3) La transpiración máxima, ( $52 \mathrm{mg} / \mathrm{dm} 2 / \mathrm{min}$ ) es dos veces y media mas grande que la obtenida para otro cultivo tropical, el café, por Nutman (27) en Africa: 20,67 $\mathrm{mg} / \mathrm{dm} 2 / \mathrm{min}$. En la copa de los árboles en condiciones tropicales de Java Stocker (45) registró un valor de 50

(*) M. G. Ferri, and I. G. Labouriau - "Water balance of plants from the "Caatinga", I Transpiration of some of the most frequent species of the Caatinga of Paulo Afonso (Eahia) in the rainy season —" 1952 - en prensa. 
$\mathrm{mg} / \mathrm{dm} 2 / \mathrm{min}$ como máximo, dato casi igual al valor cumbre obtenido en bananera.

4) La marcha diaria del déficit de saturación es la misma tanto en la época seca como en la lluviosa, siendo siempre pa-

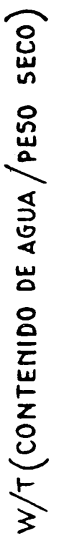

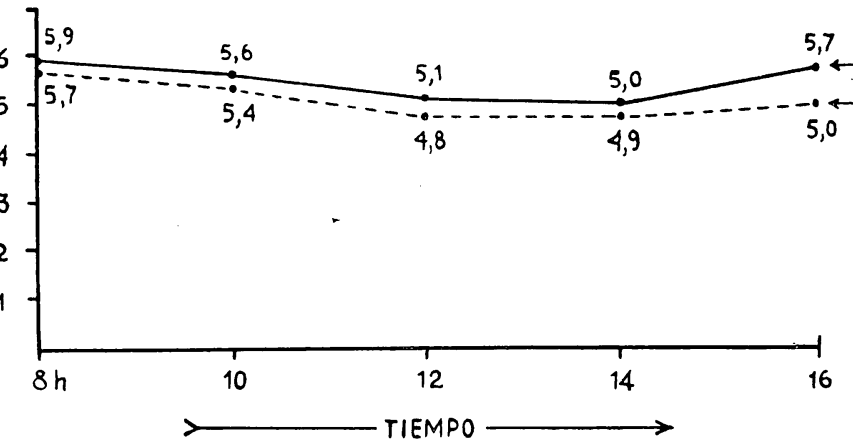

ralela a la de la transpiración (fig. 12).

Fig. 17 - Relación diaria W/T (contenido de agua/peso seco) 9-VIII-51: fin de la época seca 8-X-51: época lluviosa.

La relación $W / T$, contenido de agua/peso seco) también nos indica si hay merma o nó de las reservas hídricas durante la época seca del año y durante las horas calientes del día. La fig. 17, muestra las oscilaciones de la relación $\mathrm{W} / \mathrm{T}$ durante dos días; uno (9-VIII51 ) en el fin de la época seca y el otro (8-X-51) en la lluviosa; se ve que en ambos casos, durante todo el día, las cscilaciones son pe-. queñísimas, lo que está en concordancia con las curvas de transpiración y de déficit de saturación obtenidas.

Esto demuestra que en las condiciones de la ciudad de São Paulo, el balance de agua se encuentra perfectamente equilibrado durante todo el año y no hay necesidad de restringir la pérdida de agua.

Otras características fisiológicas son, por el contrario, de plantas que pueden economizar eficazmente agua si las circunstancias lo exigen:

1) La efectividad del cierre de los estomas es muy grande; con estomas cerados y cutícula seca, la pérdida de agua es de $29 \mathrm{mg} / \mathrm{dm} 2 /$ hora, ccmparable a la transpiración cuticular de un roble europeo (Quercus robur) con $27 \mathrm{mg} / \mathrm{dm} 2$ /hora.

Con cutícula saturada, la pérdida cuticular es de $34 \mathrm{mg} /$ $\operatorname{dm} 2 /$ hora. 
La bananera tarda de 50 a 60 minutos, en reducir la transpiración de 62 para 1,4 , pero una vez obtenido el cierre de los estomas, la pérdida de agua es mínima.

Esta planta, con estomas abiertos, puede llegar a perder, como máximo el $62 \%$ de la que cedería a la atmósfera, igual superficie libre de agua $(\mathrm{Tt} / \mathrm{E}=0,62)$; mientras que con estomas cerrados, la pérdida es 42 veces menor (Tc/ $\mathrm{E}=0,014$ ).

2) La cantidad diaria de vapor de agua que pasa a travéz de 1000 estomas es de $11,45 \mathrm{mg}$ (en el clía de máxima transpiración) valor relativamente pequeño, comparable al de una suculenta del desierto: Suaeda asphaltica $(8,06 \mathrm{mg})$ y mucho menor que el obtenido para xeromorfas (Haplophy$11 \mathrm{~m}$ tuberculatum $48 \mathrm{mg}$, Reseda muricata $66 \mathrm{mg}$ ) (8 cuadro 5 ).

Curvas diarias de transpiración: En las condiciones de São Paulo, las curvas diarias de transpiración, durante todo el año, aún al final de la época seca, corren paralelas a las de la evaporación, siendo de una sola cumbre.

Este no es el caso en los "oasis" de la "Caatinga" donde se cultiva la banana "nanica". Tuvimos oportunidad de hacer algumas observaciones en el fín de la época seca en Paulo Afonso (E. de Bahia) en plantas bajo riego: el día 7-XII-51, a las 14 horas, con evaporación (evaporímetro de Piche) de 137,71 $\mathrm{mg} / \mathrm{dm} 2 / \mathrm{min}$; temperatura $=35 .{ }^{\circ} \mathrm{C} ; \mathrm{y}$ humedad relativa $=22 \%$, no hubo infiltración con xilol; a las $16 \mathrm{~h}$ el xilol penetró con facilidad. A las 7 h 30 del día siguiente, con $\mathrm{T} .=24,5 .{ }^{\circ} \mathrm{C}$ y H. R. $=68 \%$, hubo fuerte infiltración, la que continuó hasta las 11 horas, para luego volver a cerrarse los estomas.

E1 test de infiltración no permite sacar muchas conclusiones, pero es evidente, que el compartamiento de la misma especie difiere fundamentalmente en la "Caatinga" y en la ciudad de São Paulo; en las regiones secas cierra sus estomas en las horas calientes del día.

La curva diaria de transpiración, sería de dos máximos, uno entre las 9 y 10 horas y otro a las 16 horas, con una depresión al mediodía, curva típica de aquellas plantas que en las horas más calientes del día muestran desequilibrio entre aporte y consumo de agua.

Economía de agua: Una vez conocido el comportamiento transpiratorio de la bananera, esto nos permite apreciar su balance hídrico.

Podemos calcular la cantidad de agua caída sobre el radio de acción de las raíces durante un año, y la cantidad de agua perdida por la planta durante el mismo lapso.

Una planta de bananera consume por año, alrededor de 6000 litros de agua; el volúmen abarcado por las raíces depende de la 
densidad de cultivo: en ejemplares aislados es en media de $45 \mathrm{~m} 3$; en cultivo abierto ( 3 a $3,5 \mathrm{~m}$ entre planta y planta) de $21 \mathrm{~m} 3 \mathrm{y}$ en cultivo cerrado de $12 \mathrm{~m} 3$.

Conociendo el volúmen en $\mathrm{m} 3$ abarcado por las raíces y las precipitaciones anuales (de las que hemoss excluido $300 \mathrm{~mm}$ anuales, que, cómo máximo, se perderían por diversos caminos, sin incorporarse al suelo) es posible calcular la cantidad de agua, en litros, que desciende anualmente a la zona que abarcan las raíces. Tendríamos entonces que, cada una de las plantas cultivadas aisladamente disponen de 15600 litros de agua para ser gastados anualmente por transpiración; cada una de las de un cultivo abierto, dispondría de 7300 litros y cada una de las de un cultivo cerrado ( $2 \mathrm{~m}$ de distancia entre planta y planta), de 42001.

En el primer caso (ejemplares aislados) la planta consume menos de la mitad del agua de que dispone; en el segundo, aporte y consumo se equilibran y en el último, hay un déficit, por planta de 1800 litros, que podrían sacarse de las reservas subterráneas de agua del suelo, en caso de existir y encontrar-se a una profundidad accesible a las raíces.

En la "Caatinga", hemos visto cultivar esta especie bajo riego en Paulo Afonso y Joazeiro, en ejemplares aislados o en cultivos con espaciamientos de más de 4 metros. En Joazeiro caen $502 \mathrm{~mm}$ de lluvias por añ் (promedios de observaciones entre 1914 y 1933) y en Paulo Afonso cantidad más o menos igual.

Desconocemos que cantidad de esos $500 \mathrm{~mm}$ puede estar disponible para el consumo por transpiración, pero lo cierto es que aún cuando la planta regula su pérdida de agua en las horas calientes del día, resulta insuficiente y el déficit debe cubrirse con riego artificial.

Consumo anual por hectárea: Para un cultivo con $3,5 \mathrm{~m}$ dé distancia entre planta y planta, calculamos un consumo anual por Ha. de $4900 \mathrm{~m} 3$ de agua. Resulta interesante comparar este dato con el obtenido para otro cultivo tropical en condiciones parecidas: Franco e Inforzato (11, p. 253, cuadro 1) trabajando en plantaciones de café, con idéntico espaciamiento, en Campinas (Estado de São Paulo), con precipitaciones anuales de $13913 \mathrm{~m} 3$ por Ha., obtuvieron un consumo de $5935 \mathrm{~m} 3 / \mathrm{ha} /$ año, un poco superior al nuestro. Este cafetal consumiría el $42 \%$ de las precipitaciones, en cambio un bananal, con idéntico espaciamiento, consumiría sólo el $36,4 \%$ de las lluvias.

Agradecimientos: Nuestro mayor agradecimiento a los Dres. Mario G. Ferri y Mercedes Rachid por valiosas sug stiones durante la ejecución del presente trabajo.

Agradecemos tambiém a doña María Jose Guimarães por la ejecución de odos los gráficos y dibujos que aparecem em el trabajo; al Sr. Alesio Padula por la ayuda técnica, tanto en el laboratorio como en el campo y a doña María Ignez da Rocha e Silva y doña Elsa Graf Kalmus, por la ayuda en la corrección y redacción de los originales. 


\section{IX}

\section{RESUMEN}

Este trabajo se refiere al comportamiento de la bananera (Musa cavendishii Lamb) en relación al factor agua, en las condiciones de la ciudad de São Paulo.

Desupés de una introdución en la que se considera la falta de datos precisos en la literatura tropical, sobre el consumo de agua de esta planta, se describen los métodos usados, discutiendo particularmente el de "pesadas rápidas", que fué el usado en este estudio.

Los resultados más importantes fueron:

1) Raíces: exploran hasta 5 metros de profundidad; el sistema es, tanto superficial como profundo, abarcando en ejemplares aislados, un volúmen que puede llegar a $81 \mathrm{~m} 3$.

2) Reacciones estomáticas: la fotoreacción es lenta, al oscurecer artificialmente la hoja, los estomas tardan 60 minutos para cerrar completamente.

La hidroreacción se hace visible ya con déficits de saturación del 6 al $8 \%$ (estos valores son muy útiles para la comparación por ser característicos para cada especie).

La hidroreacción dura, en promedio, de 50 a $60 \mathrm{mi}-$ nutcs desde el inicio del cierre hasta el cierre completo; este valor es bastante constante y también puede considerárselo característico para cada especie.

El tiempo que vá desde el momento en que se cortó la hoja hasta que esta comienza a cerrar sus estomas, no es un criterio de juzgamiento, pués en la misma especie varía entre limites muy amplios, debido a las condiciones interiores y exteriores.

3) Miovimiento de los estomas en hojas jóvenes y viejas: las hojas viejas todavía regulan la pérdida de agua pero la hidroreacción se atrasa con respecto a la de una hoja jóven.

4) Déficit de saturación de las hojas: en las condiciones de la ciudad de São Paulo, la curva diaria del déficit de saturación de las hojas, es paralela a la de la transpiración. Por la mañana (entre 7 y 8 horas) las hojas están saturadas (con frecuencia bajo presión positiva de raíces) o vecinas a la saturación; entre las 13 y 14 horas, se obtienen los déficits máximos diarios ( 6 a $7 \%$ ) y entre las 16 y 18 horas, los valores vuelven a acercarse a los matutinos. Las primeras señales de marchitamiento aparecen con déficits de 4 a $6 \%$. 
5) Movimiento de las dos mitades de una hoja: en días calientes y de sol las dos mitades, derecha e izquierda, de una hoja de bananera, que han estado dispuestas en un mismo plano durante la noche, continuán así en las primeras horas de la mañana, mientras que al mediodía se inclinan hacia abajo, formando un árgulo variable.

La nervadura media actúa como eje del movimiento, de manera que las caras inferiores de ambas mitades se aproximan una a otra.

Estos cambios en la posición de las 2 mitades foliares, se deben a alteraciones en el turgor de las células de dos articulaciones, situadas a ambos lados de la nervadura central y visibles en la cara inferior, existiendo una perfecta correspondencia entre los valores angulares y el déficit de saturación de la hoja.

Los resultados obtenidos fueron: aberturas angulares de $50 .^{\circ}$ coinciden con déficits de saturación de 6 a $7 \%$ y los estomas parecen no regular aún la pérdida de agua; aberturas vecinas a $0 .^{\circ}$, coinciden con estomas cerrados y los déficits de saturación oscilan alrededor del $20 \%$.

Aberturas de 130 a $150 .^{\circ}$ coinciden con déficits de saturación de 1,5 a $3 \%$.

6) Relación entre la pérdida de agua de la cara superior e inferior de la hoja: la relación entre el N. ${ }^{\circ}$ de estomas en ambas caras es de, 1 en la superior por cada 5 de la inferior. La pérdida de la cara superior representa, en media, el $11 \%$ de la inferior y el $10,2 \%$ de la transpiración total, lo que se explica por la relación estomatica antedicha.

La curva diaria de transpiración de la cara superior, es de dos máximos, uno a las 10 horas, y el otro entre las 15 h 30 y 16 horas (sólo en los días calientes).

En tales días los estomas de la cara superior están cerrados de 9 a 9 h 45 y de 11 h 27 a 14 horas aproximadamente.

7) Transpiración cuticular: la pérdida de agua que se pro.cesa cuando la cutícula desempeña su papel protector, es el 1,4 a $1,6 \%$ de la evaporación libre; su valor real es de $29 \mathrm{mg} / \mathrm{dm} 2 /$ hora. La pérdida con cutícula saturada es de $34 \mathrm{mg} / \mathrm{dm} 2 /$ hora $(2,5 \%$ de la evaporación libre), de 2 a 2,5 veces menor que la pérdida de p.antas higrofíticas estudiadas por Pisek y Berger y Kamp.

Para sustituir la pérdida cuticular seríam necesarios solamente $0,16 \mathrm{~mm}$ de lluvias diarios $(4,8 \mathrm{~mm}$ por mes) valor que no scórepasa a la caída de agua en forma de rocío. 
8) Máxima transpiración observada: fué de $52 \mathrm{mg} / \mathrm{dm} 2 /$ min, valor dos veces y media mayor que el obtenido para café por Nutman, en Africa, y muy cercano al determinado por Stocker para árboles de la floresta pluvial de Java.

9) Marcha diaria de la transpiración en el campo: en la ciudad de São Paulo, tanto en la época seca como en la lluviosa, la marcha diaria de la transpiración se presenta como una curva de una sola cumbre, paralela a las de evaporación y déficit de saturación del aire.

En la "Caatinga", al mediodía se alcanzan déficits tales que provocan el cierre de los estomas, y el doblamiento completo de las hojas (Fig. 5), obteniéndose una curva de dos máximos.

10) Estimación del consumo diario: la transpiración diaria, en media, en el campo, fué de $19 \mathrm{~g} / \mathrm{dm} 2(13,5 \mathrm{~g} / \mathrm{g})$ en días de sol; $13,5 \mathrm{~g} / \mathrm{dm}(9,64 \mathrm{~g} / \mathrm{g})$ en días semicubiertos y $7 \mathrm{~g} / \mathrm{g}$ ) en días nublados.

11) Consumo anual: el cálculo de la transpiración anual por planta fué de 6000 litros; y por m2 de superficie de suelo de:

Plantas aisladas ............ 402 litros

Cultivo abierto $(3 \mathrm{~m} \times 3 \mathrm{~m}) \ldots . .861 "$

Cultivo cerrado $(2 \mathrm{~m} \times 2 \mathrm{~m}) \ldots \ldots 1913$

Los ejemplares aislados, cuyas raíces ocupan área mayor que la proyección de la copa, consumen sólo el $31 \%$ de las precipitaciones. Cultivos abiertos, pueden todavía cubrir el grueso de sus necesidades con las lluvias, sin hechar mano de las reservas subterráneas de agua, pero en cuitivo denso, ya exceden la caída anual de lluvias en $596 \mathrm{~mm}$.

12) Consumo por hectárea: las precipitaciones en la ciudad de São Paulo son de $13270 \mathrm{~m} 3$ por $\mathrm{Ha}$ y en Santos (litoral) de $24250 \mathrm{~m} 3$ y los consumos calculados por $\mathrm{Ha}$, fueron:

Distancia entre las plantas Consumo por Ha y por año en m3

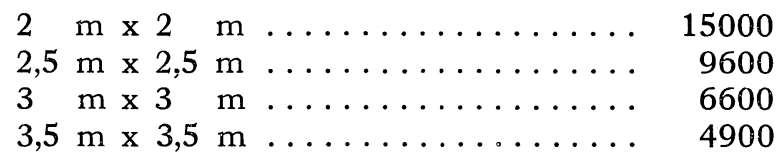

Las lluvias en Santos compensan el consumo anual, aún de plantaciones densas ( $2 \mathrm{~m} \times 2 \mathrm{~m})$; las de São Paulo, por el contrario, sólo cubren las pérdidas de aquellas donde el espaciamiento es de 2,5 a $3,5 \mathrm{~m}$, pero no alcanzan cuando se cultiva a 2 metros de distancia entre planta y planta. 


\begin{abstract}
Como las precipitaciones en el estado de São Paulo, en casi ningún lugar son menores de $1200 \mathrm{~mm}$, con espaciamientos de 2,5 metros o más, nunca habrá peligro de agotar las reservas de agua del suelo.
\end{abstract}

$\mathrm{X}$

\title{
SUMMARY
}

This paper reports some observations on the behaviour of the bananaplant (Musa cavendishii Lamb.), with regard to the waterfactor, under the conditions in the region of São Paulo.

A discussion of the techniques used is presented, especially of the "rapidweighing" method, which was largely employed by the author.

1 - Roots penetrate the soil to a depth of five meters; part of the roots is located at the superficial layers of the soil, and another part pentrate deeper. One single specimen may cover a volume of $81 \mathrm{~m}^{2}$.

2 - Stomatal photcreactions in Musa are slow; if the leaf is placed in the dark, the stomata take 60 minutes to close completely.

The average hydroreaction takes 50 to 60 minutes from the beginning until complete closure, these values are constant within large limits.

Hydroreaction can already be observed at saturation-deficits from 6 to 8 percent.

3 - Stomatal movements in old leaves are slower than in new ones.

4 - In the region of São Paulo, the daily curve of the satıration-deficit of the leaves is parallel to that of transpiration. In the morning ( 7 to 8 a. m.) the leaves are saturated; between 2 and 3 p. m., the maximum deficit is reached (6 to $7 \%$ ), and between 4 and 6 p. m., the values again approximate those of the morning. The first signs of wilting appear at a deficit of 4 to 6 percent.

5 - The movement of the right and the left halves of the leaf, during the day was studied with the following results: Angular openings of 130 to $150.0^{\circ}$ coincide with a saturation deficit of 1.5 to $3 \%$, openings of $50 .^{\circ}$ with a saturation deficit of 6 to $7 \%$, when the stomata begin to rigulate the water-loss.

When folding near to $0 .^{\circ}$ occurs, the stomata are closed and the saturation deficit oscillates around 20\% (Fig. 5).

6 -. The relation of the stomata of the upper to those of the lower side of the leaf is $1: 5$. Therefore the transpiration values of a leaf depend mainly on the inferior surface. Furthermore the superior stomata are nearly closed, during most of the day, showing in hot days two small opening maxima, one at $10 \mathrm{a} . \mathrm{m}$., and the other between 3 and $4 \mathrm{p} . \mathrm{m}$.

The water loss of the superior surface amounts to $11 \%$ of the inferior and 10.2 of the total transpiration.

7 - The cuticular transpiration, when the cuticle plays its protecting role, reaches 1.4 to $1.6 \%$ of the free evaporation (Blatt-Evaporimeter). When the cuticle is saturated, the loss is greater (2.5\% of free evaporation) but even then 2 to 2.5 times inferior to the loss by hygrophytical leaves (Pisek, Berger and Kamp).

8 - The maximum total transpiration per hour was $52 \mathrm{mg} / \mathrm{dm} / \mathrm{min}$., a value 2.5 times higher than that obtained for coffee by Nutman in Africa and very near to the values determined by Stocker for trees of the Java rain-forest.

9 - The daily transpiration curve in the field, in the region of São Paulo, during the dry-season as well as during the rain-season is parallel to 
the curves of evaporation and saturation-deficit of the air, showing one maximum in the early afternoon.

10 - The average daily transpiration in the field was $19 \mathrm{~g} \mid \mathrm{dm} 2(13.5 \mathrm{~g} / \mathrm{g})$ on sunny days; $13.5 \mathrm{~g} \mid \mathrm{dm} 2(9.64 \mathrm{~g} / \mathrm{g})$ on partly-cloudy days and 7 $\mathrm{g} \mid \mathrm{dm} 2(5 \mathrm{~g} \mid \mathrm{g})$ on cloudy days.

11 - Annual consumption per plant: 6000 liters.

12 - Annual consumption of banana cultures:

\begin{tabular}{|c|c|c|c|}
\hline $\begin{array}{l}\text { Distance between } \\
\text { the plants }\end{array}$ & $\begin{array}{c}\text { Consumpticn } \\
\text { m3 per Ha per year }\end{array}$ & \multicolumn{2}{|c|}{$\begin{array}{c}\text { Annual rainfall } \\
\text { m3 per Ha per year }\end{array}$} \\
\hline & & $\begin{array}{l}\text { São Paulo } \\
\text { (interior) }\end{array}$ & $\begin{array}{l}\text { Santos } \\
\text { (coast) }\end{array}$ \\
\hline $\begin{array}{r}2 \times 2 \mathrm{~m} \\
2.5 \times 2.5 \mathrm{~m} \\
3 \times 3 \quad \mathrm{~m} \\
3.5 \times 3.5 \mathrm{~m}\end{array}$ & $\begin{array}{r}15000 \\
9600 \\
6600 \\
4900\end{array}$ & 13270 & 24250 \\
\hline
\end{tabular}

Rains in Santos counter-balance the annual consumption even of dense plan'ations; in São Paulo on the contrary, the precipitations just cover the losses of cultures where the spaces are $2.5 \mathrm{~m}$., but not of those where the distance is $2 \mathrm{~m}$. betwen the plants.

\section{XI}

\section{OBRAS CITADAS EN EL TEXTO (1)}

1 - AUBREville, A. - 1949 -Climats, Forêts et Désertification de l'Afrique Tropicale. Paris.

2 - BERNARD, E. - 1945 - Le Climat Écologique de la Cuvette Centrale Congolaise Bruxelles.

* 3 - BROOKS, C. E. T. - 1928 - The influence of forest on rainfall and runoff. Quarterly Journal of the Meteor. Society, LIV, N. 225, pp. $1-17$.

* 4 - COSTER, F. C. - 1937 - De verdamping van verschillende vegetatie vormen op Java. Tectona, XXX, Afl. 1/2, pp. 1 - 124, Buitenzorg.

5 - EECKHOUT, L. E. - 1950 - Note au sujet de l'emploi du Bananier pour la régénération du sol. Bull. Agr. du Congo Belge, Vol. XII, N. ${ }^{\circ} 1$, pp. $220-221$.

* 6 - ENGLER, Arn - 1919 - Untersuchungen ueber den Einfluss des Waldes auf den Stand der Gewaesser. Mitteilungen der Schweizerischen Centralanstalt fuer das forstliche Versuchwesen, 12, pp. 1-626, Zuerich.

* 7 - EVENARI, M. and RICHTER, R - 1937 - Physiological-Ecological investigations in the Wilderness of Judaea. The Linn. Soc. Journ., 51: 333-381.

8 - EVENARI, M. - 1949 - Ecología de las plantas de desierto - Rev. Arg. de Agron., T. 16, N. ${ }^{\circ}$ 3, pp. 121-148.

9 - FERRI, M. G. - 1944 - Transpiração de plantas permanentes dos "Cerrados". Bol. Fac. Fil. Cienc. e Letr. S. Paulo, Botânica, 4, 161.

10 - FRANÇA, A. - 1946 - Estudo sôbre o clima da Bacia de São Paulo. Bol. Fac. Fil. Cienc. e Letr., 70 - Univ. S. Paulo, Geografia 3: 1-59.

(1) Un asterisco, indica los trabajos citados de segunda mano y que no pudieron ser consultados. 
11 - FRANCO, COARACI', M. e INFORZATO, R. - 1950 - Quantidade de agua transpirada pelo cafeeiro ao sol. Bragantia, 10: 247-257.

12 - GONZALO PlAZAS, M. - 1951 - Una afección de la Musa paradisiaca y otras Musaceas. Acta Agronomica, I, N. ${ }^{\circ} 3,143-168$, Colombia.

* 13 - GUTTENBERG, H. von. - 1927 - Studien ueber das Verhalten der immergruenen Laubblaetter der Mediterran-flora zu vミrschiedenen Jahreszeiten. Plan'a, 4, 726.

* 14 - HARDER, R. - 1930 - Beobachtungen ueber die Temperatur der Assimilationsorgane sommergruener Pflanzen der algexischen Wueste. Ztschr. Bot. 23, 703.

15 - HEATH, O. V. S. and WILliamS, W T. - 1948 - Studies in Stomatal action - Adequacy of Porometer in the Investigation of stomatal Aperture. Nattire, CLXI, p. 178-i79.

16 - HENDRICKX, F. L. y HENDERICKX, J. - 1949 - La Jachère à bananière. Comptes Rendus de la Conférence Africaine des sols, Goma (Kivú) Congo Belge, Vol. II, p. 1735.

17 - HENRICI, M. - 1927 - Physiological plan? studies in South Africa. Part II, Transpiration of grasses and other plants under arid conditions. Part. I of 1 !th and 12th, Rep. Vet. Res. S. Africa, Tretoria.

18 - - - - - 1927 - The transpiration of South African Plant Association Part Iíi, Indigenous and exotic trees in the Drakensburg area Depart. of Agricul. Pre'oria, Science Bulletin N. ${ }^{\circ} 247$.

19 - HUBER, B. 1951 - Wasserumsatz und Stoffbew乏gungen. Fortschritte der Botanik, T. XIII, pp. 227-249.

20 - JAUMAIN, M. M. H. - 1949 - La Conservation des sols et la Rentabilité des Cultures indigènes en territoire de Lubero et zone Bashu-Beni. Bull: Agric. du Congo Belge, Vol. XL, N. ${ }^{\circ}$ 2, pp. 14161454 .

21 - KAMP, H. - 1930 - Untersuchungen ueber Kutikularbau und Transpiration von Blaettern. Jahrb. f. wiss. Bot., 72, 413-465.

22 - LIVENS, J. - 1951 - Exigences édaphiques des principales cultures tropicales. Bull. Agric. du Congo Belge, Vol. XLII, N. ${ }^{\circ}$ 2, pp. 295308.

* 23 - MARTENS, P. - 1942 - Eléments de Botanique (cours de ler cand. sc. nat. Univ. Louvain) fasc. 3, Physiologie veg., 126 p., polygr.

24 - MAXIMOV, N. A. - 1935 - The plant in relation to water (Trad. de R. H. Yapp) Londion.

25 - MEDEIROS, N. - 1935 - A Bananeira - Instruções praticas para a sua cultura. Secr. da Agric. Indus. e Commercio do Estado de S. Paulo.

26 - MORIZE, H. - 1922 - Contribuição ao estudo do Clima do Brasil. Min. de Agric. Ind. e Com., Observatorio Nac. Rio de Janeiro.

* 27 - NUTMAN, F. J. - 1941 - Studies of the physiology of Coffea arabica. III' - Transpiration rates of whole trees in relation to natural environmental conditions. Annals of Botany, 5:59-81.

28 - OPPENHEIMER, H. R. and MENDEL, K. - 1939 - Orange Leaf transpiration under Orchard Conditions - A bioclimatic study. Agric. Research Station, Rehovot (The Jew Ag. for Palestine) Bull. 25 u. 27.

29 - PISEK, A. und BERGER, E. - 1938 - Kutikulaere Transpiration und Trokenresistenz isolierter Blaetter und Sprosse - Flanta, Bd. 28, H. 1, pp. 124-155.

30 - PISEK, A. und CARTELLIERI, E. - 1931-32-39 - Zur Kenntnis des Wasserhaushaltes der Pflanzen. IV, Jb. wiss. Bot. 88, 22.

31 - POLJAKOFF, A. 1945 - Ecological investigation in Palestine. I The water balance of some Mediterranean trees. Pal Journ of Bot. $3: 138$. 
32 - RACHID, M. - 1947 - Transpiração e sistemas subterrâneos da vegelação de verão dos "Campos Cerrados" de Emas. Bol. Fac. Fil. Cien. e Letr., Bo: 5.

33 - RAWITSCHER, F. - 1942 - Algumas noções sobre a transpiração e o Balanço de Agua de Plantas Brasileiras. An. Acad. Bras. Ciência, is: (1).

34 - - - 1942-43 - Problemas de Fitoecología com c’onsiderações espccia:s sôbre o Brasil Meridional. Bol. Fac. Fil. Ciênc. e Letr., Bo: 3 y 4 .

35 - - - - 1952 - B iträge zur Frage der natuerlichen Verbreitung tropischer Savannen. Mitteilungen der Geographischen Geselleschaft, Hamburg. (En pren $₫ a)$.

36 - RAWITSCHER, F. e FERRI, M. G. - 1942 - Obesrvações sobre a Metodologia para o estudo da Transpiração cuticular em plantas Brasıleiras, especialmente en Cedrela fissilis. Bol. Fac. Fil. Ciên. e Letr., Bot. 3, 115-133.

37 - RAWITSCHER, F., FERRI, M. G., y RACHID, M. - 1943 - Profundidade dos solos e vege'ação em Campos Cerrados do Brasil Meridional. Ain. Acad. Bras. Ciên., 15, 267.

38 - RAWITSCHER, F. y MORELLO, J. - 1952 - Eficacia del método de pesćdas rápidas para medir la transpiración de plantas. Ciencia e Investigación (En prensa).

89 - SCHUBART, O. e RAWITSCHER, F. - 1950 - Nota sobre o movimento de água subte:rânea de Emas - Pirassununga. Bol. Fac. Fil. Ciên. e Letr., Bct. 8.

40 - SETZER, J. - 1943-44-45 - Contribuição ao estudo do clima de São Paulo. Bol. D. E. R. N. ${ }^{\circ} 33$ a 39.

41 - SEYBOLD, A. - 1929 - Die physikalische Komponente der pflanzlichen Transpiration. Beilin, IX and $214 \mathrm{pp}$.

42 - SEYBOLD, A. - 1929-30 - Die pflanzliche Transpiration. I e II. Erg. d. Biologie, V, VI.

- 43 - STALFELT, M. G. - 1932 - Der Stomataere Regulator in der pfianzlicheil Transpiration. Planta, 17, 32.

44 - STOCKER, O. - 1933 - Transpiration und Wasserhaushalt in verschiedenen Klimazonen - II - Untersuchungen in der ungarischen Alkalisterpe - Jahrb. f. wiss. Bot., 78, 751 .

45 - _-_ 1634 - Transpiration und Wasserhaushal: in verischiedenen Klimazonen - III - Ein Beitrag zur Transpirationsgroesse in Javan. Regenwald. Jahrb. f. wiss. Bot., 81, 414.

46 - TIELISASE, S. - 1923 - Night and day rates of elongation cf banana leaves. The Philippine Journal of Science, Vol. 23, N. ${ }^{\circ} 1$.

47 - WALTER, H. - 1939 - Grasland, Savanne und Busch der ariden Teile Afrikas in iherer oekologischen Bedingheit. Jah:b. f. wiss. Bot. $87-750$. 